Wellington Silva Fernandez

\title{
Dinâmica populacional de Atherinella brasiliensis (Quoy \& Gaimard, 1824) da praia de Itamambuca, Ubatuba (SP)
}

Dissertação apresentada ao Instituto
Oceanográfico da Universidade de São
Paulo, como parte dos requisitos para
obtenção do título de Mestre em Ciências,
área de Oceanografia Biológica.

Orientadora: Profa. Dra. June Ferraz Dias 
Universidade de São Paulo

Instituto Oceanográfico

\title{
Dinâmica populacional de Atherinella brasiliensis (Quoy \& Gaimard, 1824) da praia de Itamambuca, Ubatuba (SP)
}

\author{
Wellington Silva Fernandez
}

Dissertação apresentada ao Instituto Oceanográfico da Universidade de São Paulo, como parte dos requisitos para obtenção do título de Mestre em Ciências, área de Oceanografia Biológica.

Julgada em

Prof. Dr.

Conceito

Prof. Dr.

Conceito

Prof. Dr.

Conceito 
"Quando alguém quer muito alguma coisa, todo o universo conspira a seu favor".

Paulo Coelho (O Alquimista) 
In memoriam

Irene Célia Fernandez de Almeida $(\star 1951$ - † 1998)

José Fernandez Gonzalez ( $\star 1926$ - † 2001)

Iracema dos Santos Fernandez ( $\star 1925-$ † 2003)

Walter dos Santos Silva $(\star 1934-$ † 2005) 
ÍNDICE

AGRADECIMENTOS

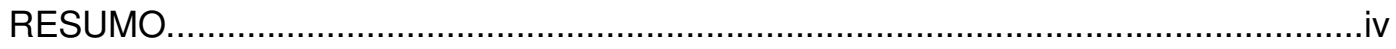

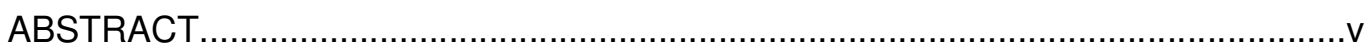

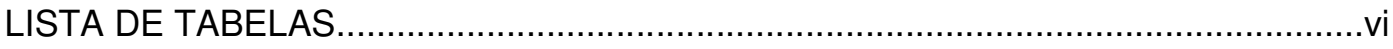

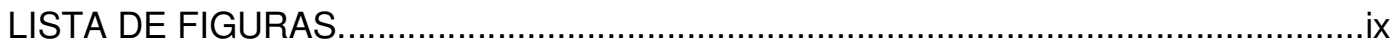

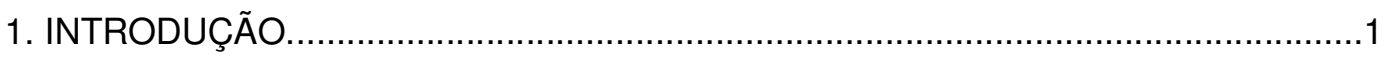

2. OBJETIVOS

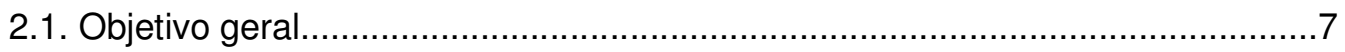

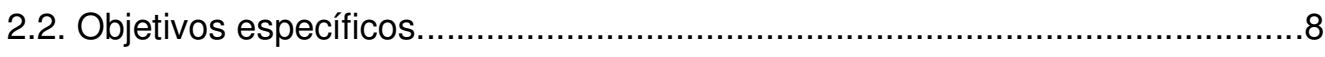

3. CARACTERIZAÇÃO DA ÁREA DE ESTUDO.................................................

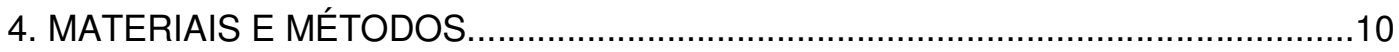

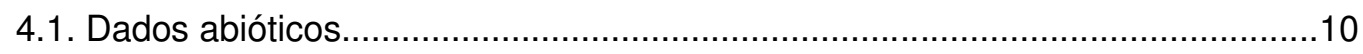

4.2. Coleta de exemplares.............................................................................10

4.3. Freqüência de ocorrência e abundância no espaço e no tempo........................11

4.4. Estudo do crescimento............................................................................13

4.4.1. Obtenção dos dados......................................................................13

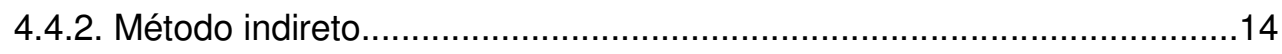

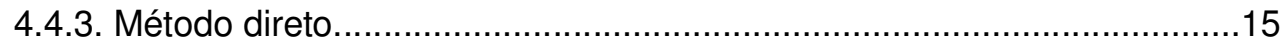

a. Relações entre 0 crescimento do otólito e 0 crescimento da espécie. .15

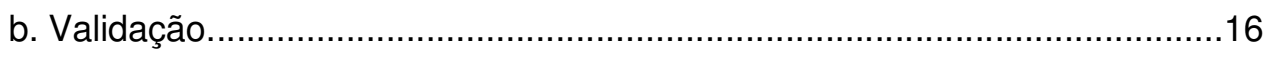

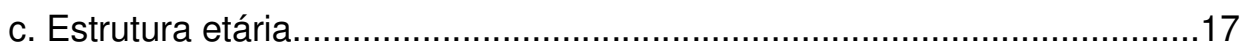

d. Estimativa dos parâmetros das variáveis de crescimento...........................18 
d.1. Método de Gulland e Holt (Gulland \& Holt, 1959)........................18

d.2. Método de Ford-Walford (Walford, 1946)..................................20

d.3. Método de Von Bertalanffy (Sparre \& Venema, 1998)...................21

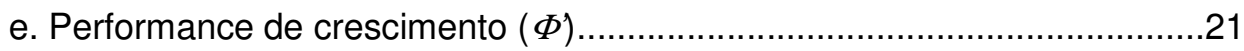

4.4.4. Estudo de mortalidade.............................................................22

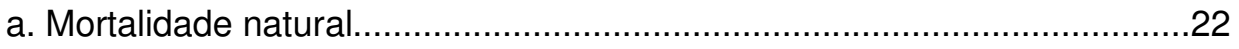

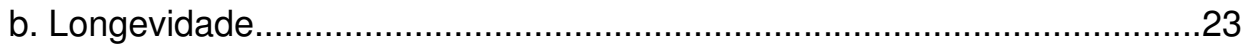

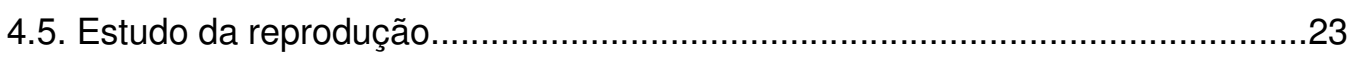

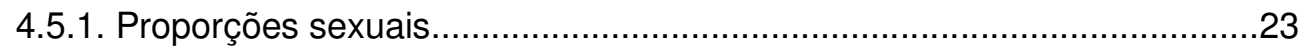

4.5.2. Identificação dos estádios de maturidade gonadal..............................23

4.5.3. Comprimento médio de início de primeira maturação gonadal.................25

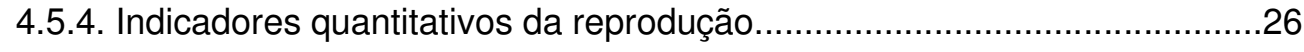

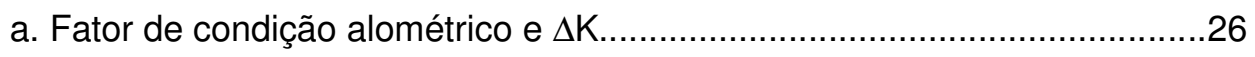

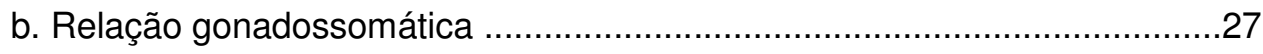

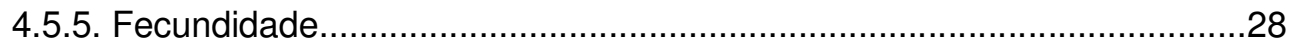

4.6. Análise espectroscópica por emissão de raios-x induzida por partículas ....28

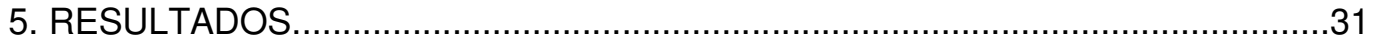

5.1. Ocorrência e abundância no espaço e no tempo e sua relação com as variáveis

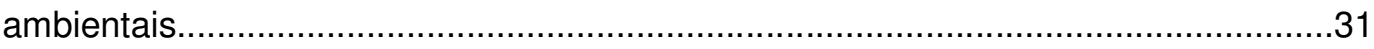

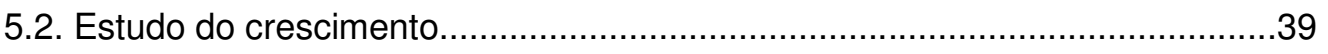

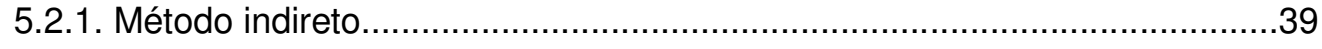

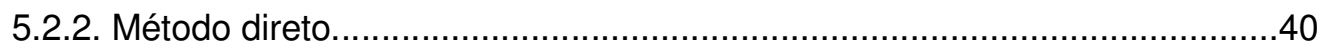

a. Relações entre o crescimento do otólito e o crescimento da

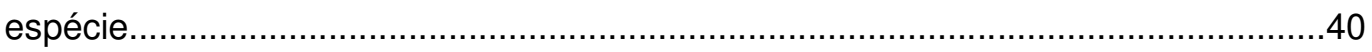

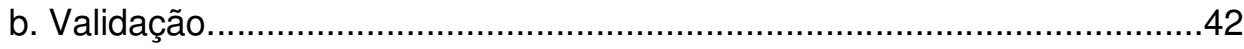


c. Periodicidade de formação dos anéis nos otólitos................................43

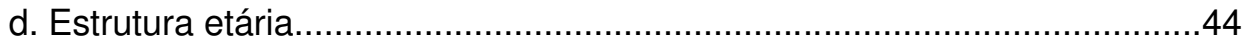

e. Estimativa dos parâmetros das variáveis de crescimento......................45

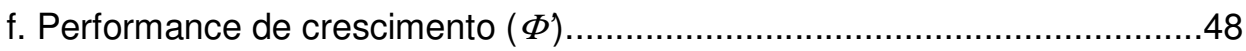

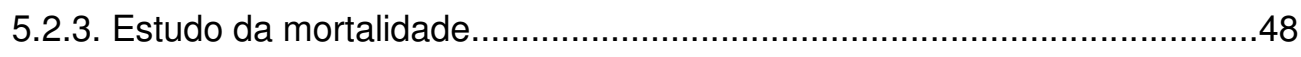

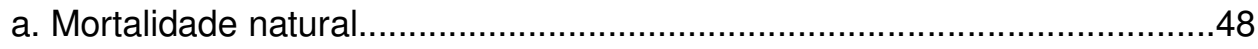

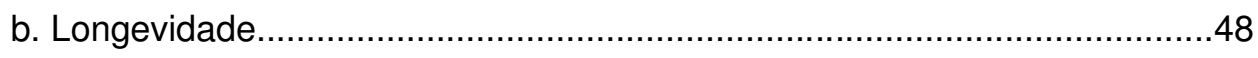

5.3. Estudo da reprodução...................................................................... 49

5.3.1. Proporções sexuais...................................................................... 49

5.3.2. Identificação dos estádios de maturidade gonadal: ocorrência de jovens e adultos e de fêmeas desovantes........................................................................

5.3.3. Tamanho médio de início de maturação gonadal..................................62

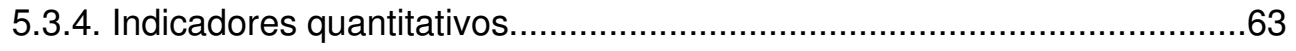

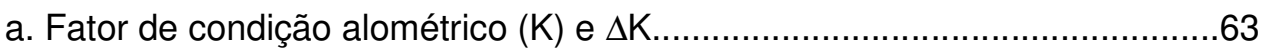

b. Relação gonadossomática (RGS) ...................................................65

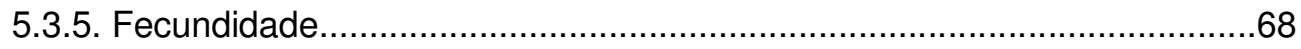

5.4. Análise espectroscópica por emissão de raios-x induzida por

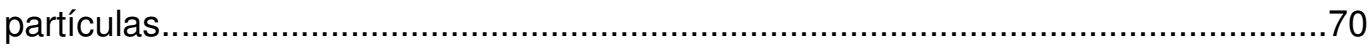

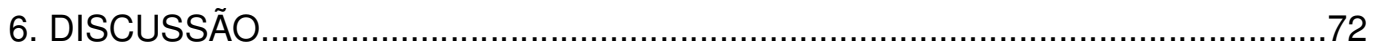

6.1. Ocupação espaço-temporal de Atherinella brasiliensis na praia de Itamambuca 72

6.2. Crescimento de Atherinella brasiliensis na praia de Itamambuca...................75

6.3. A praia de Itamambuca como local de reprodução de Atherinella

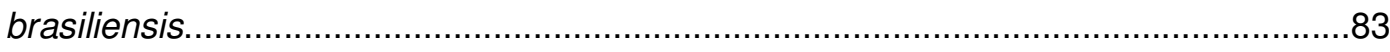

6.4. Avaliação da ocorrência de metais traço na população de $A$. brasiliensis da praia de Itamambuca: uma análise preliminar........................................................91 
7. CONCLUSÕES..

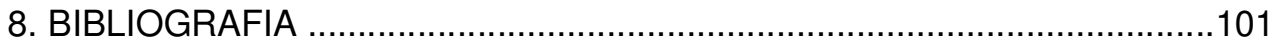




\section{AGRADECIMENTOS}

Antes de tudo gostaria de agradecer a todos aqueles que de alguma forma ou outra me ajudaram, sendo da forma bem simples, tal como um simples afeto, até aquelas mais complexas, cuja dedicação na maioria das vezes não tem como ser agradecidas simplesmente com palavras.

Mas, mesmo assim tenho alguns agradecimentos especiais a fazer principalmente as pessoas que me ensinaram e me ensinam até hoje, não só no lado acadêmico, mas também no lado pessoal, a ser uma pessoa melhor.

Agradeço ao meu pai Requeredo Fernandez dos Santos e minha mãe Waldenize Silva Fernandez e meus irmãos Fernando Silva Fernandez e Francyne Silva Fernandez, pelo amor, dedicação, apoio, incentivo, amizade, compreensão e paciência dadas a mim ao longo desses anos e que de forma alguma tem como ser retribuídas... amo muito vocês.

Aos meus avôs Lourdes Amália de Jesus e llídio Capozzi por me incentivar e apoiar desde criança, nas minhas experiências malucas com insetos e sapos, até os dias de hoje. E apesar de estar meio desaparecido nesses últimos tempos fiquem sabendo que amo vocês... serei eternamente gratos a vocês.

Ao meu tio Lourval dos Santos Silva pelo carinho, dedicação e principalmente incentivos dado a mim desde criança, não conseguiria realizar muitas coisas em minha vida sem sua ajuda. $E$ também gostaria de agradecer pelas aulas particulares quando criança de oceanografia, que mesmo não entender muitas coisas na época, me ajudou bastante na escolha de minha profissão.

À Byanca Galante Araujo a minha atual e futura esposa pelo carinho, dedicação, apoio, incentivo, amizade, compreensão e paciência durante todos esses anos e por me mostrar o verdadeiro significado da palavra "amor" e sem você para alegrar a minha vida tudo teria sido bem mais difícil.... te amo muito.

A todos as pessoas da minha família, principalmente meus tios Walker e Marcelo, minhas tias Ana, Avanize e Rosângela, meus primos Brunno, Felipe, Julio (Julinho), Rafael, Rennan e Felipe e minhas primas Caroline, Walkiria e Wania, pelo carinho, amparo, paciência e por estarem sempre ao meu lado quando precisava.

À minha orientadora Profa. Dra. June Ferraz Dias, pela orientação, apoio, compreensão, conselhos e amizade e principalmente por me acolher no laboratório e me dar oportunidade de poder fazer parte desse grandioso laboratório. E que sem você, eu não teria conseguido nem começar, imagina terminar, essa dissertação.

Aos estagiários (por enquanto) e alunos do Laboratório de recrutamento e reprodução de organismos marinhos (o famoso LERROM) Carla, Cecília, Diego (Zé Lelé), Maria Luiza (Isa), Michel (Miguelix), Natália (Dra. Bexiga) e Thassya, pelas ajudas e discussões importantíssimas para a realização desse estudo, sem vocês não 
teria conseguido. E também gostaria de pedir desculpas por todas as vezes que sem querer me espalhei pelo laboratório colocando sobre suas mesas meus papers, xerox, livros, teses, cd's, otólitos, aquários, frascos de salinidade, lâminas, lixas e as mais diversas tranqueiras... me desculpem pela folga e obrigado por tudo.

Ao pessoal do laboratório de dinâmica bêntica, Angelo (gominha), Cintia (van veen), Marcos (japonês), Andreia, Paula e ao professor Paulo Sumida (Paulinho), pela ajuda antes mesmo de ingressar no mestrado, pelas conversas na hora do café e as discussões importantíssimas na realização desse estudo.

Aos amigos uruguaios Pablo Maciel (negão) e Nathalia Venturine (Naty) pela ajuda nos bons ou maus momentos, estando sempre presentes quando mais precisava de um ombro amigo e as valiosas dicas que contribui muito (muito mesmo) para o presente estudo. E que apesar das inúmeras discussões ainda insistem que o Uruguai é tetra campeão.

Aos amigos do laboratório de ictioplancton, Lourdes, professor Mario K. pelas conversas e momentos de descontração na hora do "cafézinho" e principalmente ao Marcio (bãr) pela amizade e a grande ajuda nos trabalhos de campo, que nem sempre era fácil, acordar antes do sol raiar para fazer arrasto de picaré com infinitos "mosquitos" nos devorando, não é para qualquer um ... esse é "o cara".

A todos os docentes e funcionários do Instituto Oceanográfico da Universidade de São Paulo que me ajudaram muito na realização desse estudo, em especial a professora Patrícia Cunningham por ceder parte do material para o presente estudo e ao pessoal da biblioteca por me ajudar a encontrar as bibliografias que eu nunca conseguia encontrar.

Aos meus amigos de Santos "a melhor cidade do mundo", André (Chico Loco), Marcelo Pacheco (pachequinho), Thiago (baiano), Carol (oompa loompa), Gustavo Duarte (baratinha), Tais (Taisinha), Marcelo (baratinha II), Danilo (Danilera) e Bárbara (cunhadinha) pela agradável companhia durante todos esses anos e incentivos dados a mim para continuar em busca de meus sonhos e não desistir nunca deles. 


\section{RESUMO}

O presente estudo analisou aspectos do ciclo de vida e níveis de metais em Atherinella brasiliensis da praia de Itamambuca, Ubatuba (SP). As coletas foram mensais, nos períodos diurno e noturno, de setembro de 2003 a fevereiro de 2005, em quatro estações na praia e uma no rio Itamambuca, utilizando-se picaré. Os indivíduos migram diariamente para dentro do rio no período noturno. O melhor ajuste ao modelo de von Bertalanffy $\left(C T=164,85 *\left(1-e^{-2,16(t+0,0038)}\right)\right)$ e à longevidade $\left(A_{0,95}=1,378\right.$ ano $)$ foi obtido pelo método de Ford-Walford. $O$ índice de performance de crescimento e a mortalidade variaram de 2,77 a 2,91 e 1,64 a 1,82 ano ${ }^{-1}$, respectivamente. $O$ valor de $L_{50}$ estimado para sexos agrupados foi $86,6 \mathrm{~mm}$, e os de $R G S, \Delta K$ e a freqüência de desovantes sugerem desova durante todo o ano, com maior intensidade do final da primavera até início do outono. A desova é parcelada, com alta freqüência e em pequenos lotes. Altas concentrações de $\mathrm{Cr}$, Fe e $\mathrm{Zn}$ foram detectadas na musculatura, sendo maiores em indivíduos jovens e na alta temporada turística. Pode-se concluir que o peixe-rei passa todo seu ciclo de vida na praia de Itamambuca, apresenta altas taxas de crescimento e mortalidade natural, e desova ao longo de todo o ano.

Palavras-chave: Atherinella brasiliensis, reprodução, crescimento, mortalidade, longevidade, metais traço, Ubatuba, Brasil 


\section{ABSTRACT}

The present study analyzed the life history and metal levels of Atherinella brasiliensis from Itamambuca beach, Ubatuba (SP). Surveys were conducted monthly, in diurnal and nocturnal periods, between September 2003 and February 2005, in four stations at the beach and one at the Itamambuca river, using beach seine. Individuals showed daily migration into the river at nocturnal period. The better adjustment to von Bertalanffy's model $\left(\mathrm{Lt}=164.85^{\star}\left(1-\mathrm{e}^{-2.16(t+0.0038)}\right)\right)$ and to longevity $\left(A_{0.95}=1.378\right.$ year $)$ was obtained through Ford-Walford method. The value of estimated $L_{50}$ for grouped gender was $86.6 \mathrm{~mm}$, and the GSR, the $\Delta K$ and the spawning frequency suggest spawning during all year around, with higher intensity in late spring until middle autumn. The high frequency of spawning and the low batch fecundity indicate that the species is a batch spawner. High concentrations of $\mathrm{Cr}$, Fe and $\mathrm{Zn}$ were detected in musculature, being higher among young individuals, and during tourist high season. In conclusion, the Brazilian silverside spends its life cycle on the Itamambuca beach, shows high growth and natural mortality rates, and spawning throughout the year.

Key words: Atherinella brasiliensis, reproduction, growth, mortality, longevity, trace metals, Ubatuba, Brazil. 


\section{LISTA DE TABELAS}

Tabela 1. Valores das temperaturas da água obtidos nas estações de coletas da praia de Itamambuca - Ubatuba (SP) para todo o período estudado. .33

Tabela 2. Valores de $\mathrm{F}$ (ANOVA) ou H (Kruskal-Wallis) dos fatores ambientais e da captura total de Atherinella brasiliensis da praia de Itamambuca - Ubatuba (SP).

Tabela 3. Valores da salinidade da água obtidos nas estações de coletas da praia de Itamambuca - Ubatuba (SP) para todo o período estudado .35

Tabela 4. Valores H (Kruskal-Wallis) das capturas do dia e da noite por estação de

coleta de A. brasiliensis da praia de Itamambuca - Ubatuba (SP). 38

Tabela 5. Parâmetros das variáveis de crescimento $\left(C T \infty, K\right.$ e $\left.t_{0}\right)$, mortalidade natural $(\mathrm{M})$, longevidade $\left(A_{0,95}\right)$ e o índice de crescimento $(\Phi)$ de Atherinella brasiliensis da praia de Itamambuca (SP) realizados no programa FISAT II e suas variáveis para a amostra total. 
Tabela 6. Chave idade-comprimento de Atherinella brasiliensis da praia de Itamambuca - Ubatuba (SP) Onde $\mathrm{CT}_{\mathrm{m}}$ é o comprimento total médio por banda e DP os desvios padrão. .45

Tabela 7. Parâmetros das variáveis de crescimento e o índice de performance das curvas de crescimento de Atherinella brasiliensis da praia de Itamambuca estimados por diferentes métodos. .46

Tabela 8. Mortalidade natural $(M)$ de Atherinella brasiliensis da praia de Itamambuca, calculada a partir dos parâmetros de crescimento estimados pelos diferentes métodos. 48

Tabela 9. Longevidade $\left(\mathrm{A}_{0,95}\right)$ de Atherinella brasiliensis da praia de Itamambuca, estimada a partir dos parâmetros de crescimento calculados pelos diferentes métodos. 49

Tabela 10. Valores numéricos, proporção sexual e valores de $\chi^{2}$ (1:1 e encontrado) de Atherinella brasiliensis por época do ano para todo o periodo estudado na praia de Itamambuca (SP). .50

Tabela 11. Freqüência de preparações permanentes com cortes de ovários retirados de Atherinella brasiliensis da praia de Itamambuca (SP) de todo o período estudado. .55 
Tabela 12. Classificação dos estádios macroscópicos e microscópicos de ovários de Atherinella brasiliensis na praia de Itamambuca (SP) de todo o período estudado. .55

Tabela 13. Valores numéricos, proporção sexual e valores de $\chi^{2}$ (1:1 e encontrado) corrigidos de Atherinella brasiliensis por época do ano para todo o período estudado na praia de Itamambuca (SP). .61

Tabela 14. Parâmetros de crescimento estimados por diferentes autores para espécies da família Atherinopsidae, obtidos da literatura. Em subscrito as diferentes metodologias empregadas para as estimativas 81

Tabela 15. Concentrações (ppm) dos elementos $\mathrm{Cr}$, Fe e $\mathrm{Zn}$ na musculatura de diferentes espécies de teleósteos, estimadas a partir de diferentes técnicas. PIXE = Particle Induced X-Ray Emission; ICP-AES= Inductively Coupled Plasma Atomic Emission Spectrometry; AAS= Atomic Absorption Spectrometry; GFAA= Graphite Furnace Atomic Absorption; $\mathrm{FAAS}=$ Flame Atomic Absorption

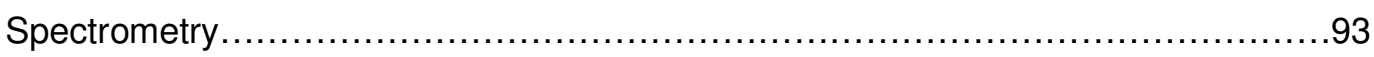




\section{LISTA DE FIGURAS}

Figura 1. Representação da região costeira entre Santos e Ilha Grande, com detalhe da praia de Itamambuca, litoral norte do estado de São Paulo, com a localização das estações de coleta de amostras e de dados ambientais. 11

Figura 2. Medidas realizadas nos otólitos de Atherinella brasiliensis da praia de Itamambuca - Ubatuba (SP). CO é o comprimento $(\mathrm{mm})$ e AO é a altura do otólito $(\mathrm{mm})$ .15

Figura 3. Análise de agrupamento das estações de coleta por similaridade euclidiana da temperatura na praia de Itamambuca (SP), para todo o período estudado. 34

Figura 4. Análise de agrupamento das estações de coleta por similaridade euclidiana dos valores de salinidade, na praia e rio Itamambuca (SP) para todo o período estudado. .36

Figura 5. Análise de agrupamento das estações de coleta por similaridade euclidiana da captura diurna de Atherinella brasiliensis na praia de Itamambuca (SP) para todo o período estudado. 
Figura 6. Análise de agrupamento das estações por similaridade euclidiana da captura noturna de Atherinella brasiliensis na praia de Itamambuca (SP) para todo o período estudado 38

Figura 7. Curvas de crescimento de $A$. brasiliensis da praia de Itamambuca (SP) obtidas pela rotina Shepherd utilizando os dados de freqüência mensal por classe de comprimento para todo o período estudado.

Figura 8. (A) Relação do comprimento do otólito $(\mu \mathrm{m})$ e massa do otólito $(\mathrm{g})$; (B) diagrama de dispersão dos resíduos padronizados do comprimento do otólito ( $\mu \mathrm{m})$ e a massa do otólito (g) de Atherinella brasiliensis da praia de Itamambuca $(\mathrm{SP})$. 40

Figura 9. (A) Relação do comprimento do otólito $(\mu \mathrm{m})$ e o comprimento total dos indivíduos (mm); (B) diagrama de dispersão dos resíduos padronizados do comprimento do otólito $(\mu \mathrm{m})$ e comprimento total dos indivíduos $(\mathrm{mm})$ de Atherinella brasiliensis da praia de Itamambuca (SP).

Figura 10. (A) Relação do comprimento total dos exemplares $(\mathrm{mm})$ e a massa do otólito (g); (B) diagrama de dispersão dos resíduos padronizados da massa do otólito (g) e comprimento total dos indivíduos $(\mathrm{mm})$ de Atherinella brasiliensis da praia de Itamambuca (SP). 42 
Figura 11. Otólito de Atherinella brasiliensis após duas marcações com alizarina. (A) sob microscópio de fluorescência com aumento de 4x; (B) evidenciando com setas as duas marcações; (C) sob microscópio de luz branca com um aumento de 10x evidenciando as duas marcações com alizarina e os anéis diários. 43

Figura 12. Otólito lixado de Atherinella brasiliensis da praia de Itamambuca - Ubatuba (SP) evidenciando as bandas e os anéis diários de crescimento 44

Figura 13. Curvas de crescimento obtidas através da equação de von Bertalanffy para os parâmetros calculados por diferentes métodos para Atherinella brasiliensis da praia de Itamambuca - Ubatuba (SP).

Figura 14. Porcentagens de machos e fêmeas de Atherinella brasiliensis, por classe de comprimento total da praia de Itamambuca (SP) de todo o período estudado .51

Figura 15. Proporção de jovens e adultos (machos e fêmeas agrupados) de Atherinella brasiliensis da praia de Itamambuca (SP) por época de coleta em todo o período estudado. O asterisco indica os meses em que não houve diferença significativa na proporção de jovens e adultos. .52 
Figura 16. Porcentagem de indivíduos jovens e adultos de Atherinella brasiliensis capturados durante o dia (A) e de noite (B), por estação de coleta da praia de Itamambuca (SP), em todo o período estudado. .53

Figura 17. Proporção de fêmeas adultas de Atherinella brasiliensis capturadas na praia de Itamambuca (SP), em todo o período, nos diferentes estádios de maturidade gonadal verificados a partir da avaliação macroscópica. .54

Figura 18. Cortes de gônadas de fêmeas de Atherinella brasiliensis coletadas na praia de Itamambuca - Ubatuba (SP). (A) = representação das fases de desenvolvimento ovocitário (HE, 4x); (B) = ocorrência de ovócitos hidratados e folículos pós-ovulatórios $(\mathrm{HE}, 10 \mathrm{x}) ;(\mathrm{C})$ = detalhe do folículo pós-ovulatório. II= ovócitos avitelogênicos; III= ovócitos com início de vitelogênese lipídica; IV= ovócitos com início de vitelogênese protéica; $\mathrm{V}=$ ovócito maduro; $\mathrm{VI}=$ ovócito hidratado; $\mathrm{FPO}=$ folículo pós-ovulatório; $\mathrm{FA}=$ filamentos adesivos. .57

Figura 19. Proporção de fêmeas adultas de Atherinella brasiliensis da praia de Itamambuca (SP) de todo o período estudado por estádio de maturação gonadal, a partir da identificação macro- e microscópica proposta, com a introdução do estádio D/E, que representa a ocorrência de ovários com ovócitos hidratados e folículos pósovulatórios. 58

Figura 20. Variação mensal da proporção de fêmeas adultas de Atherinella brasiliensis da praia de Itamambuca (SP) de todo o período estudado em diferentes estádios de maturação gonadal. .59 
Figura 21. Variação sazonal da proporção de fêmeas adultas de Atherinella brasiliensis da praia de Itamambuca (SP) de todo o período estudado em diferentes estádios de maturação gonadal

Figura 22. Porcentagens de machos e fêmeas corrigidas de Atherinella brasiliensis, por classe de comprimento total da praia de Itamambuca (SP) de todo o período estudado .62

Figura 23. Porcentagem de indivíduos adultos por classe de comprimento total para Atherinella brasiliensis da praia de Itamambuca (SP) em todo o período estudado. A linha tracejada indica o tamanho médio de início de primeira maturação gonadal $\left(\mathrm{L}_{50}\right)$ .63

Figura 24. Valores do valor de condição $(K)$ em função do comprimento total de Atherinella brasiliensis da praia de Itamambuca (SP) de todo o período estudado. A reta tracejada representa o valor de "a" da relação peso/comprimento .63

Figura 25. Variação mensal dos valores médios do fator de condição total $(K)$ e somático (K') com seus respectivos desvios padrão, em Atherinella brasiliensis da praia de Itamambuca (SP) para todo o período 
Figura 26. Variação mensal dos valores médios da diferença do fator de condição total e somático $(\Delta \mathrm{K})$, em Atherinella brasiliensis da praia de Itamambuca (SP) para todo o período. 65

Figura 27. Variação mensal da média da relação gonadossomática (RGS) de fêmeas adultas de Atherinella brasiliensis da praia de Itamambuca (SP) de todo o período estudado. As barras verticais indicam os desvios padrão. 66

Figura 28. Valores da relação gonadossomática (RGS) em relação ao comprimento total das fêmeas adultas de Atherinella brasiliensis da praia de Itamambuca (SP) de todo 0 período estudado por estádio de maturação gonadal. 67

Figura 29. Valores médios da relação gonadossomática (RGS) por estádio de maturação gônadas das fêmeas adultas de Atherinella brasiliensis da praia de Itamambuca (SP) de todo o período estudado. .67

Figura 30. Relação entre o comprimento total $(\mathrm{mm})$ e a quantidade de ovócitos hidratados nas gônadas de Atherinella brasiliensis da praia de Itamambuca - Ubatuba $(\mathrm{SP})$ 69

Figura 31. Relação entre a massa corpórea (g) e a quantidade de ovócitos hidratados nas gônadas de Atherinella brasiliensis da praia de Itamambuca - Ubatuba (SP). 
Figura 32. Composição elemental da musculatura médio-lateral de $A$. brasiliensis da praia de Itamambuca - Ubatuba (SP) em dois períodos do ano, medidas a partir da técnica PIXE.

Figura 33. Composição elemental da musculatura médio-lateral de jovens e adultos de A. brasiliensis da praia de Itamambuca - Ubatuba (SP), medidas a partir da técnica PIXE. 


\section{INTRODUÇÃO}

As praias constituem sistemas dinâmicos, onde elementos básicos como ventos, água e areia interagem, resultando em processos hidrodinâmicos e deposicionais complexos (Brown \& McLachlan, 1990). Compreendem uma porção subaérea, composta pelo supra- e médio-litoral, e outra subaquática que inclui a zona de arrebentação e se estende até a base orbital das ondas (Wright \& Short, 1983).

A dinâmica costeira, que condiciona a construção geomorfológica da linha da costa, é a principal responsável pelo desenvolvimento das praias arenosas e pelos processos de erosão e deposição que as mantém em constante alteração. A morfologia dos perfis praiais em uma determinada região é função do nível energético das ondas nas zonas costeiras (Wright \& Short, 1983).

Quanto ao grau de exposição, as praias podem ser classificadas como desde muito expostas a muito protegidas, sendo a variabilidade física resultante da combinação de parâmetros de variáveis básicas, como característica das ondas e granulometria do sedimento (McLachlan, 1990), da morfologia do fundo, do padrão de circulação e da dinâmica de correntes (Villwock, 1987). De acordo com o grau de intensidade destes fatores, as praias podem ser classificadas quanto à morfodinâmica em dois estados extremos, dissipativas e refletivas, e quatro estados intermediários (Short \& Wright, 1983).

As praias arenosas dominam a maior parte da linha de costa em regiões temperadas e tropicais, representando uma importante área de 
recreação e abrigando uma grande variedade de recursos naturais (Brown \& McLachalan, 1990). Ainda que represente um ambiente estressante, suporta uma variada fauna, principalmente de zooplâncton e peixes, mesmo com uma pequena variedade de nichos ecológicos (Spring \& Woodbum, 1960). Essas regiões podem oferecer também uma série de vantagens aos organismos residentes, tais como maior proteção contra predadores e a maior abundância de alimento. Essas características tornam este ambiente um importante local de criadouro e desenvolvimento para várias espécies de peixes costeiros, servindo como refúgio contra predadores e como áreas de alimentação (Layman 2000).

As espécies de peixes que se encontram nessa estreita região podem ser classificadas em cinco categorias, dependendo do seu ciclo de vida: juvenis de residência temporária, adultos não residentes, residentes durante todo o ciclo de vida, migratórios sazonais ou noturnos e residentes ocasionais (Layman, 2000).

$\mathrm{Na}$ costa brasileira, a ictiofauna da zona de arrebentação é bastante variada, sendo que na costa do estado de São Paulo as famílias mais abundantes e freqüentes são Sciaenidae, Atherinopsidae, Carangidae, Engraulidae e Clupeidae no litoral norte; Engraulidae, Carangidae, Mugilidae, Sciaenidae e Atherinopsidae no litoral central; e Carangidae, Scianidae, Mugilidae, Clupeidae e Atherinopsidae no litoral Sul do estado (Giannini \& Paiva Filho, 1995).

A família Atherinopsidae é composta por 46 gêneros e 200 espécies, com ampla distribuição geográfica, sendo que sua taxonomia ainda não está completamente esclarecida (Chernoff, 1986). Seus representantes ocorrem em 
ambientes límnicos, estuarinos e marinhos, com maior freqüência em águas costeiras (Figueiredo \& Menezes, 1978). No Brasil a família é composta por quatro gêneros, sendo Odontesthes representado por 11 espécies e Atherinella, Atherinomus e Membra representados por somente uma espécie cada. Entretanto, no litoral do estado de São Paulo os aterinopsídeos são representados por 3 gêneros e 5 espécies: Odontesthes incisa, O. iguapensis, O. bonariensis, Membras dissimilis e Atherinella brasiliensis (Menezes et al., 2003).

Atherinella brasiliensis (Quoy \& Gaimard, 1824), popularmente conhecida como peixe-rei, destaca-se por apresentar uma distribuição abrangente, desde a Venezuela ao extremo sul do Brasil (Rio Grande do Sul), encontrada principalmente na desembocadura de rios e em águas salobras (Figueiredo \& Menezes, 1978). Até 1992 era nomeada na literatura como Xenomelaniris brasiliensis. É o membro mais comum dessa família em arrastos de praias e estuários no litoral sudeste-sul do Brasil, durante todo o ano, principalmente no verão e outono, quando a água apresenta maiores temperaturas, havendo correlação positiva entre a abundância dessa espécie e a temperatura da água (Paiva-Filho \& Giannini, 1990).

O peixe-rei é considerado um peixe de pequeno porte, atingindo no máximo $160 \mathrm{~mm}$ de comprimento, não sendo eficientemente capturado pela pesca artesanal. Por essas características não é considerado de grande interesse comercial, mas sua abundância faz com que seja utilizado pelas comunidades pesqueiras como isca e em determinadas épocas do ano como complemento de renda, ou mesmo na alimentação (Santos et al., 1999). 
Seu papel na cadeia trófica foi evidenciado por Gasalla (1995), que constatou que o peixe-rei é o principal item alimentar identificado dos conteúdos estomacais do peixe-espada (Trichiurus lepturus) na região do saco do Mamanguá, Parati (RJ), estando presente em até $25 \%$ dos estômagos analisados. Assim, devido a sua ocorrência e abundância ao longo das áreas rasas, essa espécie é exportadora de matéria e energia para além dos limites da zona de arrebentação, em áreas mais ao largo na plataforma continental, através de espécies de maior porte, como os carnívoros que são explorados comercialmente.

Embora no Brasil existam alguns trabalhos mencionando a espécie (Carvalho, 1953, 1954; Bemvenuti, 1984, 1987, 1990; Paiva-Filho \& Giannini, 1990; Hostin-Silva et al.,1995; Santos et al.,1999; Pessanha \& Araújo, 2001; da Silva Cortinhas et al., 2003; Favaro et al., 2003; Neves et al., 2006), a maioria das informações está relacionada à sua distribuição e abundância e inseridas em trabalhos sobre levantamento ictiofaunístico em áreas distintas do litoral brasileiro, sem foco em estudos específicos sobre reprodução, idade e crescimento para a espécie, embora Favaro et al. (op. cit.) tenham estudado aspectos da reprodução no litoral do Paraná.

A importância desses estudos específicos reside na caracterização da história de vida dos peixes, e na busca de padrões de crescimento e reprodução, que evidenciem particularidades sobre respostas de uma mesma população, em diferentes anos, às forçantes ambientais (Becker et al., 2003).

Estudos sobre o crescimento de Atherinella brasilienis se restringem a poucos trabalhos, que utilizaram estimativas dos parâmetros das variáveis de crescimento através do método indireto. Pessanha \& Araújo (2001) e Neves et 
al. (2006) calcularam taxa de crescimento e comprimento assintótico através da sub-rotina ELEFAN I do programa FISAT, com base na freqüência de comprimento de indivíduos capturados em cinco praias e no manguezal de Guaratiba, ambos na baía de Sepetiba (RJ), sendo os valores da taxa de crescimento 0,93 e 0,90 e o do comprimento assintótico $112,60 \mathrm{~mm}$ e 168,40 $\mathrm{mm}$, respectivamente. Nos dois trabalhos foram estimados altos valores da taxa de crescimento para a espécie. Neves et al. (2006) sugerem que o maior valor do comprimento assintótico calculado, quando comparado com o estimado por Pessanha \& Araújo (2001), estaria relacionado à maior disponibilidade de alimento na área de manguezal. Entretanto, em nenhum dos dois trabalhos foi calculado o comprimento na idade zero $\left(\mathrm{t}_{0}\right)$ nem a mortalidade para a espécie nas regiões estudadas.

Por sua vez Santos et al. (1999), na margem oeste da baía de Todos os Santos (BA), e Paiva Filho \& Giannini (1990), no complexo baía-estuário de Santos e São Vicente (SP), conseguiram acompanhar o crescimento populacional de Atherinella brasiliensis através das classes modais de tamanho.

Com relação à reprodução, alguns pontos permanecem conflitantes na literatura, enquanto outros têm se mostrado mais consistentes. Paiva Filho \& Giannini (1990) sugerem outubro como o início da época reprodutiva de $A$. brasiliensis, avaliando que ocorreria uma desova única no verão na baíaestuário de Santos e São Vicente (SP). Por outro lado, Peres-Rios (2001) observou que esta espécie no sistema costeiro Cananéia-Iguape (SP) apresenta indicação de desova em todas as épocas do ano, com maior intensidade no inverno e na primavera. Favaro et al. (2003) constataram, em 
uma planície de maré adjacente à gamboa do Baguaçu, baía de Paranaguá (PR), que ocorrem indivíduos maduros e semi-desovados de $A$. brasiliensis ao longo de todo o ano, com maior freqüência entre dezembro e maio, e entre os meses de junho a setembro, caracterizando uma desova parcelada. Mais ao sul, na região estuarina da Lagoa dos Patos, Bemvenuti (1987) concluiu que a desova ocorre em uma época do ano, o verão, e que no restante do ano os indivíduos encontravam-se em repouso reprodutivo. Assim, entre o litoral central do estado de São Paulo (Santos) e o Rio Grande do Sul, a desova do peixe-rei ocorre do final da primavera ao verão, enquanto que nos estuários de Cananéia e em Paranaguá haveria desova ao longo de todo o ano, com picos de maior intensidade em épocas diferentes.

Apesar da abundância de Atherinella brasiliensis no litoral da região sudeste-sul do Brasil, estudos integrando aspectos do crescimento, reprodução, mortalidade e a longevidade sobre a espécie são inexistentes. $\mathrm{O}$ presente estudo visa estudar a biologia populacional da espécie, através de seu crescimento, reprodução, mortalidade e longevidade, fornecendo subsídios para o entendimento de sua dinâmica populacional e de seu ciclo de vida.

Por outro lado, o crescimento e a reprodução de todos os organismos marinhos, entre eles os peixes, podem ser afetados significativamente por atividades antropogênicas, como, por exemplo, pelo acúmulo de contaminantes causados pelo despejo de substâncias no ambiente, tais como esgotos, óleos, PCB's, DTT's, metais pesados, entre outros. Dentre as apresentadas, a contaminação por metais pesados pode ser considerada das mais sérias devido à toxicidade desses elementos, sua longa persistência no ambiente, sua bioacumulação e biomagnificação na cadeia trófica, podendo causar doenças 
ao homem e danos ambientais muitas vezes irreparáveis (Perugini et al., 2004).

Fígado, gônadas, pele e musculatura são os órgãos que mais apresentam bioacumulação, principalmente de metais pesados, nas diversas espécies de peixes, independente de seu hábito ou tipo de alimentação (Yilmaz, 2003).

Os panoramas traçados anteriormente justificam a necessidade do presente estudo, que preencheria lacunas de conhecimento sobre o ciclo de vida desta espécie da ictiofauna brasileira, principalmente para a região sudeste-sul do Brasil.

\section{OBJETIVOS}

A proposição dos objetivos considera que os resultados obtidos fornecerão subsídios para compreender o ciclo de vida desta espécie.

\subsection{Objetivo geral}

- Estudar a estrutura e a dinâmica da população de Atherinella brasiliensis da praia de Itamambuca, Ubatuba (SP);

- Avaliar o modelo de crescimento corporal, aspectos reprodutivos, mortalidade natural e longevidade.

- Verificar, de forma preliminar, os possíveis impactos antrópicos exercidos sobre a população desta espécie na região, representados pela análise de metais na musculatura. 


\subsection{Objetivos específicos}

- Verificar a distribuição espaço-temporal da espécie na região;

- Identificar a estrutura em tamanho e a estrutura etária da população existente no local;

- Estimar as taxas de mortalidade natural e longevidade;

- Estimar a época de desova da população, a partir das estimativas dos parâmetros das variáveis reprodutivas.

- Verificar a ocorrência e a acumulação de metais traço em Atherinella brasiliensis na região.

\section{CARACTERIZAÇÃO DA ÁREA DE ESTUDO}

A área de estudo localiza-se na região de Ubatuba, no litoral norte do estado de São Paulo. Segundo Negreiros-Fransozo et al. (1991), a região apresenta o relevo subjacente emerso, sendo que a conformação topográfica do fundo evidencia o afogamento dos esporões terminais da Serra do Mar. Tais aspectos promovem a formação de um litoral extremamente recortado (enseadas e baías) no qual se encontram ambientes propícios ao estabelecimento e desenvolvimento de uma grande variedade de organismos. Além disso, raros são os corpos de água doce que se constituem em drenos das fontes terrígenas e em dependência direta da pluviosidade local.

Um fato relevante ocorre na região costeira de Ubatuba onde três tipos de massas d'água se encontram (Castro-Filho et al., 1987):

- Água Central do Atlântico Sul (ACAS) - água relativamente fria com temperatura variando entre $6^{\circ}$ a $18^{\circ} \mathrm{C}$ e salinidade entre 34,5 a 35,9 ; 
- Água Tropical (AT) - água quente e salina com temperatura maior do que $18^{\circ} \mathrm{C}$ e salinidade maior do que $35,9, \mathrm{e}$

- Água costeira (AC) - água resultante da mistura da descarga continental de água doce com as águas da plataforma continental, tendo baixos valores de salinidade e temperatura média de $22^{\circ} \mathrm{C}$.

Durante os meses de novembro e março a maior freqüência de ocorrência da ACAS na camada de fundo em contato com a AC, favorece a formação de uma termoclina marcante (entre 20 e $50 \mathrm{~m}$ ), período em que os ventos NE são predominantes nas proximidades da costa. O período outonoinverno caracteriza-se pelo resfriamento das águas superficiais (ventos SW) e intensificação dos processos de mistura, eventos responsáveis pelo desaparecimento da termoclina sazonal. No inverno a AT domina a camada superficial na plataforma externa, e a plataforma interna é ocupada principalmente pela $A C$, sendo que há um recuo da ACAS em direção ao talude, ocorrendo menos eventos de penetração dessa massa de água sobre a plataforma continental (Castro-Filho et al., 1987; Castro \& Miranda, 1998).

A praia de Itamambuca (aprox. 23 $24^{\prime} S-45^{\circ} 00^{\prime} \mathrm{W}$ ) encontra-se localizada ao norte da cidade de Ubatuba, sendo a praia, dentro do município, mais exposta para o oceano. Possui $1.800 \mathrm{~m}$ de extensão e orientação NE SW voltada para SE, declividade variada e areia média (Barros, 1997), apresentando pequeno aporte de águas interiores nas suas duas extremidades, sendo que ao sul está localizado o rio Itamambuca, que contribui com um maior aporte de água.

Como em toda a região sudeste do Brasil, a praia de Itamambuca apresenta um regime de maré semidiurna, ocorrendo diariamente dois ciclos de 
maré, com amplitude máxima registrada durante o período estudado de 1,3 m e a mínima de $-0,1 \mathrm{~m}$, tendo o sentido anticiclônico predominante de circulação na região (Mesquita \& Harari, 1999).

Apesar de estar fora da área das unidades de conservação, até meados da década de 1990 a praia de Itamambuca apresentava uma ocupação rarefeita, causando poucas alterações em seu ambiente natural (Barros, 1997). Entretanto, nos últimos anos o número de casas de veraneio, áreas de "camping", restaurantes e pousadas têm aumentado rapidamente, albergando grande quantidade de turistas.

\section{MATERIAIS E MÉTODOS}

\subsection{Dados abióticos}

A tomada dos dados abióticos se restringiu à temperatura da água, com termômetro de mercúrio e à salinidade, com refratômetro

A tábua de maré utilizada foi disponibilizada pelo Laboratório de Marés e Processos Temporais Oceânicos (MAPTOLAB) do Instituto Oceanográfico da Universidade de São Paulo (IOUSP), cujos dados foram obtidos através de um marégrafo instalado na Base Clarimundo de Jesus (IOUSP), em Ubatuba, na praia do Lamberto.

\subsection{Coleta de exemplares}

As coletas foram realizadas mensalmente no período de 18 meses (setembro de 2003 a fevereiro de 2005), utilizando uma rede de picaré, com 9 
$\mathrm{m}$ de comprimento e 1,5 $\mathrm{m}$ de altura, panagem central de $3 \mathrm{~m}$ de comprimento e malha de $10 \mathrm{~mm}$ entre nós consecutivos e com panos laterais de $3 \mathrm{~m}$ de comprimento e malha de 20 mm entre nós consecutivos.

Uma unidade de esforço foi representada por três arrastos de $50 \mathrm{~m}$ cada, a uma profundidade menor que 1m, em cinco estações (Figura 1), sendo quatro ao longo da praia e uma estação situada dentro do rio Itamambuca. Tendo-se em vista um período de 24 horas foram feitas duas coletas, uma no período diurno (primeiras horas de luz) e outra no período noturno (primeiras horas de escuro).

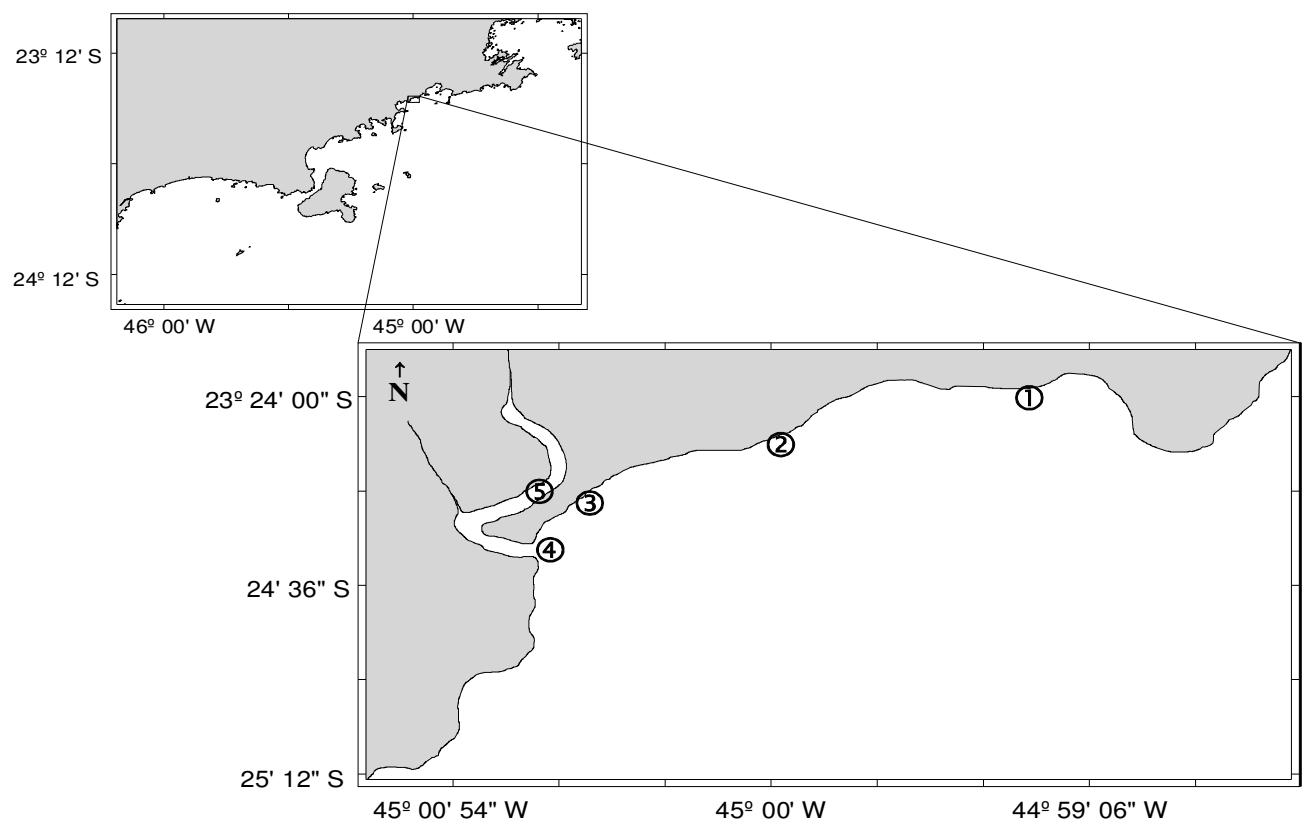

Figura 1. Representação da região costeira entre Santos e llha Grande, com detalhe da praia de Itamambuca, litoral norte do estado de São Paulo, com a localização das estações de coleta de amostras e de dados ambientais.

\subsection{Freqüência de ocorrência e abundância no espaço e no tempo}

A distribuição e abundância relativa dos espécimes foram calculadas com base no número de indivíduos e biomassa. Não foram efetuados cálculos 
por CPUE (captura por unidade de esforço), porque todas as coletas foram realizadas com o mesmo esforço de pesca. As variações espaciais foram estudadas, considerando-se as estações de coleta, ao longo da praia e dentro do rio Itamambuca. O critério temporal considerou os meses individuais de amostragens e o agrupamento por estações do ano: verão (dezembro, janeiro e fevereiro), outono (março, abril e maio), inverno (junho, julho e agosto) e primavera (setembro, outubro e novembro).

Os dados foram analisados estatisticamente visando detectar padrões de variação espacial e temporal. Para avaliar a significância das diferenças entre os valores obtidos e os valores médios dos dados bióticos e abióticos, foi utilizada a Análise de Variância (ANOVA) ao nível de confiança de 95\% ( $p<$ $0,05)$ para os dados com distribuição normal. Para os conjuntos de dados com distribuição não normal foi utilizado o teste não-paramétrico Kruskal-Wallis.

A partir dos dados de captura (dia, noite e total) e dos dados abióticos (temperatura e salinidade) de cada estação de coleta foram realizadas análises de agrupamento UPGMA utilizando o programa MVSP $3.01^{1}$ (Multi-Variate Statistical Package), através dos valores de distância euclidiana calculados. Esta análise permite compreender e descrever mais adequadamente a estrutura dos dados e suas relações, agrupando conjuntos que possuem mesma similaridade euclidiana, já que os grupos são determinados de forma a obter-se um elevado grau de homogeneidade dentro dos grupos e um alto nível de heterogeneidade entre eles.

\footnotetext{
${ }^{1}$ A menção da marca/modelo não implica em sugestão de uso.
} 


\subsection{Estudo do crescimento}

\subsubsection{Obtenção dos dados}

Para a obtenção dos dados e para a coleta das estruturas para o estudo do crescimento do peixe-rei, realizou-se a biometria dos indivíduos e a retirada dos otólitos sagitta de todos os indivíduos capturados para tomada de medidas e leitura de anéis etários.

Os peixes foram medidos em ictiômetro com de precisão de $1 \mathrm{~mm}$, tomando-se a medida do comprimento total $(C T)$, descrita como sendo a distância da ponta do focinho até o término da nadadeira caudal, em milímetros $(\mathrm{mm})$. Obteve-se também a massa total $(M T)$ em gramas $(\mathrm{g})$ com precisão de 0,01 g. A partir desses dados, obteve-se a distribuição mensal da freqüência por classes de comprimento e a relação massa-comprimento por período e por sexos separados e agrupados. Com o ajuste dos valores pelo modelo potencial, a expressão derivada, ajustada pelo método dos mínimos quadrados, é $M T=\mathrm{aCT}^{\mathrm{b}}$, em que $M T$ corresponde à massa total $(\mathrm{g}), C T$ ao comprimento total $(\mathrm{mm})$, a corresponde à estimativa dos parâmetros de correlação e $\underline{b}$ à estimativa dos parâmetros de curvatura.

Os otólitos sagitta foram retirados da cápsula auditiva, lavados, secos e acondicionados em sacos plásticos devidamente identificados, para posterior processamento.

A morfometria dos otólitos foi realizada em mesa digitalizadora acoplada a um estereomicroscópio, onde foram tomados os dados de comprimento $(\mathrm{Co})$, altura $(\mathrm{Ho})$ e, posteriormente, tomada a massa dos otólitos (Mo) em balança analítica. 
A preparação dos otólitos para a leitura dos anéis foi realizada de forma que cada um foi limpo com hidróxido de sódio a 10\% para a remoção de qualquer vestígio de matéria orgânica e, posteriormente, colado em lâmina de vidro com etil-acetato butil-acetato ("Ethil Acetate Butylacetate") incolor. Após a colagem, os otólitos foram lixados. A seguir, os otólitos foram examinados sob microscópio de luz, quando foi traçado um raio de leitura do núcleo para o pósrostro ("post-rostrum"), tendo sido realizadas duas leituras independentes, sem consulta aos resultados anteriores. Quando não houve coerência no número de anéis em ambas as leituras era realizada uma terceira leitura. Se o erro persistia após a terceira leitura, o otólito era excluído das análises.

\subsubsection{Método indireto}

Com o intuito de gerar resultados que pudessem ser comparados com aqueles obtidos pelo método direto, foi aplicada a rotina "Shepherd" do programa FISAT II (FAO-ICLARM Fish Stock Assessment Tools / versão 1.2.0), aos dados de distribuição mensal da freqüência por classe de comprimento dos indivíduos capturados. A aplicação dessa rotina permite calcular alguns parâmetros das variáveis de crescimento, tais como o comprimento total assintótico $\left(C T_{\infty}\right)$, a taxa de crescimento $(K)$ da espécie na região, a quantidade de coortes, o comprimento total no primeiro ano de vida e o mês de recrutamento. Como o programa não calcula a longevidade nem $t_{0}$, foi utilizada a fórmula proposta por Taylor (1960) para a estimativa da longevidade e a equação empírica de Pauly (1979) para a estimativa de $t_{0}$, utilizando as variáveis calculadas pelo programa, sendo: 


$$
\log \left(-t_{0}\right)=-0,3922-0,2753 * \log C T_{\infty}-1,038 * \log K
$$

em que $t_{0}$ é a idade teórica no comprimento zero, $C T_{\infty}$ é o comprimento máximo teórico esperado para a população e $k$ é a taxa de crescimento.

\subsubsection{Método direto}

a. Relações entre o crescimento do otólito e o crescimento da

\section{espécie}

Visando correlacionar o crescimento do otólito com o crescimento da espécie, foram medidos o comprimento e a altura dos otólitos, considerando o comprimento $(\mathrm{CO})$ como a maior distância entre as margens anterior e posterior e a altura $(A O)$ a maior distância entre as margens dorsal e ventral (Figura 2), com precisão de 0,00001 mm, utilizando uma mesa digitalizadora acoplada a um estereomicroscópio. Os otólitos foram pesados $(M O)$ em uma balança analítica com precisão de $0,0001 \mathrm{~g}$.

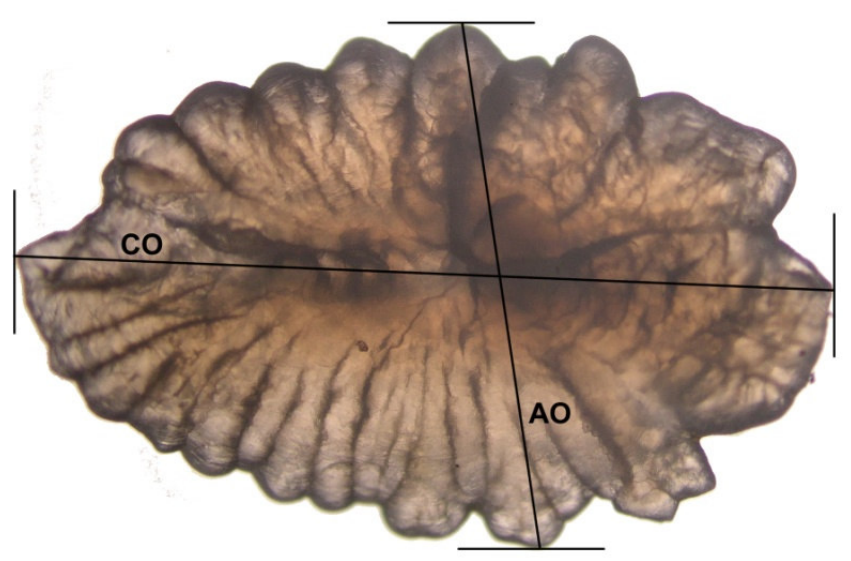

Figura 2. Medidas realizadas nos otólitos de Atherinella brasiliensis da praia de Itamambuca - Ubatuba (SP). CO é o comprimento $(\mathrm{mm})$ e $A O$ é a altura do otólito (mm). 
As massas e medidas do otólito esquerdo e direito de um universo amostral de 100 pares foram submetidos a um teste estatístico ("teste $t$ Student" pareado) para verificar a existência ou não de diferença significativa entre eles. Após verificar que as medidas dos otólitos direito e esquerdo não apresentaram diferenças significativas, foram realizadas as medições e a pesagem somente do otólito direito para o restante do material.

Diagramas de dispersão foram obtidos com os valores do comprimento e massa do otólito e comprimento total dos espécimes. Com base nos padrões de dispersão dos pontos, foi verificado qual o modelo que melhor representa estas relações. Para a escolha do modelo, foram considerados os seguintes aspectos: o coeficiente de determinação $\left(r^{2}\right)$; a dispersão dos valores dos resíduos padronizados; o significado biológico dos dados analisados.

\section{b. Validação}

Para estabelecer a periodicidade de formação dos anéis nos otólitos foi utilizado o método direto de marcação do otólito. Esse método de validação consiste no reconhecimento de dois anéis marcados com um componente químico, em um intervalo de tempo pré-estabelecido (Folkvord, et al. 2000). Vinte juvenis de Atherinella brasiliensis (variando de 30 a $55 \mathrm{~mm}$ de comprimento total) foram capturados em campo e mantidos em laboratório em aquários, onde foram separados em dois lotes de 10 indivíduos submetidos ao marcador "alizarina S" $\left(\mathrm{C}_{14} \mathrm{H}_{7} \mathrm{NaO}_{7} \mathrm{~S} \mathrm{H}_{2} \mathrm{O}\right)$ a uma concentração de $350 \mathrm{mg} / \mathrm{l}$ durante 24 horas. A alizarina foi adicionada à água dos aquários, sendo que 
depois de transcorridas 24 horas a água foi totalmente trocada. Após nove dias da troca de água, se repetiu o procedimento com o marcador químico.

Após o processo de marcação, os indivíduos foram mantidos nos aquários e após suas mortes seus otólitos sagitta foram retirados para a montagem em lâminas e contagem dos anéis diários, sendo que entre os dois anéis marcados com alizarina supõe-se que existam 9 anéis, se a deposição dos incrementos for circadiana. Para melhor visualização dos anéis marcados nos otólitos, os mesmos foram examinados sob um microscópio de fluorescência com luz ultravioleta (UV) em comprimento de onda de $472 \mathrm{~nm}$. Devido à composição química da alizarina, ocorre emissão de luz visível quando há excitação através da luz UV, realçando os anéis marcados e possibilitando uma leitura mais confiável.

\section{c. Estrutura etária}

Constatada a periodicidade dos anéis ou bandas de crescimento através do método direto, torna-se possível considerar como idade os grupos de anéis. Foram utilizados diversos otólitos por classe de comprimento, mas considerados apenas 10 , cujas leituras foram coincidentes e consistentes. Desta forma, foi possível caracterizar a estrutura etária do conjunto de

indivíduos subamostrados de Atherinella brasiliensis, possibilitando a construção de uma chave idade-comprimento para a espécie para a praia de Itamambuca, com as médias dos comprimentos em cada anel ou banda de crescimento e seus desvios-padrão. 


\section{d. Estimativa dos parâmetros das variáveis de crescimento}

A descrição do crescimento, pelo método direto, foi feita através do modelo de von Bertalanffy (1938), que segue a seguinte equação:

$$
C T_{i}=C T_{\infty}\left(1-e^{-k\left(t-t_{0}\right)}\right)
$$

em que CTi é o comprimento do peixe na idade $i, C T_{\infty}$ é o comprimento máximo teórico esperado para a população, $k$ é a taxa de crescimento, $t$ é o momento na idade í e no comprimento CTi e to a idade teórica no comprimento zero.

Para a estimação dos parâmetros de crescimento foram utilizados diferentes métodos, para comparar seus resultados. Os seguintes métodos foram aplicados: Gulland e Holt (1959), Ford-Waldford (Walford, 1946) e von Bertalanffy (Sparre \& Venema, 1998).

\section{d.1. Método de Gulland e Holt (Gulland \& Holt, 1959)}

O método gráfico de Gulland e Holt (1959) é descrito pela equação:

$$
\frac{\Delta C T}{\Delta i}=k * C T_{\infty}-k * C T_{\text {médio }}
$$

Para o calculo do comprimento total médio $\left(C T_{\text {médio }}\right)$, os valores de comprimento total médio do peixe na idade i $\left(C T_{i}\right)$ e o comprimento total médio dos peixes na idade seguinte $\left(C T_{i+1}\right)$ foram somados e divididos por 2 como mostra a equação a seguir:

$$
C T_{\text {médio }}=\frac{C T_{i+1}+C T_{i}}{2}
$$


A seguir foram calculados o $\Delta i$ como sendo a diferença entre a idade $i \mathrm{e}$ a idade $i+1$ e o $\triangle C T$ sendo também a diferença entre o comprimento total médio na idade $i\left(C T_{i}\right)$ e o comprimento total médio dos peixes na idade seguinte $\left(C T_{i+1}\right)$. Após realizar esses cálculos, foi realizada a divisão entre esses valores $\Delta C T / \Delta i$.

Usando o comprimento total médio $\left(C T_{\text {médio }}\right)$ como a variável independente e $\Delta C T / \Delta i$ como variável dependente, os valores foram lançados em gráficos de dispersão e a seguir calculados os parâmetros ( $a$ e b) da regressão, pelo método dos mínimos quadrados:

$$
\frac{\Delta C T}{\Delta i}=a+b C T_{\text {médio }}
$$

Os parâmetros de crescimento $k$ e $C T_{\infty}$ foram obtidos através de:

$$
\begin{gathered}
k=-b \\
C T_{\infty}=\frac{-a}{b}
\end{gathered}
$$

Para estimar do valor de $t_{0}$ utilizou-se a equação de crescimento de von Bertalanffy transformada:

$$
t_{0}=t+\left(\frac{1}{k}\right) *\left(\ln \left(\frac{C T_{\infty}-C T_{i}}{C T_{\infty}}\right)\right)
$$

Utilizando os valores de $k$ e $C T_{\infty}$ obtidos e os valores de comprimento médio de cada grupo $\left(C T_{i}\right)$ calculou-se o to para cada um destes grupos, considerando-se as média dos valores de $t_{0}$ obtidos. 


\section{d.2. Método de Ford-Walford (Walford, 1946)}

Trata-se de um modo gráfico simples, sendo adotado o seguinte protocolo para cálculo, baseado em Vazzoler (1981).

Os valores de comprimento total médio dos exemplares na idade i $\left(C T_{i}\right)$ e o comprimento total médio dos exemplares na idade seguinte $\left(C T_{i+1}\right)$ foram lançados em gráficos de dispersão e a seguir calculados, pelo método dos mínimos quadrados, os parâmetros ( $a$ e b) da regressão:

$$
C T_{i+1}=a+b C T_{i}
$$

Estimou-se o $C T_{\infty}$ considerando, na equação acima, $C T_{i+1}=C T_{i}$, ou seja, o momento em que o crescimento da espécie pode ser descrito por:

$$
C T_{\infty}=\frac{a}{1-b}
$$

Lançaram-se em gráfico de dispersão os valores do logaritmo natural de $\left(C T_{\infty}-C T_{i}\right)$ e a idade (i), estimando-se os parâmetros ( $c$ e $\left.d\right)$ da regressão abaixo, também pelo método dos mínimos quadrados.

$$
\ln \left(C T_{\infty}-C T_{i}\right)=c+d i
$$

em que a taxa de crescimento ( $k$ ) é igual ao valor, em módulo, da inclinação da reta $(d)$ e o $t_{0}$, corresponde ao tempo $(I)$ em que o peixe teria o comprimento total igual a 0 :

$$
\begin{gathered}
k=|b| \\
t_{0}=\frac{c-\ln C T_{\infty}}{k}
\end{gathered}
$$




\section{d.3. Método de Von Bertalanffy (Sparre \& Venema, 1998)}

Este método estima o valor de $t_{0}$ e $k$, porém o valor de $C T_{\infty}$ deve estar disponível (Sparre \& Venema, 1998).

Inicialmente calculou-se os parâmetros da regressão linear entre a idade $i$ e o logaritmo natural de $1-C T_{i} / C T_{\infty}$.

$$
-\ln \left(1-\frac{C T_{i}}{C T_{\infty}}\right)=a+b i
$$

O valor de $k$ corresponde à inclinação da reta $(b)$ e o valor de $t_{0}$ foi estimado a partir da equação:

$$
t_{0}=\frac{-a}{b}
$$

Foi utilizada a fórmula de Taylor (Taylor, 1962) para estimar o $C T_{\infty}$ :

$$
C T_{\infty}=\frac{C T_{\max }}{0,95}
$$

em que $C T_{\max }$ é o tamanho do maior peixe amostrado; porém, optou-se por utilizar o maior comprimento encontrado em literatura para a região do litoral sul-sudeste do Brasil.

\section{e. Performance de crescimento ( $\left.\Phi^{\prime}\right)$}

Com o objetivo de comparar o crescimento de peixes e invertebrados, cujo crescimento pudesse ser descrito pelo modelo de von Bertalanffy, Munro \& Pauly (1983) propuseram o Índice de performance de crescimento $(\Phi)$. Como os valores do índice obtidos para indivíduos de uma mesma família 
apresentavam valores próximos e com distribuição normal, os autores concluíram que os valores do índice de performance de crescimento podem representar a energia de um dado habitat ou nicho, pois estariam diretamente relacionados à performance de crescimento e, portanto, ao metabolismo e ao consumo alimentar.

Assim, com o intuito de comparar as curvas de crescimento obtidas no presente estudo, a partir de diferentes métodos, utilizou-se o índice de performance de crescimento, o phi-prima $(\Phi)$, estabelecido por Munro \& Pauly (1983), que utiliza os parâmetros da equação de von Bertalanffy como mostra a fórmula abaixo:

$$
\emptyset^{\prime}=\log k+2 \log C T_{\infty}
$$

\subsubsection{Estudo de mortalidade}

\section{a. Mortalidade natural}

O coeficiente de mortalidade natural $(M)$ foi estimado pelo método baseado na relação de $M$ com outros parâmetros do ciclo de vida do peixe, utilizando-se a fórmula empírica de Pauly (1980):

$$
\ln M=-0,0152-0,279 * \ln C T_{\infty}+0,6543 * \ln k+0,463 * \ln \bar{T}
$$

em que $K$ é a constante de crescimento, CTळ o comprimento total assintótico e $T$ a temperatura média do ambiente. 


\section{b. Longevidade}

A longevidade foi estimada com base na fórmula proposta por Taylor (1960), que é o tempo que um indivíduo leva para alcançar 95\% do comprimento assintótico $\left(A_{0,95}\right)$ :

$$
A_{0,95}=t_{0}+\frac{2,996}{k}
$$

\subsection{Estudo da reprodução}

\subsubsection{Proporções sexuais}

A estrutura da população em sexo, ou as proporções sexuais, pode variar em função do tempo, espaço e do tamanho dos indivíduos, indicando modificações em seu comportamento reprodutivo (Wootton, 1990). Para isso foram realizados cálculos sobre as proporções sexuais visando analisar três aspectos importantes: estrutura da população para o período estudado; variação temporal das proporções entre machos e fêmeas; e a variação das proporções sexuais por classe de comprimento. A identificação do sexo foi baseada na descrição de características listadas em Vazzoler (1996) e a hipótese de que as proporções entre machos e fêmeas são 1:1 foi averiguada pelo teste do $\chi^{2}$ (Zar, 1996). Devido às dificuldades de se identificar macroscopicamente o sexo dos indivíduos imaturos, optou-se por considerar apenas os indivíduos adultos para os cálculos.

\subsubsection{Identificação dos estádios de maturidade gonadal}

A freqüência de ocorrência dos indivíduos em diferentes estádios de maturidade gonadal foi calculada por época do ano para todas as fêmeas 
coletadas. A classificação dos estádios de maturação gonadal foi realizada macroscopicamente, seguindo a escala proposta por Dias et al. (1998).

A partir dessa classificação, foi possível avaliar as proporções entre jovens e adultos por época e por local de coleta, o que pode sugerir períodos e áreas de recrutamento. Assim, são considerados indivíduos jovens aqueles que apresentavam o estádio A (imaturo) de maturação gonadal e peixes adultos aqueles classificados com os demais estádios. Além disso, é possível verificar a ocorrência de desova na área pela presença de indivíduos hidratados (estádio D) e desovados (estádio E).

As gônadas foram retiradas e pesadas após a identificação macroscópica do sexo e do estádio de maturação gonadal. Posteriormente, foram fixadas com formalina a $10 \%$ neutralizada, em frascos devidamente identificados.

Foi também realizada a classificação microscópica dos estádios de maturação gonadal para $58,3 \%$ de fêmeas amostradas. Usando-se a metodologia sugerida por Vazzoler (1996) e Bremer et al. (1976) foram montadas as preparações permanentes com cortes de tecidos somente para os ovários. Este detalhamento, através da análise microscópica, teve como objetivo verificar a acuidade da classificação macroscópica, minimizando erros na classificação (Dias et al., 1998; Dias et al., 2005), a partir da verificação da ocorrência das diferentes fases do desenvolvimento ovocitário nas gônadas, bem como confirmar o sexo dos exemplares.

Quando foi possível a identificação do sexo para os machos, estes foram classificados simplesmente como adultos, uma vez que mesmo machos com gônadas muito pequenas já possuem espermatozóides (Grier, 1981). 
Normalmente as fêmeas são utilizadas nos estudos sobre reprodução, pois são potencialmente capazes de fornecer informações sobre o grau de maturação, e sobre o número de descendentes (West, 1990).

\subsubsection{Comprimento médio de início de primeira maturação gonadal}

Segundo Vazzoler (1996), o tamanho médio de início de primeira maturação gonadal $\left(L_{50}\right)$ é o comprimento com o qual $50 \%$ dos indivíduos já participa do conjunto de adultos da população.

A partir da proporção de indivíduos adultos, classificados nos estádios B, C, D e E, em relação aos indivíduos jovens e imaturos (estádio A), por classe de comprimento, foi estimado o comprimento médio de primeira maturação gonadal. O ajuste de uma curva média aos pontos obtidos foi calculado para para os sexos agrupados, através do método proposto por King (1995), utilizando a equação da curva logística ajustada à proporção de

indivíduos adultos por classe de comprimento. A proporção de adultos é descrita pela equação:

$$
P=\frac{1}{\left(1+e^{-r\left(C T-C T_{m}\right)}\right)}
$$

em que $C T$ é o comprimento total do peixe, $r$ é a inclinação da curva e $C T_{m}$ é o comprimento médio na primeira maturação, ou o comprimento que corresponde a $50 \%(0,5)$ de adultos.

Para a estimativa do $C T_{m}$, a equação deve ser linearizada, com a seguinte equação 


$$
\ln \frac{(1-P)}{P}=r C T_{m}-r C T
$$

que se torna igual à equação de uma reta, $y=a-b x$, em que $a=r C T$ e $b=r$.

$$
\begin{aligned}
& r=-(b) \\
& C T_{m}=\frac{a}{r}
\end{aligned}
$$

\subsubsection{Indicadores quantitativos da reprodução}

\section{a. Fator de condição alométrico e $\Delta K$}

O fator de condição (K) (Le Cren, 1951) tem sido usado como indicador quantitativo do grau de higidez ou do bem estar do peixe, refletindo condições alimentares recentes e é dado pela relação entre a massa e o comprimento do indivíduo (Vazzoler, 1996). Apesar do fator de condição em si nem sempre apresentar relação direta com a reprodução, para um melhor entendimento do processo reprodutivo, a partir do uso de indicadores quantitativos, foi estimada a diferença entre os valores do fator de condição alométrico calculados com a massa total (K) e com a massa total sem a massa das gônadas (K’) (Vazzoler, op. cit.). Essa diferença $(\Delta K)$ expressaria, de modo relativo, a parcela da massa gonadal, reforçando os resultados obtidos por outros indicadores da reprodução.

Foi calculado o fator de condição alométrico para todas as épocas de coleta, que exige a estimativa preliminar dos parâmetros das variáveis expressas na relação massa-comprimento, expressa por $M T=a C T^{b}$. Para facilitar o manuseio e a representação gráfica dos mesmos, esses indicadores foram 
multiplicados pela potencia de $10^{4}$, sendo expressa da seguinte forma:

$$
\begin{gathered}
K=\frac{M T}{C T^{b}} * 10^{4} \\
K^{\prime}=\frac{M T-M_{g}}{C T^{b}} * 10^{4}
\end{gathered}
$$

em que $C T$ é o comprimento total do peixe, $M T$ é a massa total do peixe, $M_{g}$ é a massa das gônadas e $b$ é o coeficiente angular do modelo potencial que expressa a relação massa-comprimento.

\section{b. Relação gonadossomática}

A relação gonadossomática (RGS) expressa a razão, em porcentagem, entre a massa da gônada e a massa dos indivíduos (total ou sem as gônadas). Sua variação temporal pode indicar o período de maior atividade reprodutiva das espécies.

A RGS foi calculada para cada indivíduo, para todo o período de coleta, considerando o comprimento total, as épocas de coletas, os sexos e os estádios de maturação gonadal, através da equação apresentada por Vazzoler (1996):

$$
R G S=\frac{M_{g}}{M T} * 100
$$

em que $M_{g}$ é a massa das gônadas e $M T$ a massa total do espécime. 


\subsubsection{Fecundidade}

Para o estudo da fecundidade por lote foram retiras três alíquotas (anterior, mediana e posterior), com cerca de $0,5 \mathrm{~cm}$ de comprimento, de 30 gônadas em que houve a comprovação histológica de que se tratavam de ovários no estádio D (hidratados) de Atherinella brasiliensis para a contagem dos ovócitos hidratados.

As alíquotas foram pesadas separadamente em uma balança com precisão de $0,0001 \mathrm{~g}$ e os ovócitos hidratados identificados e contados com o auxílio de um estereomicroscópio. Após contagem dos ovócitos realizou-se um teste estatístico para verificar se havia ou não diferenças significativas entre as alíquotas (Collins et. al.,1996).

A fecundidade por lote para cada exemplar foi calculada utilizando-se a equação abaixo:

$$
F L=\frac{N_{\text {lote }} * M_{g}}{M_{\text {lote }}}
$$

onde, $N_{\text {lote }}$ e $M_{\text {lote }}$ são o número médio de ovócitos hidratados e a massa média dos três lotes e $M_{g}$ a massa total da gônada.

\subsection{Análise espectroscópica por emissão de raios-x induzida por}

\section{partículas}

Para a identificação e quantificação de contaminantes, uma das técnicas incorporadas no Brasil desde o final dos anos 70, pelo Instituto de Física da Universidade de São Paulo (IF-USP), é a espectroscopia por emissão de raios-x induzida por partículas (PIXE), sobre a quais diversos trabalhos 
científicos foram publicados, especialmente na área ambiental (Yoneama et al., 2004). A utilização desta técnica apresenta diversas vantagens comparadas às outras técnicas usuais por ser rápida (Elfman et al., 1999), ter alta sensibilidade à deteç̧ão de elementos traços (Tükmen et al., 2005), e ser não destrutiva. De fato, as amostras irradiadas pelo PIXE podem posteriormente ser analisadas por outras técnicas físicas complementares, tais como a Retroespalhamento Rutherford (RBS), Análise de Átomos por Recuo Elástico (ERDA) e Análise por Reações Nucleares (NRA) (Yoneama et al., 2004), ou por técnicas químicas, como a cromatografia acoplada a um espectrômetro de massa.

A análise PIXE vem sendo utilizada em otólitos de peixes para pesquisar níveis de contaminação ao longo do seu ciclo de vida (e.g. Elfman et al.,1999; Babaluk et al.,2002; Saquet et al., 2002 e Barry et al., 2004). Por sua vez, alguns elementos traços podem apresentar alterações na sua concentração, devido ao processo de cristalização do otólito, que varia dependendo da temperatura do ambiente (Arai et al., 1996). Contudo, estudos utilizando essa técnica no Brasil, aplicados à ictiologia, são praticamente inexistentes.

A análise espectroscópica por emissão de raios-x induzida por partículas (PIXE) foi realizada em compostos ("pools") de tecido da musculatura médio-lateral de 84 exemplares de Atherinella brasiliensis das cinco estações de coleta (praia de Itamambuca e rio) em dois períodos diferentes: fora da temporada turística (julho e setembro de 2004) e na época de maior afluência turística (janeiro e fevereiro de 2005). A musculatura foi o tecido-alvo escolhido para as análises, pois é o consumido pelas populações 
humanas, embora seja conhecido como um tecido que apresenta menores concentrações de metais do que fígado ou gônadas (Yilmaz, 2003).

Para avaliar uma possível biocumulação dos contaminantes em $A$. brasiliensis da praia de Itamambuca, a análise PIXE também foi realizada com o tecido da musculatura médio-lateral de indivíduos jovens, de pequeno porte (<100 mm) e de indivíduos maiores $(>100 \mathrm{~mm})$, de forma a separar duas classes de tamanho e fases do ciclo de vida diferentes, totalizando 17 indivíduos pequenos e 67 indivíduos maiores.

As amostras de tecido foram liofilizadas no próprio Instituto Oceanográfico (USP) e mandadas ao Laboratório de Implantação lônica da Universidade Federal do Rio Grande do $\mathrm{Sul}^{2}$, para análise.

Uma explicação resumida da técnica pode ser encontrada a seguir. Um próton, ou outra partícula carregada com alguns MeV de energia, passa perto de um átomo, transferindo-lhe energia. Nesse processo pode ocorrer a emissão de um elétron das camadas mais internas do átomo. O átomo se deexcita, ou seja, volta ao seu estado de menor energia, através de um re-arranjo de suas camadas eletrônicas. Assim, elétrons de camadas mais externas preenchem as lacunas deixadas em camadas mais internas. Quando isso acontece, um dos processos possíveis é a emissão de um raio-X. Esse raio-X possui uma energia que é característica de cada elemento da tabela periódica. Desta forma, medindo-se a energia do raio-X saber-se-á de qual elemento ele veio, podendo-se analisar qualitativamente e quantitativamente os elementos que a amostra possui. Os raios-X são detectados com um detector de Si (Li)

\footnotetext{
${ }^{2}$ Laboratório de Implantação lônica do Instituto de Física da Universidade Federal do Rio Grande do Sul, sob a coordenação do Prof. Dr Johnny Ferraz Dias.
} 
refrigerado em nitrogênio líqüido e o sinal armazenado em um analisador multicanal. Igualmente a análise por Fluorescência de Raios-X, a posterior redução dos espectros de raio-X identifica e quantifica os elementos constituintes. Limitado pela absorção na janela do detector, o método PIXE é capaz de identificar e quantificar elementos com $Z=11$, com limite de detecção de $10^{-6} \mathrm{~g}^{*} \mathrm{~g}^{-1}(\mathrm{ppm})$, ou $10^{14} \mathrm{~atm}^{*} \mathrm{~cm}^{-2}$ no caso de filmes finos, e precisão absoluta de 5 a 30\% (Tabacniks, 1998).

Apesar de identificar e quantificar uma grande parte da tabela periódica, as análises serão focadas para os metais pesados. Esses metais pesados, tais como zinco, cobre, chumbo, estanho, cromo e níquel entram no ambiente através de baterias, vasilhas de plástico ou metálicas e tintas, principalmente por despejos clandestinos de esgotos (Motelica-Heino et al.,1998), ou através de ocorrência natural nas rochas do ambiente.

\section{RESULTADOS}

\subsection{Ocorrência e abundância no espaço e no tempo e sua relação}

\section{com as variáveis ambientais}

Durante os 18 meses de coleta foram realizados 108 arrastos na praia e no rio Itamambuca, sendo capturados 203 indivíduos de Atherinella brasiliensis durante o dia e 300 indivíduos durante a noite, num total de 503 exemplares, variando de 20 a $145 \mathrm{~mm}$ de comprimento total. Em todo o período estudado, A. brasiliensis apresentou uma ampla distribuição, ocorrendo em todas as estações de coleta, tendo-se concentrado principalmente na estação 4 durante o período do dia e na estação 5 durante o período da noite. 
As temperaturas da água das estações de coleta (Tabela 1) apresentaram diferenças significativas $(p<0,01$, ANOVA) durante o período estudado (Tabela 2), sendo registradas as menores temperaturas na estação 5 , que se encontra dentro do rio Itamambuca (média de $20,2^{\circ}$ C) e as maiores temperaturas na estação 1 (media de 22, $8^{\circ} \mathrm{C}$ ). A maior temperatura da água registrada foi $28,3^{\circ} \mathrm{C}$ na estação 3 durante fevereiro de 2005 , e a menor $15^{\circ} \mathrm{C}$ durante janeiro de 2005 na estação 5. Foram também encontradas diferenças significativas entre as estações do ano ( $p<0,01$, Kruskal-Wallis) (Tabela 2), com as maiores médias de temperatura nos meses de outono de 2004 e as menores durante os meses de primavera de 2004.

A análise de agrupamento por similaridade euclidiana das estações, levando em consideração a temperatura (Figura 3), agrupou as estações em dois grandes grupos $(A$ e $B)$, sendo que o grupo A contém somente a estação 5, localizada dentro do rio Itamambuca, que apresenta menores temperaturas, e o grupo B, representado pelas estações que estão localizadas ao longo da praia, subdividido em dois subgrupos $\left(B_{1}\right.$ e $\left.B_{2}\right)$. $O$ subgrupo $B_{1}$ contém as estações 1 e 2 que sofrem pouca ou nenhuma influência das águas com menores temperaturas provenientes do rio Itamambuca, enquanto o subgrupo $B_{2}$ contém as estações 3 e 4 que sofrem maior influência do rio e que apresentam as maiores variações de temperatura. 
Tabela 1. Valores das temperaturas da água obtidos nas estações de coletas da praia de Itamambuca - Ubatuba (SP) para todo o período estudado.

\begin{tabular}{|c|c|c|c|c|c|c|}
\hline & & & & staçõe & & \\
\hline Mês & Período & 1 & 2 & 3 & 4 & 5 \\
\hline C5T/0? & Dia & 22,1 & 22,0 & 22,0 & 18,5 & 18,5 \\
\hline SEI/US & Noite & 21,5 & 20,0 & 21,0 & 19,5 & 19,0 \\
\hline & Dia & 21,0 & 21,5 & 22,5 & 22,0 & 20,8 \\
\hline SOI/US & Noite & 20,0 & 21,0 & 19,0 & 17,8 & 17,6 \\
\hline & Dia & 24,0 & 24,5 & 19,5 & 19,0 & 19,0 \\
\hline NOV/03 & Noite & 23,5 & 19,0 & 23,5 & 22,0 & 22,0 \\
\hline & Dia & 24,5 & 24,5 & 24,5 & 24,0 & 22,5 \\
\hline DEZ/03 & Noite & 25,5 & 25,0 & 25,5 & 25,0 & 25,0 \\
\hline JNN/0 & Dia & 24,0 & 24,0 & 24,0 & 22,5 & 22,5 \\
\hline JAIV/U 4 & Noite & 25,0 & 25,0 & 24,0 & 24,0 & 23,0 \\
\hline FEY & Dia & 26,0 & 25,5 & 24,5 & 23,5 & 22,0 \\
\hline REVIU 4 & Noite & 25,0 & 25,0 & 24,0 & 22,5 & 22,0 \\
\hline MP & Dia & 25,5 & 25,0 & 23,5 & 22,0 & 21,5 \\
\hline IVIAR/U4 & Noite & 25,0 & 25,0 & 24,5 & 22,5 & 22,0 \\
\hline $\mathrm{ABR} / 04$ & Dia & 26,0 & 26,0 & 24,0 & 25,0 & 22,0 \\
\hline ABR/ $/ 04$ & Noite & 26,0 & 26,5 & 26,0 & 26,0 & 24,0 \\
\hline MAL/04 & Dia & 24,0 & 24,5 & 24,0 & 22,0 & 20,5 \\
\hline $\mathrm{MIAI} / 04$ & Noite & 24,0 & 24,0 & 24,0 & 23,0 & 21,5 \\
\hline & Dia & 21,0 & 22,0 & 22,0 & 21,5 & 18,0 \\
\hline JUN/U4 & Noite & 21,5 & 22,0 & 21,5 & 21,0 & 18,0 \\
\hline & Dia & 22,0 & 22,0 & 21,0 & 20,5 & 20,0 \\
\hline L//04 & Noite & 23,0 & 22,5 & 23,0 & 22,0 & 21,5 \\
\hline & Dia & 21,0 & 21,0 & 18,0 & 18,2 & 17,9 \\
\hline $\mathrm{AGO} / 04$ & Noite & 22,0 & 22,0 & 21,5 & 20,5 & 20,0 \\
\hline & Dia & 22,0 & 23,0 & 22,0 & 21,0 & 19,5 \\
\hline SET/04 & Noite & 23,0 & 23,0 & 22,0 & 22,0 & 21,5 \\
\hline & Dia & 20,0 & 19,8 & -- & -- & -- \\
\hline $001 / 04$ & Noite & 23,0 & 22,0 & 21,0 & 21,0 & 23,0 \\
\hline & Dia & 18,0 & 18,0 & 18,0 & 18,0 & 17,5 \\
\hline NOV $/ 04$ & Noite & 19,5 & 20,5 & 20,0 & 19,5 & 19,5 \\
\hline & Dia & 18,5 & 19,5 & 19,5 & 18,5 & 17,0 \\
\hline DEZ/04 & Noite & 20,0 & 20,0 & 20,0 & 19,0 & 18,0 \\
\hline$J A N / 05$ & Dia & 18,5 & 19,0 & 18,0 & 18,0 & 15,0 \\
\hline & Noite & 18,0 & 19,0 & 19,0 & 16,0 & 15,0 \\
\hline FE & Dia & 26,3 & 26,3 & 28,3 & 26,4 & 20,0 \\
\hline & Noite & 27,1 & 27,2 & 26,5 & 26,4 & 24,5 \\
\hline
\end{tabular}

Tabela 2. Valores de F (ANOVA) ou H (Kruskal-Wallis) dos fatores ambientais e da captura total de Atherinella brasiliensis da praia de Itamambuca - Ubatuba (SP).

\begin{tabular}{|c|c|c|c|}
\hline Fatores & $\begin{array}{l}\text { Estação de coleta } \\
\text { gl = } 4\end{array}$ & $\begin{array}{c}\text { Estação do ano } \\
\mathrm{gl}=3\end{array}$ & $\begin{array}{c}\text { Período do dia } \\
\mathrm{gl}=1\end{array}$ \\
\hline Temperatura & 6,0309 & $42,6914^{\star}$ & 1,3557 \\
\hline Salinidade & $131,2438^{*}$ & 0,5674 & 0,0001 \\
\hline Captura total & $24,6461^{*}$ & 0,0001 & 0,1675 \\
\hline
\end{tabular}

${ }^{*}$ Kruskal-Wallis; negrito = diferença significativa 


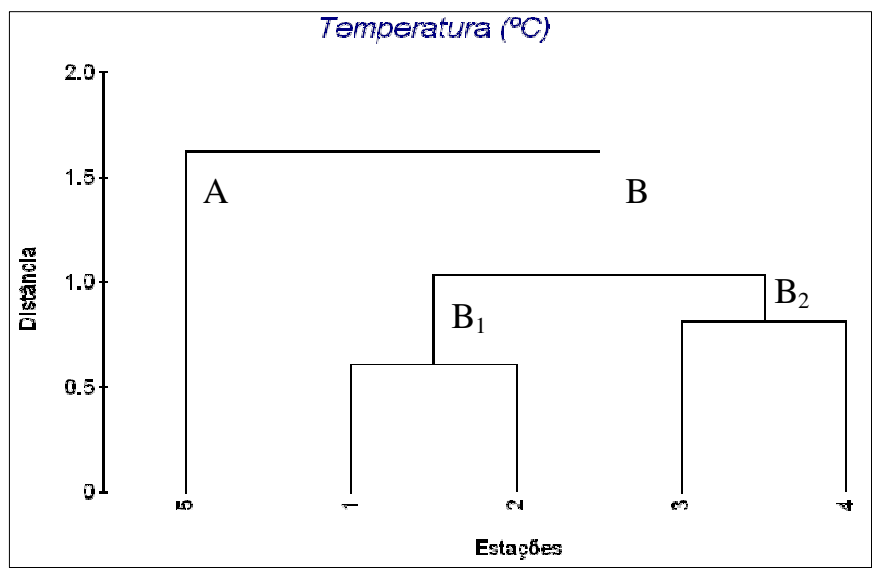

Figura 3. Análise de agrupamento das estações de coleta por similaridade euclidiana da temperatura na praia de Itamambuca (SP), para todo o período estudado.

A salinidade da água (Tabela 3) apresentou diferenças significativas $(p<0,01$, ANOVA) durante o período estudado (Tabela 2$)$, sendo as menores salinidades registradas na estação 5 (média de 0,70 e desvio padrão de 1,08) e maiores na estação 2 (média de 32,29 e desvio padrão de 2,67). A maior salinidade registrada foi 36 nas estações 1 e 2 em janeiro de 2005 e a menor, registrada quase em todos os meses do ano na estação 5 , cujo valor registrado foi zero. Não foram encontradas diferenças significativas na salinidade entre as estações do ano (Tabela 3). A análise de agrupamento das estações de coleta por similaridade euclidiana considerando a salinidade (Figura 4) identificou 2 grupos de estações ( $A$ e $B$ ) e dois subgrupos $B_{1}$ e $B_{2}$, cujo resultado também está relacionado com o rio Itamambuca. O grupo A, onde está localizada somente a estação 5 (dentro do rio Itamambuca), apresenta uma salinidade média próxima de zero e, quanto mais longe do rio, maiores são os valores de salinidade encontrados, formando o grupo B. Porém, a subdivisão do grupo está associada a estações que são menos influenciadas pelo rio: no subgrupo $B_{1}$ está localizada a estação 4 que, por se encontrar na boca do rio Itamambuca, sofre continuamente a ação do rio e está sujeita às maiores 
variações de salinidade encontradas no presente estudo; no subgrupo $\mathrm{B}_{2}$ estão as estações que apresentam pouca (estação 3) ou quase nenhuma influência do rio Itamambuca (estações 1 e 2).

Tabela 3. Valores da salinidade da água obtidos nas estações de coletas da praia de Itamambuca - Ubatuba (SP) para todo o período estudado.

\begin{tabular}{|c|c|c|c|c|c|c|}
\hline & & & & (⿻ & & \\
\hline Mês & ríodo & 1 & 2 & 3 & 4 & 5 \\
\hline & ia & 30 & 31 & 30 & 0 & 0 \\
\hline & Noite & 2 & 32 & 24 & c & 0 \\
\hline & ia & 0 & 30,0 & 32,0 & 17,0 & 2,0 \\
\hline & Noite & 2,0 & 19,5 & 1,8 & 0,3 & 0,0 \\
\hline & ia & 2,0 & 32,5 & 2,5 & 1,0 & 0,0 \\
\hline & Noite & 1,0 & 32,5 & 31,0 & 2,5 & 0,0 \\
\hline & ia & 32,0 & 33,0 & 31,0 & 32,0 & 2,0 \\
\hline & Noite & 32,0 & 31,0 & 30,0 & 10,0 & 1,0 \\
\hline & & 33,0 & 33,0 & 24,0 & 12,0 & 0,0 \\
\hline & Noit & 27,5 & 32,0 & 5,0 & 6,0 & 0,5 \\
\hline & & 33,0 & 31,0 & 25,0 & 16,0 & 0,0 \\
\hline & Noi & 32,0 & 30,0 & 20,0 & 6,0 & 2,0 \\
\hline & & 32,0 & 32,0 & 20,0 & 3,0 & 0,0 \\
\hline & Noit & 28,0 & 31,0 & 26,0 & 3,0 & 0,0 \\
\hline & & 2,0 & 32,0 & 14,0 & 24,0 & 0,0 \\
\hline & $\mathbf{N}$ & 31,0 & 33,0 & 25,0 & 23,0 & 2,0 \\
\hline & & 30,0 & 32,0 & 26,0 & 6,0 & 0,0 \\
\hline & Noi & 31,0 & 32,0 & 32,0 & 17,0 & 0,0 \\
\hline & & 18,0 & 30,0 & 27,0 & 26,0 & 0,0 \\
\hline & Noit & 32,0 & 31,0 & 29,0 & 29,0 & 0,0 \\
\hline & & 33,0 & 33,0 & 18,0 & 10,0 & 0,0 \\
\hline & Noit & 33,0 & 33,0 & 28,0 & 20,0 & 0,0 \\
\hline & & 34,0 & 34,0 & 4,0 & 2,0 & 0,0 \\
\hline & Noit & 25,0 & 34,0 & 17,0 & 10,0 & 0,0 \\
\hline & & 32,0 & 34,0 & 23,0 & 10,0 & 2,0 \\
\hline & Noit & 34,0 & 34,0 & 12,0 & 10,0 & 1,0 \\
\hline & & 30,0 & 33,0 & 20,0 & 12,0 & 1,0 \\
\hline & $\mathrm{N}$ & 5,0 & 35,0 & 32,0 & 32,0 & 0,0 \\
\hline & & 32,0 & 31,0 & 27,0 & 16,0 & 0,0 \\
\hline & $\mathbf{N}$ & 34,0 & 34,0 & 32,0 & 29,0 & 1,0 \\
\hline & & 35,0 & 35,0 & 35,0 & 27,0 & 1,0 \\
\hline & Noit & 34,0 & 35,0 & 25,0 & 21,0 & 0,0 \\
\hline & & 36,0 & 36,0 & 29,0 & 25,0 & 3,0 \\
\hline & Noite & 35,0 & 34,0 & 25,0 & 11,0 & 3,0 \\
\hline & & 35,0 & 34,0 & 30,0 & 27,0 & 0,0 \\
\hline & Noite & 31,0 & 33,0 & 26,0 & 30,0 & 4,0 \\
\hline
\end{tabular}




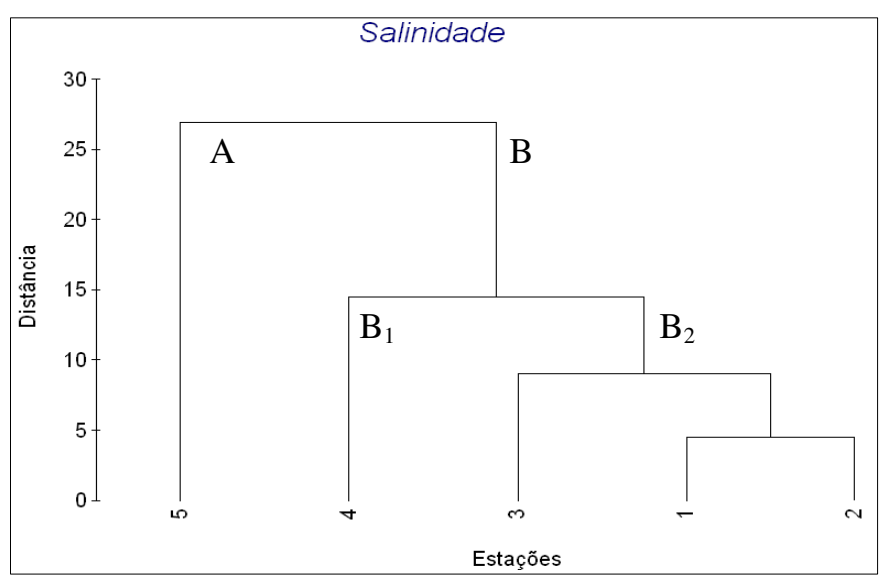

Figura 4. Análise de agrupamento das estações de coleta por similaridade euclidiana dos valores de salinidade, na praia e rio Itamambuca (SP) para todo o período estudado.

A temperatura e a salinidade da água não apresentaram diferenças significativas comparando-se o período diurno com o noturno (Tabela 2), apesar dos valores apresentarem uma pequena variação durante esses dois períodos. Os valores de temperatura e salinidade estão associados à presença dos dois aportes de águas interiores nas duas extremidades da praia, sendo que o rio Itamambuca afeta continuamente a praia de Itamambuca, mas o outro rio, localizado na extremidade norte, é relativamente pequeno e sua descarga na praia não influi consideravelmente na salinidade local, como o constatado pelos valores de salinidade obtidos na estação 1.

Verificou-se que não existe correlação entre a abundância de indivíduos de Atherinella brasiliensis e a temperatura e nem a salinidade (coeficiente de Pearson de $r^{2}=0,0071$ para a temperatura e $r^{2}=0,1274$ para a salinidade). Portanto, as maiores e as menores capturas desses indivíduos na praia de Itamambuca não estão associadas a nenhum desses fatores abióticos.

Não foram observadas diferenças significativas nas capturas para as 
estações do ano nem durante o período diurno ou noturno. Os meses de outono apresentaram maiores capturas e os meses de verão os menores valores; no entanto, entre as estações de coletas, observaram-se diferenças significativas entre os valores de captura ( $p<0.01$, Kruskal-Wallis) (Tabela 2).

Em relação às estações de coleta, as maiores capturas ocorreram na estação 5 durante a noite (256 indivíduos) e na estação 4 durante o dia (76 indivíduos). Os menores valores foram registrados na estação 1 durante o dia, com cinco indivíduos, e na estação 2 durante a noite, com nenhum indivíduo capturado. Ocorreram diferenças significativas na captura entre o dia e a noite por estação de coleta (Tabela 4) ( $p<0.01$, Kruskal-Wallis) nas estações 3 e 5 , devido à grande diferença de indivíduos capturados nos dois períodos, mas nas outras estações não houve diferenças significativas. Nas estações 1 e 2 houve pouca captura tanto de dia quanto de noite, e na estação 4 houve grande captura nos dois períodos do dia. A análise de agrupamento de similaridade da captura do dia (figura 5) e da noite (figura 6) corroborou as estatísticas realizadas anteriormente, evidenciando a formação de dois grandes grupos ( $\mathrm{A}$ e B), tanto na análise realizada para amostras capturadas durante 0 dia quanto de noite. Nas capturas do dia o grupo A é formado pelas estações 1, 2 e 5, que apresentaram pouca captura, e o grupo B, pelas estações 3 e 4 que, ao contrário do grupo $\mathrm{A}$, apresentaram grande número de indivíduos capturados. Já nas capturas da noite, o grupo A é formado somente pela estação 5, que apresenta uma captura muito superior (cerca de 6 vezes mais) do que a somatória das capturas do grupo $B$, em que as estações apresentaram pouca captura. 
Tabela 4. Valores $\mathrm{H}$ (Kruskal-Wallis) das capturas do dia e da noite por estação de coleta de Atherinella brasiliensis da praia de Itamambuca - Ubatuba (SP).

\begin{tabular}{cc}
\hline Estações & $\begin{array}{c}\text { Período do dia } \\
\text { gl =1 }\end{array}$ \\
\hline $\mathbf{1}$ & 0,0641 \\
$\mathbf{2}$ & 0,3243 \\
$\mathbf{3}$ & $\mathbf{7 , 0 9 6 9}$ \\
$\mathbf{4}$ & 1,7124 \\
$\mathbf{5}$ & $\mathbf{1 7 , 7 4 1}$ \\
\hline
\end{tabular}

negrito = diferença significativa

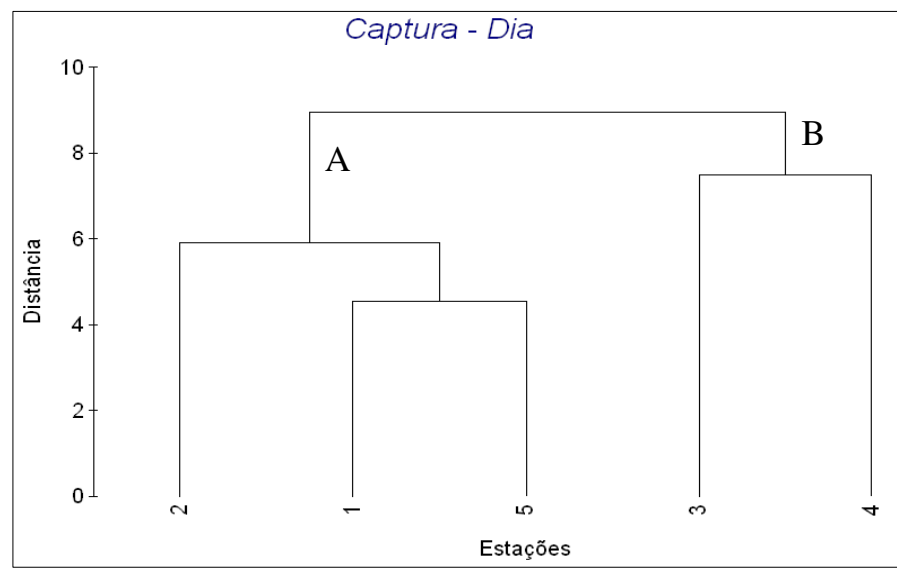

Figura 5. Análise de agrupamento das estações de coleta por similaridade euclidiana da captura diurna de Atherinella brasiliensis na praia de Itamambuca (SP) para todo o período estudado.

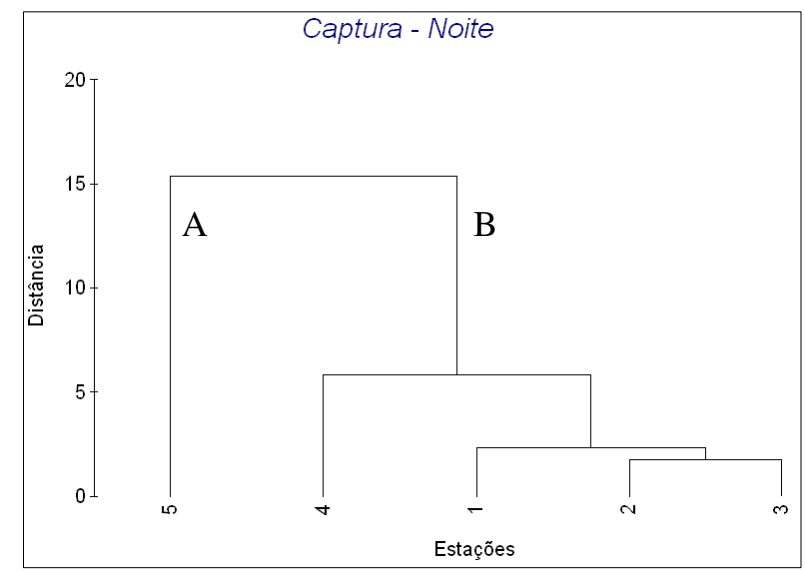

Figura 6. Análise de agrupamento das estações por similaridade euclidiana da captura noturna de Atherinella brasiliensis na praia de Itamambuca (SP) para todo o período estudado. 


\subsection{Estudo do crescimento}

\subsubsection{Método indireto}

Os valores das variáveis $C T \infty, K, t_{0}$, mortalidade natural, longevidade e o índice de crescimento de Atherinella brasiliensis na praia de Itamambuca, obtidos através do método indireto, estão apresentados na tabela 5, enquanto as curvas de crescimento representadas na figura 7. Foram evidenciadas duas coortes, sendo o comprimento médio localizado na classe de 110-119 mm no primeiro ano de vida e o recrutamento em janeiro, para as amostras coletadas.

Tabela 5. Parâmetros das variáveis de crescimento $\left(C T \infty, K\right.$ e $\left.t_{0}\right)$, mortalidade natural $(M)$, longevidade $\left(A_{0,95}\right)$ e o índice de crescimento $\left(\Phi^{\prime}\right)$ de Atherinella brasiliensis da praia de Itamambuca (SP) realizados no programa FISAT II e suas variáveis para a amostra total.

\begin{tabular}{cccccc}
\hline $\mathbf{C t}_{\infty}(\mathbf{m m})$ & $\mathbf{K}\left(\right.$ ano $\left.^{-1}\right)$ & $\mathbf{M}\left(\mathbf{a n o}^{-1}\right)$ & $\mathbf{t}_{0}$ (ano) & $\mathbf{A}_{0.95}$ (ano) & $\boldsymbol{\Phi}^{\prime}$ \\
\hline 147,00 & 1,210 & 1,13042 & 0,03128 & 2,50732 & 2,41 \\
\hline
\end{tabular}

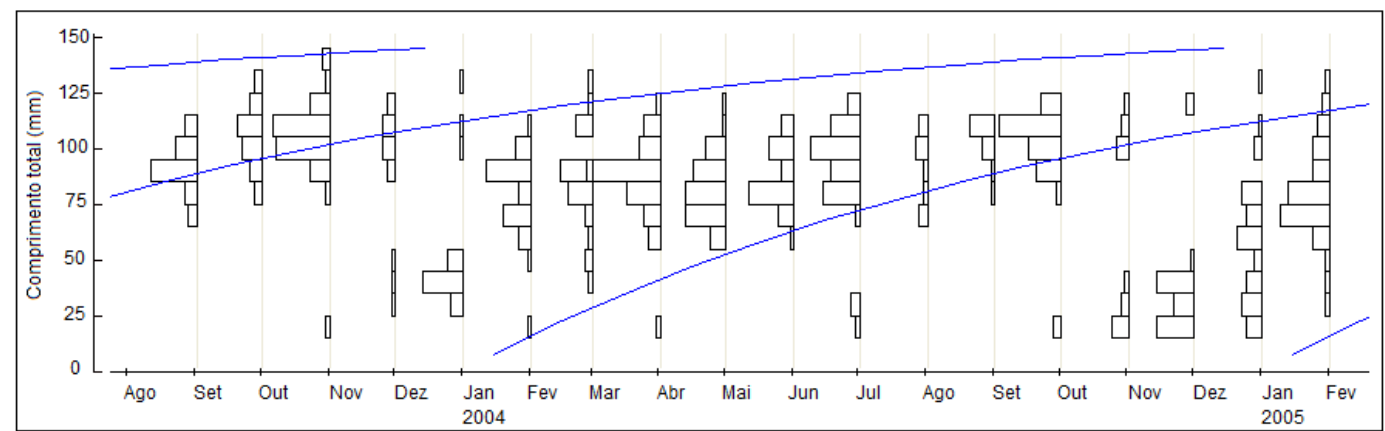

Figura 7. Curvas de crescimento de Atherinella brasiliensis da praia de Itamambuca (SP) obtidas pela rotina Shepherd utilizando os dados de freqüência mensal por classe de comprimento para todo o período estudado. 


\subsubsection{Método direto}

\section{a. Relações entre o crescimento do otólito e o crescimento da} espécie

A relação entre o comprimento (Co) e a massa do otólito (Mo) (Figura 8A) do conjunto de dados evidenciou melhor adequação ao ajuste do modelo potencial, cujo valor do coeficiente de determinação $\left(r^{2}\right)$ foi 0,94. A ausência de tendência significativa na análise dos resíduos padronizados (Figura 8B) corrobora o modelo ajustado, obtendo-se a seguinte equação potencial:

$$
M_{o}=0,035 * 10^{12} C T^{3,16}
$$
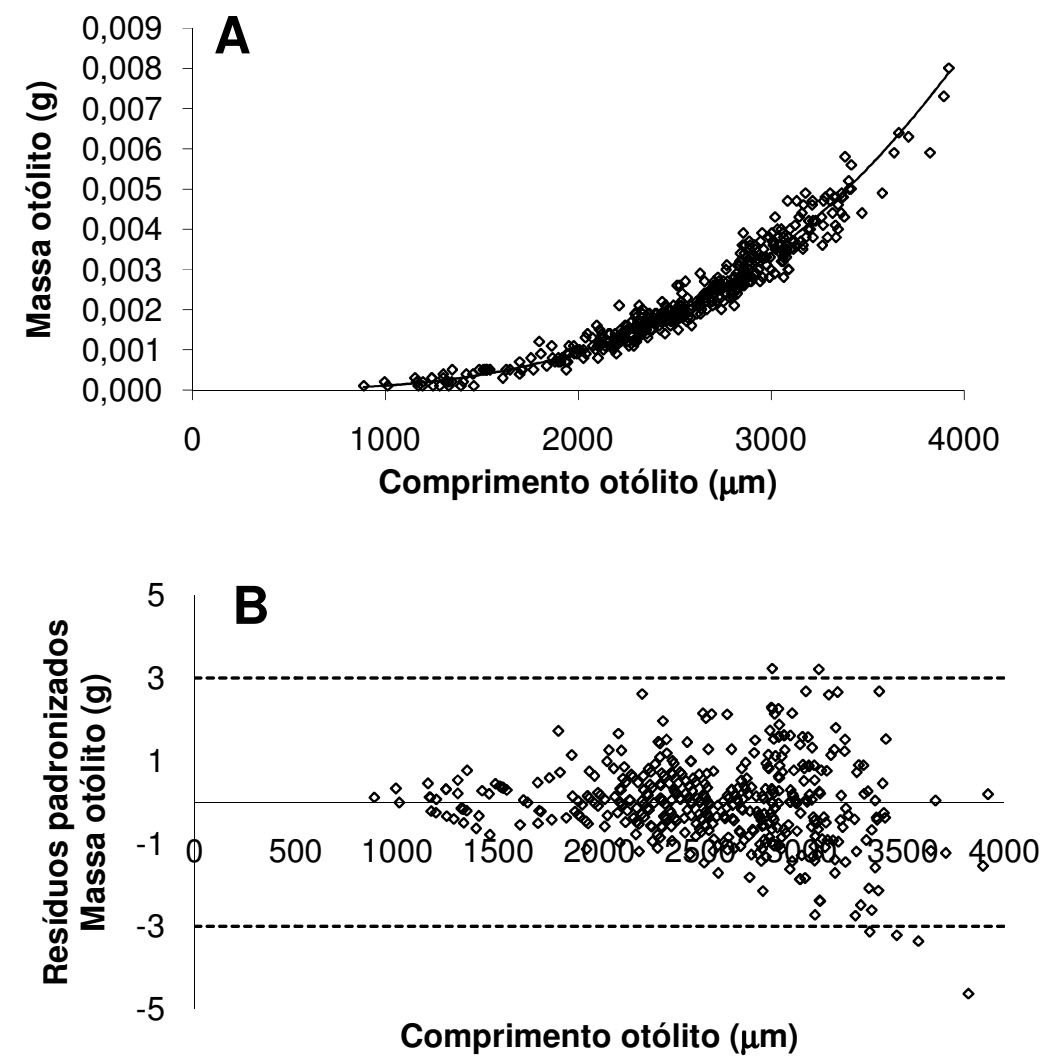

Figura 8. (A) Relação do comprimento do otólito $(\mu \mathrm{m})$ e massa do otólito (g); (B) diagrama de dispersão dos resíduos padronizados do comprimento do otólito $(\mu \mathrm{m})$ e a massa do otólito (g) de Atherinella brasiliensis da praia de Itamambuca (SP). 
A relação do comprimento total dos exemplares (CT) e o comprimento dos otólitos (Co) (Figura 9A) mostrou melhor adequação ao ajuste do modelo linear, cujo valor do coeficiente de determinação $\left(r^{2}\right)$ foi 0,95 e a ausência de tendência significativa na análise dos resíduos padronizados (Figura 9B) corroborou tal ajuste, obtendo-se a seguinte equação linear:

$$
C_{o}=25,29 C T+197,79
$$
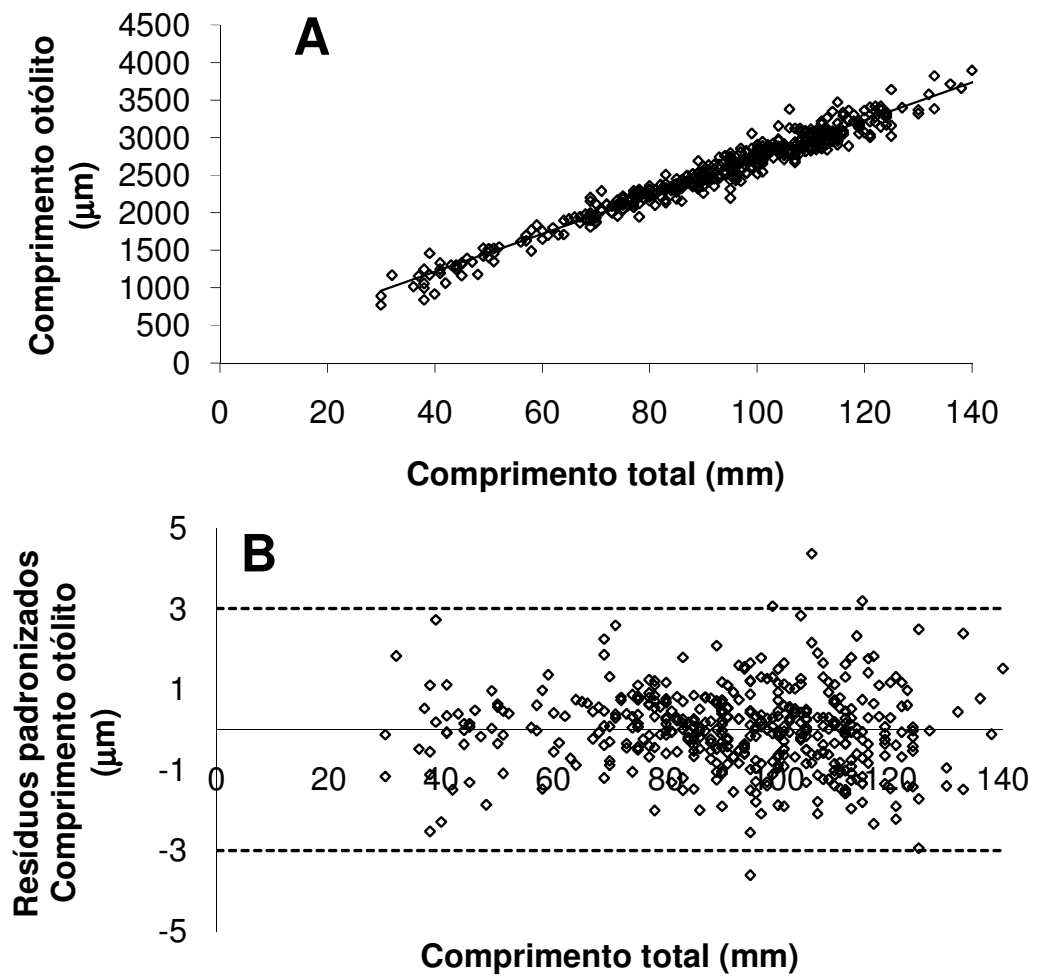

Figura 9. (A) Relação do comprimento do otólito $(\mu \mathrm{m})$ e o comprimento total dos indivíduos $(\mathrm{mm})$; (B) diagrama de dispersão dos resíduos padronizados do comprimento do otólito $(\mu \mathrm{m})$ e comprimento total dos indivíduos $(\mathrm{mm})$ de Atherinella brasiliensis da praia de Itamambuca (SP).

A relação do comprimento total dos exemplares (CT) e a massa dos otólitos (Mo) (Figura 10A) também evidenciou uma melhor adequação do conjunto de dados ao ajuste do modelo potencial, cujo valor do coeficiente de determinação $\left(r^{2}\right)$ foi 0,93 e a ausência de tendência significativa na análise dos 
resíduos padronizados (Figura 10B) corroborou o modelo ajustado, obtendo-se a seguinte equação potencial:

$$
M_{o}=0,047 * 10^{7} C T^{2,86}
$$
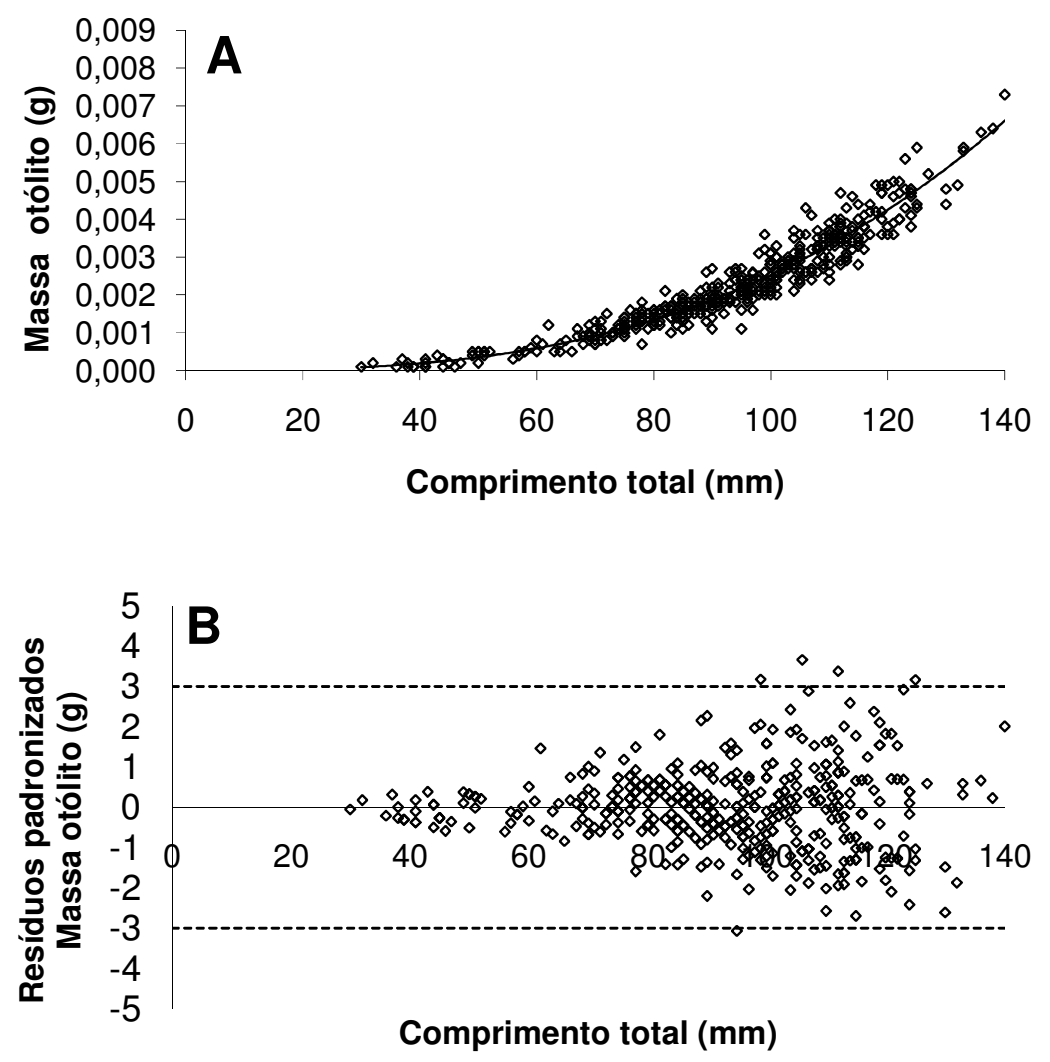

Figura 10. (A) Relação do comprimento total dos exemplares $(\mathrm{mm})$ e a massa do otólito (g); (B) diagrama de dispersão dos resíduos padronizados da massa do otólito (g) e comprimento total dos indivíduos $(\mathrm{mm})$ de Atherinella brasiliensis da praia de Itamambuca (SP).

\section{b. Validação}

Foram visualizados sob microscópio de fluorescência, utilizando luz ultravioleta com comprimento de onda de $472 \mathrm{~nm}$, os otólitos sagitta de dez indivíduos que sobreviveram após terem sido submetidos a duas marcações com "alizarina S". Apesar das marcações dos anéis de crescimento terem ocorrido em todos os indivíduos, foi possível a leitura somente em dois otólitos. 
Os outros foram descartados devido à dificuldade do reconhecimento dos anéis marcados, principalmente devido à morte precoce dos indivíduos logo após o processo de marcação, e cujas marcas estavam localizadas próximas à borda dos otólitos. Vale ressaltar a diminuição da espessura do incremento marginal no otólito que ocorre ao longo do crescimento dos indivíduos, sendo preciso um número relativamente grande de dias após a exposição ao agente marcador para que haja um afastamento relativo entre as marcas e a margem.

O número de anéis formados nos dois otólitos analisados entre as duas marcações foi nove, sendo um anel hialino e um opaco (Figura 11). Esse resultado corrobora a hipótese da formação diária de anéis para os indivíduos de Atherinella brasiliensis.

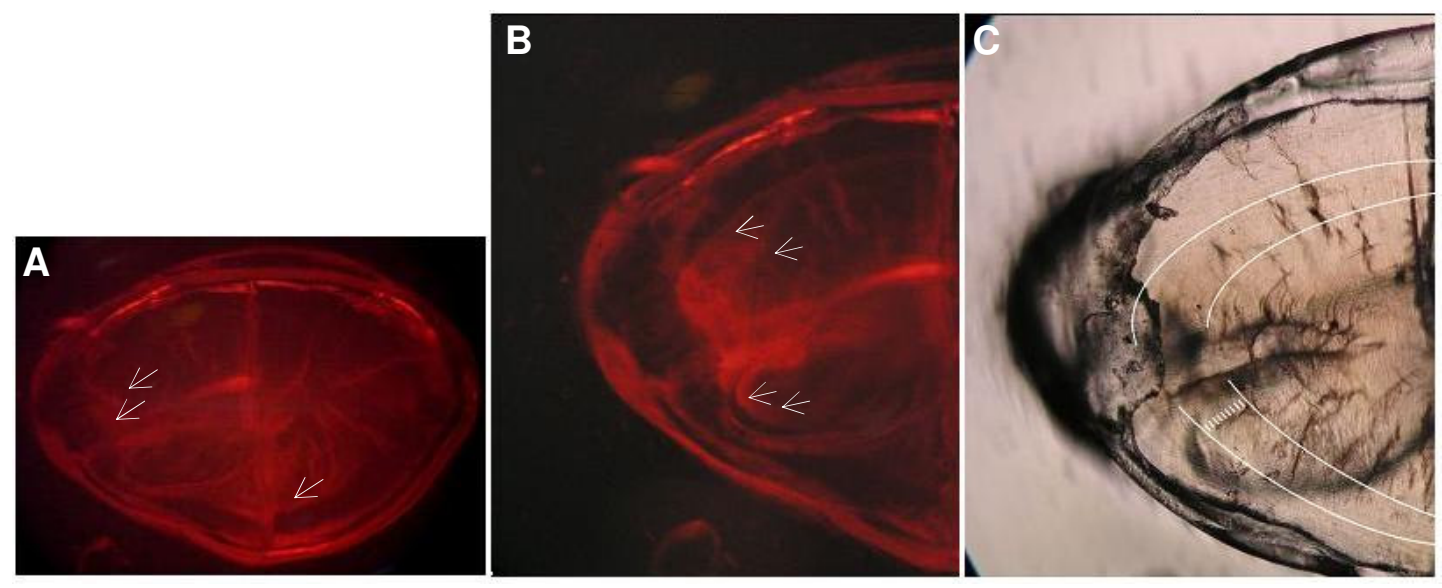

Figura 11. Otólito de Atherinella brasiliensis após duas marcações com alizarina . (A) sob microscópio de fluorescência com aumento de 4x; (B) evidenciando com setas as duas marcações; (C) sob microscópio de luz branca com um aumento de 10x evidenciando as duas marcações com alizarina e os anéis diários.

\section{c. Periodicidade de formação dos anéis nos otólitos}

Foram analisados 112 otólitos, porém 10 não foram considerados nas análises devido às dificuldades nas leituras dos anéis de crescimento após a terceira leitura (ou seja, não houve coincidência nas leituras) ou a quebra dos 
otólitos em alguma etapa de preparação ou leitura, sendo impossível sua substituição.

Nos otólitos analisados foram encontradas de 3 a 25 bandas, cada uma formada por 14 anéis diários (Figura 12), sendo o último anel mais evidente. Essa periodicidade dos números dos anéis diários formando bandas foi constatada para todos os otólitos analisados. Porém, devido à diminuição da espessura dos anéis nos otólitos ao longo do crescimento individual, a contagem desses anéis diários dos otólitos dos indivíduos maiores foi bastante complicada por causa da aparente sobreposição dos mesmos devido ao limite de resolução do microscópio de luz.

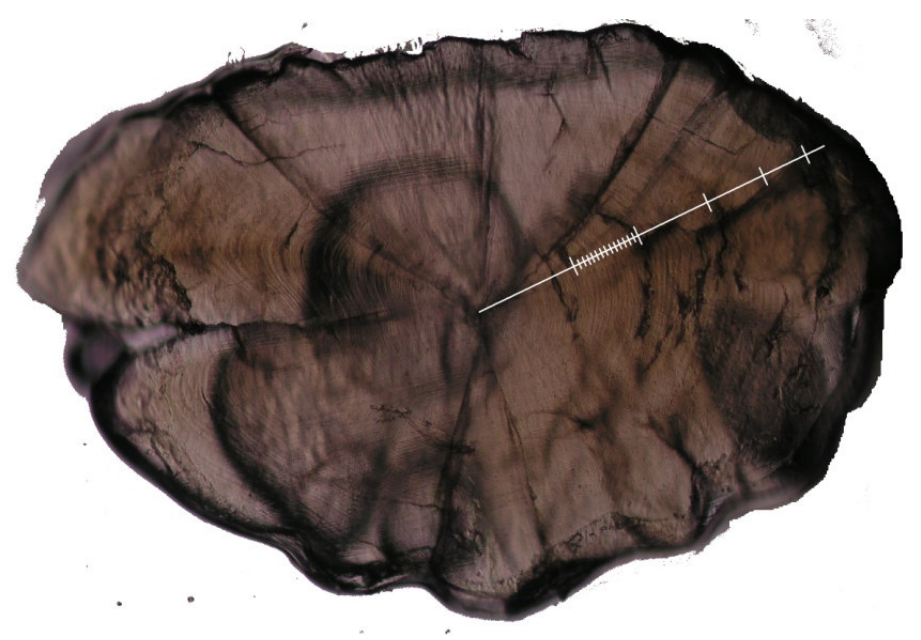

Figura 12. Otólito lixado de Atherinella brasiliensis da praia de Itamambuca - Ubatuba (SP) evidenciando as bandas e os anéis diários de crescimento.

\section{d. Estrutura etária}

O comprimento total dos indivíduos cujos otólitos foram analisados variou de 30 a $145 \mathrm{~mm}$, tendo sido constatada a presença de 3 a 25 bandas. Não foram capturados indivíduos que possuíam 23 e 24 bandas. A tabela 6 
mostra uma chave idade-comprimento para a sub-amostra de Atherinella brasiliensis da praia de Itamambuca para todo o período estudado. A chave indica maior freqüência de indivíduos que apresentaram 8 bandas, cujo comprimento médio foi $83,24 \pm 5,96 \mathrm{~mm}$, seguidos por indivíduos com 5 e 6 bandas, sendo seus comprimentos médios 47,64 $\pm 3,11 \mathrm{~mm}$ e $62,67 \pm 5,50$ $\mathrm{mm}$, respectivamente, totalizando $42,15 \%$ do capturado. Foi constatado um padrão de aumento dos comprimentos e do número de bandas. Pôde-se também verificar o aumento das médias do comprimento total com o aumento do número de bandas, sendo os desvios padrão dos comprimentos totais médios relativamente maiores nas primeiras bandas, evidenciando um maior crescimento no inicio da vida desses indivíduos.

Tabela 6. Chave idade-comprimento de Atherinella brasiliensis da praia de Itamambuca - Ubatuba (SP) Onde $\mathrm{CT}_{\mathrm{m}}$ é o comprimento total médio por banda e DP os desvios padrão.

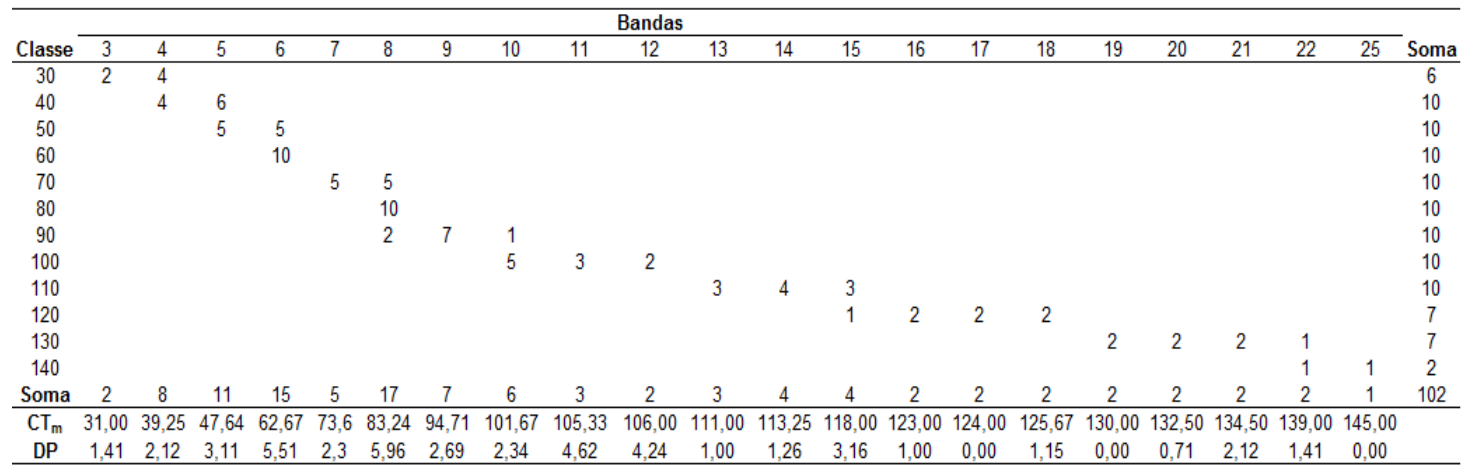

\section{e. Estimativa dos parâmetros das variáveis de crescimento}

Utilizando os comprimentos totais médios obtidos pela leitura dos anéis de crescimento foram calculados os parâmetros de crescimento pelos métodos citados, cujos valores da taxa de crescimento $(k)$, Idade no comprimento zero 
$\left(t_{0}\right)$, comprimento total assintótico $\left(C T_{\infty}\right)$ e Índice de performance $(\Phi)$ estão representados na tabela 7 .

Tabela 7. Parâmetros das variáveis de crescimento e o índice de performance das curvas de crescimento de Atherinella brasiliensis da praia de Itamambuca estimados por diferentes métodos.

\begin{tabular}{ccc} 
Método & Método & Método \\
Ford-Walford & von Bertalanffy & Gulland e Holt \\
\hline
\end{tabular}

\begin{tabular}{lccc}
\hline Comprimento assintótico $\left(\mathrm{CT}_{\infty}\right)$ & $164,85 \mathrm{~mm}$ & $168,42 \mathrm{~mm}$ & $159,74 \mathrm{~mm}$ \\
Taxa de crescimento $(K)$ & $2,1676 \mathrm{ano}^{-1}$ & $2,8785 \mathrm{ano}^{-1}$ & $2,5118 \mathrm{ano}^{-1}$ \\
Idade no comprimento zero $\left(\mathrm{t}_{0}\right)$ & $-0,0038 \mathrm{ano}$ & $-0,0032 \mathrm{ano}$ & $-0,0856$ ano \\
Índice de performance $(\Phi)$ & 2,77 & 2,91 & 2,80 \\
\hline
\end{tabular}

Verificou-se que o comprimento assintótico $\left(C T_{\infty}\right)$ e a taxa de crescimento $(k)$ calculados através do método de von Bertalanffy foram os maiores resultados obtidos no presente estudo, sendo que este é o único método a ter o comprimento total máximo previamente estipulado. A estimativa usou o comprimento total do maior indivíduo capturado da espécie, descrito na literatura, que é $160 \mathrm{~mm}$. O método de Gulland e Holt apresentou o menor valor de comprimento assintótico e o maior valor para a idade de comprimento zero $\left(\mathrm{t}_{0}\right)$. Este resultado estimado de $\mathrm{t}_{0}$ deve-se à inexistência de uma equação apropriada para o cálculo do parâmetro desta variável; porém, o valor do comprimento assintótico, estimado por Gulland \& Holt, foi o mais baixo encontrado no presente estudo, porém dentro da variação esperada para a população de Atherinella brasiliensis da praia de Itamambuca. Menores valores da taxa de crescimento e da idade no comprimento zero foram encontrados através do método de Ford-Walford e, diferentemente dos outros métodos, este apresenta a possibilidade de realizar todos os cálculos para as estimativas dos 
parâmetros das variáveis de crescimento, mostrando-se o mais completo entre os três utilizados.

Para comparação foram traçadas as curvas de crescimento através do modelo de von Bertalanffy (1938) a partir dos parâmetros obtidos pelos diferentes métodos (Figura 13). Nas curvas de crescimento em que se utiliza parâmetros calculados pelos métodos de von Bertalanffy e Gulland e Holt, o comprimento total da espécie é superestimado, principalmente no início da curva no caso do método de Gulland e Holt, e no final da mesma no método de von Bertalanffy. Os parâmetros calculados através do método de Ford-Walford foram os que melhor se ajustaram ao conjunto de dados, sendo o mais fidedigno a expressar o crescimento de Atherinella brasiliensis da praia de Itamambuca - Ubatuba (SP)

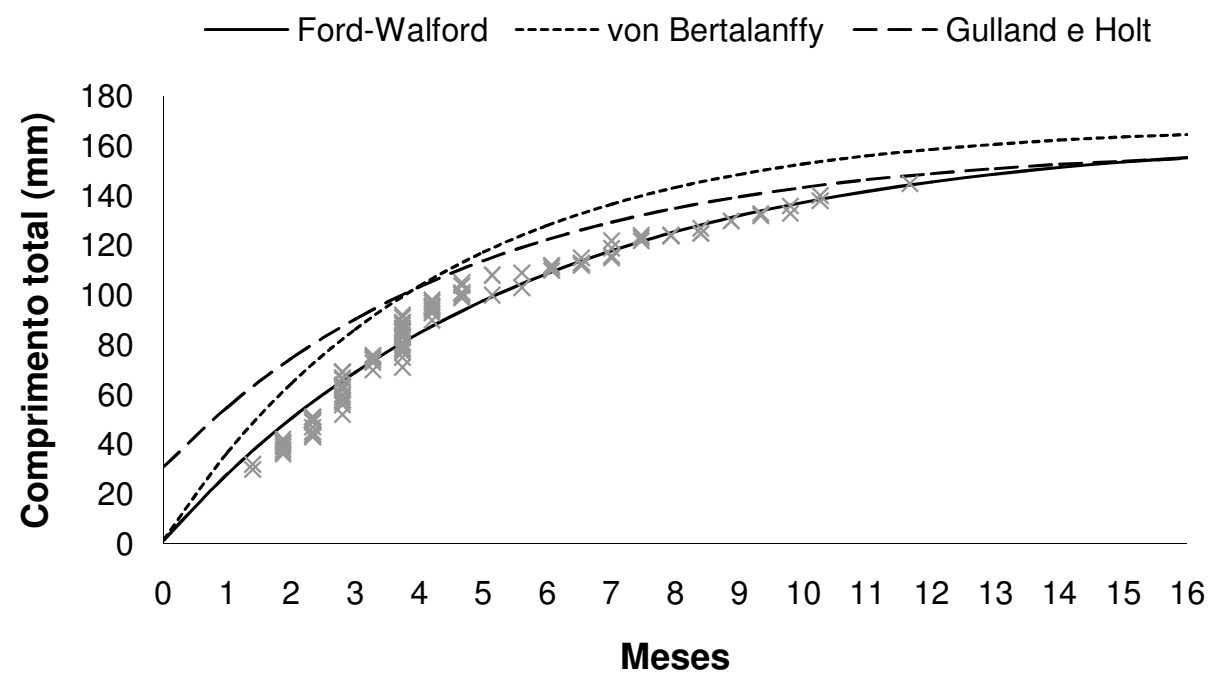

Figura 13. Curvas de crescimento obtidas através da equação de von Bertalanffy para os parâmetros calculados por diferentes métodos para Atherinella brasiliensis da praia de Itamambuca - Ubatuba (SP). 


\section{f. Performance de crescimento $\left(\Phi^{\prime}\right)$}

Os valores estimados dos índices de performance de crescimento, que representariam a energia de um dado habitat, foram estimados, tendo sido utilizados os parâmetros calculados pelos diferentes métodos. Os valores obtidos variaram entre 2,77 a 2,91 (Tabela 6).

\subsubsection{Estudo da mortalidade}

\section{a. Mortalidade natural}

Os resultados das estimativas da mortalidade natural $(M)$, para a temperatura média de $21,90{ }^{\circ} \mathrm{C}$, usando os parâmetros de crescimento calculados pelos diferentes métodos, estão representados na tabela 8.

Tabela 8. Mortalidade natural (M) de Atherinella brasiliensis da praia de Itamambuca, calculada a partir dos parâmetros de crescimento estimados pelos diferentes métodos.

\begin{tabular}{cc}
\hline Método & Mortalidade Natural (M) \\
\hline Ford-Walford & $1.6417 \mathrm{ano}^{-1}$ \\
von Bertalanffy & $1.9647 \mathrm{ano}^{-1}$ \\
Gulland e Holt & $1.8239 \mathrm{ano}^{-1}$ \\
\hline
\end{tabular}

\section{b. Longevidade}

A estimativa de longevidade $\left(A_{0,95}\right)$, que expressa o período de tempo em que os indivíduos de uma determinada espécie demora para atingir $95 \%$ do seu comprimento assintótico $\left(C_{\infty}\right)$, considerando a taxa de crescimento $(k)$ e a idade de comprimento zero $\left(\mathrm{t}_{0}\right)$. Os valores das estimativas de longevidade usando os parâmetros de crescimento calculados pelos diferentes métodos 
estão apresentados na tabela 9.

Tabela 9. Longevidade $\left(A_{0,95}\right)$ de Atherinella brasiliensis da praia de Itamambuca, estimada a partir dos parâmetros de crescimento calculados pelos diferentes métodos.

\begin{tabular}{cc}
\hline Método & Longevidade $\left(\mathbf{A}_{\mathbf{0 , 9 5}}\right)$ \\
\hline Ford-Walford & 1,37827 ano \\
von Bertalanffy & 1,03761 ano \\
Gulland e Holt & 1,10716 ano \\
\hline
\end{tabular}

Os resultados apresentaram uma grande variação, sendo os menores obtidos através do método de von Bertalanffy e Gulland e Holt: um ano e nove dias e um ano e um mês, respectivamente. Esses valores baixos são decorrentes da superestimativa dos valores da taxa de crescimento, já relatada anteriormente. O valor da longevidade obtido com os parâmetros de crescimento calculados com o método de Ford-Walford foi o que melhor representa o ciclo de vida de Atherinella brasiliensis da praia de Itamambuca, sendo de aproximadamente um ano e cinco meses.

\subsection{Estudo da reprodução}

\subsubsection{Proporções sexuais}

A tabela 10 apresenta as proporções sexuais dos exemplares capturados em todos os períodos de coleta e o resultado do $\mathrm{X}^{2}$, considerando a proporção 1:1, bem como a proporção encontrada no presente estudo na região $(1: 2,2)$ em favor das fêmeas. Dos dezoito meses, em seis meses (setembro e dezembro de 2003; maio, junho e outubro de 2004 e fevereiro de 2005) houve diferença significativa $(p<0,05)$, levando em consideração as 
proporções sexuais 1:1, e apenas em quatro meses (setembro e dezembro de 2003 e março e maio de 2004) houve diferença significativa entre as proporções encontradas no total dos dezoito meses e os valores das proporções mensais. Somente em setembro de 2003 e maio de 2004 houve coincidência na diferença significativa entre proporções de machos e fêmeas no $\chi^{2}$ (esperado 1:1 e encontrado), quando ocorreu uma freqüência muito superior de fêmeas. Não se pôde constatar qualquer padrão espaço-temporal na distribuição de machos e de fêmeas, mas somente a ocorrência significativamente maior de fêmeas do que de machos na região, para o período estudado.

Tabela 10. Valores numéricos, proporção sexual e valores de $\chi^{2}$ (1:1 e encontrado) de Atherinella brasiliensis por época do ano para todo o periodo estudado na praia de Itamambuca (SP).

\begin{tabular}{|c|c|c|c|c|c|c|}
\hline \multirow{2}{*}{ Meses/Ano } & \multicolumn{2}{|c|}{ Fêmeas } & \multicolumn{2}{|c|}{ Machos } & \multirow{2}{*}{$\chi^{2}(1: 1)$} & \multirow{2}{*}{$\chi 2$ (encontrado) } \\
\hline & $\mathbf{N}$ & $\%$ & $\mathbf{N}$ & $\%$ & & \\
\hline Set/03 & 10 & 83,33 & 2 & 16,67 & 5,42 & 2,30 \\
\hline Out/03 & 8 & 44,44 & 10 & 55,56 & 0,28 & 2,76 \\
\hline Nov/03 & 22 & 57,89 & 16 & 42,11 & 0,97 & 0,54 \\
\hline Dez/03 & 7 & 87,50 & 1 & 12,50 & 4,63 & 2,36 \\
\hline Jan/04 & 2 & 66,67 & 1 & 33,33 & 0,67 & 0,41 \\
\hline Fev/04 & 3 & 50,00 & 3 & 50,00 & 0,17 & 0,51 \\
\hline Mar/04 & 1 & 16,67 & 5 & 83,33 & 2,83 & 5,40 \\
\hline $\mathrm{Abr} / 04$ & 7 & 58,33 & 5 & 41,67 & 0,42 & 0,18 \\
\hline Mai/04 & 14 & 93,33 & 1 & 6,67 & 11,33 & 6,08 \\
\hline Jun/04 & 8 & 88,89 & 1 & 11,11 & 5,56 & 2,87 \\
\hline $\mathrm{Jul} / 04$ & 18 & 60,00 & 12 & 40,00 & 1,23 & 0,18 \\
\hline Ago/04 & 6 & 75,00 & 2 & 25,00 & 2,13 & 0,70 \\
\hline Set/04 & 8 & 72,73 & 3 & 27,27 & 2,36 & 0,58 \\
\hline Out/04 & 18 & 52,94 & 16 & 47,06 & 0,15 & 1,65 \\
\hline Nov/04 & 4 & 66,67 & 2 & 33,33 & 0,83 & 0,24 \\
\hline Dez/04 & 1 & 50,00 & 1 & 50,00 & 0,50 & 0,54 \\
\hline Jan/05 & 4 & 80,00 & 1 & 20,00 & 2,00 & 0,98 \\
\hline $\mathrm{Fev} / 05$ & 9 & 75,00 & 3 & 25,00 & 3,08 & 0,87 \\
\hline Total & 150 & 63,83 & 85 & 36,17 & 17,98 & 0,00 \\
\hline
\end{tabular}


Quanto às proporções sexuais por classe de comprimento total (Figura 14), os indivíduos jovens foram excluídos dos cálculos, devido à difícil identificação do sexo. Observou-se uma diminuição gradativa da diferença entre as proporções de machos e fêmeas ao longo das classes de comprimento, sendo na classe de 140 - 149 ocorre uma igualdade entre as proporções.

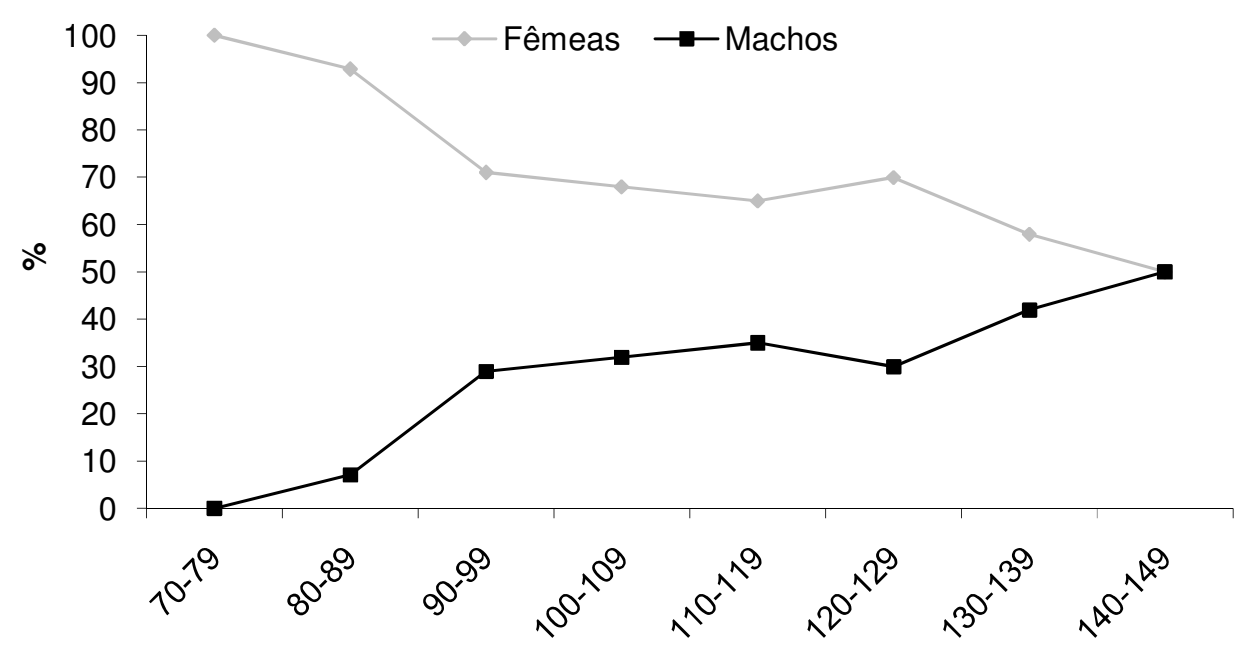

Comprimento total (mm)

Figura 14. Porcentagens de machos e fêmeas de Atherinella brasiliensis, por classe de comprimento total da praia de Itamambuca (SP) de todo o período estudado.

\subsubsection{Identificação dos estádios de maturidade gonadal: ocorrência} de jovens e adultos e de fêmeas desovantes

A partir da identificação dos indivíduos imaturos, dentre o conjunto amostrado, e da verificação do sexo para aqueles a partir do estádio B (em maturação), foi possível estudar a estrutura populacional em jovens e adultos para cada mês de coleta (Figura 15), Ocorreram indivíduos adultos e jovens em 
todos os períodos coletados, exceto nos meses de setembro de 2003 e de 2004, em que não ocorreram indivíduos jovens. Observa-se que a porcentagem de indivíduos jovens aumenta significativamente a partir de janeiro e novembro de 2004, com uma ligeira queda gradual nos valores a partir de fevereiro e dezembro de 2004, sugerindo que houve o recrutamento desses indivíduos no final da primavera e começo do verão nos dois anos amostrados. Houve, em quase todos os meses de coleta, diferença significativa entre a presença de jovens e adultos na área, com exceção dos meses de dezembro de 2003, maio e novembro de 2004.

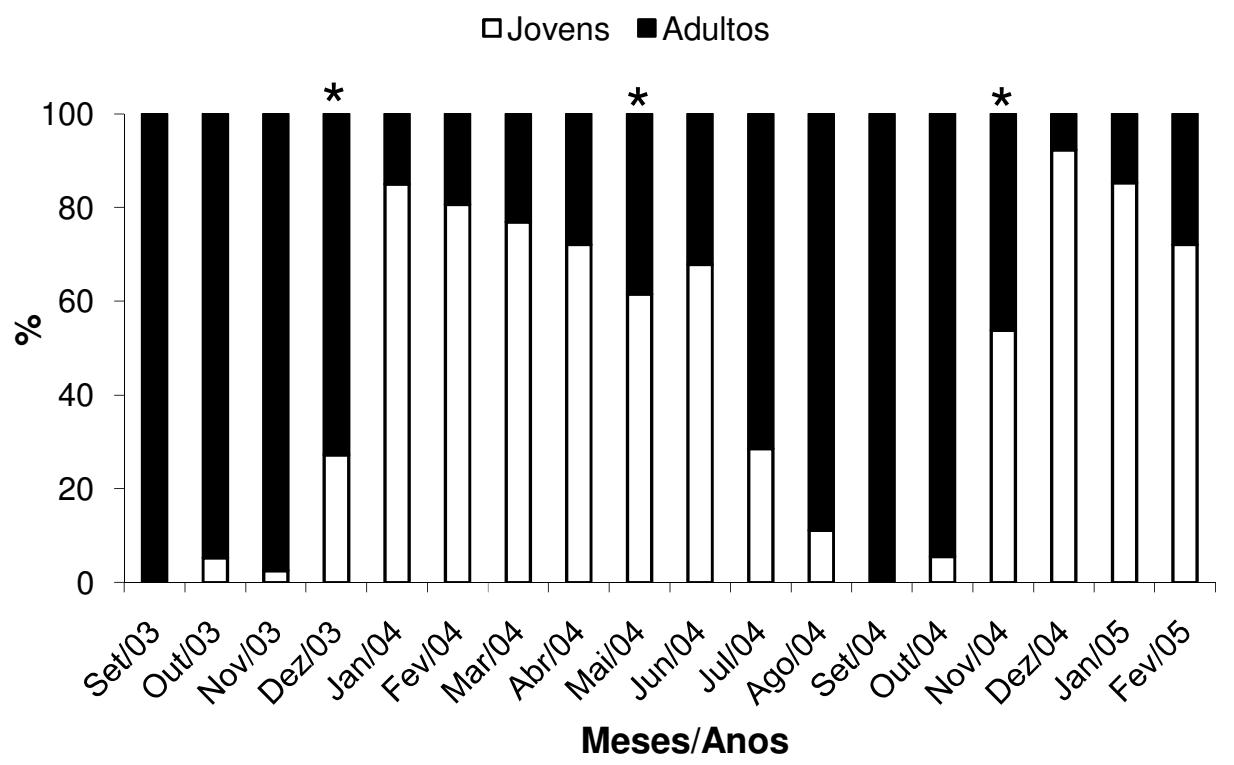

Figura 15. Proporção de jovens e adultos (machos e fêmeas agrupados) de Atherinella brasiliensis da praia de Itamambuca (SP) por época de coleta em todo o período estudado. $O$ asterisco indica os meses em que não houve diferença significativa na proporção de jovens e adultos.

As proporções de jovens e adultos entre as estações de coletas no período diurno (Figura 16A) indicaram uma maior ocorrência de indivíduos adultos nas estações 3 e 4, porém sem diferenças significativas. Nas demais 
estações de coleta a maior freqüência foi de indivíduos jovens, também não havendo diferenças significativas entre os valores, apesar de, nas estações $1 \mathrm{e}$ 5, haver ocorrido somente a captura de indivíduos jovens. Durante o período noturno (Figura 16B) a proporção entre jovens e adultos dentre as estações de coleta apresentou uma maior captura de indivíduos jovens somente na estação 5; entretanto, no restante das estações de coleta, a captura de adultos foi maior, não havendo diferenças significativas entre jovens e adultos em nenhuma estação.
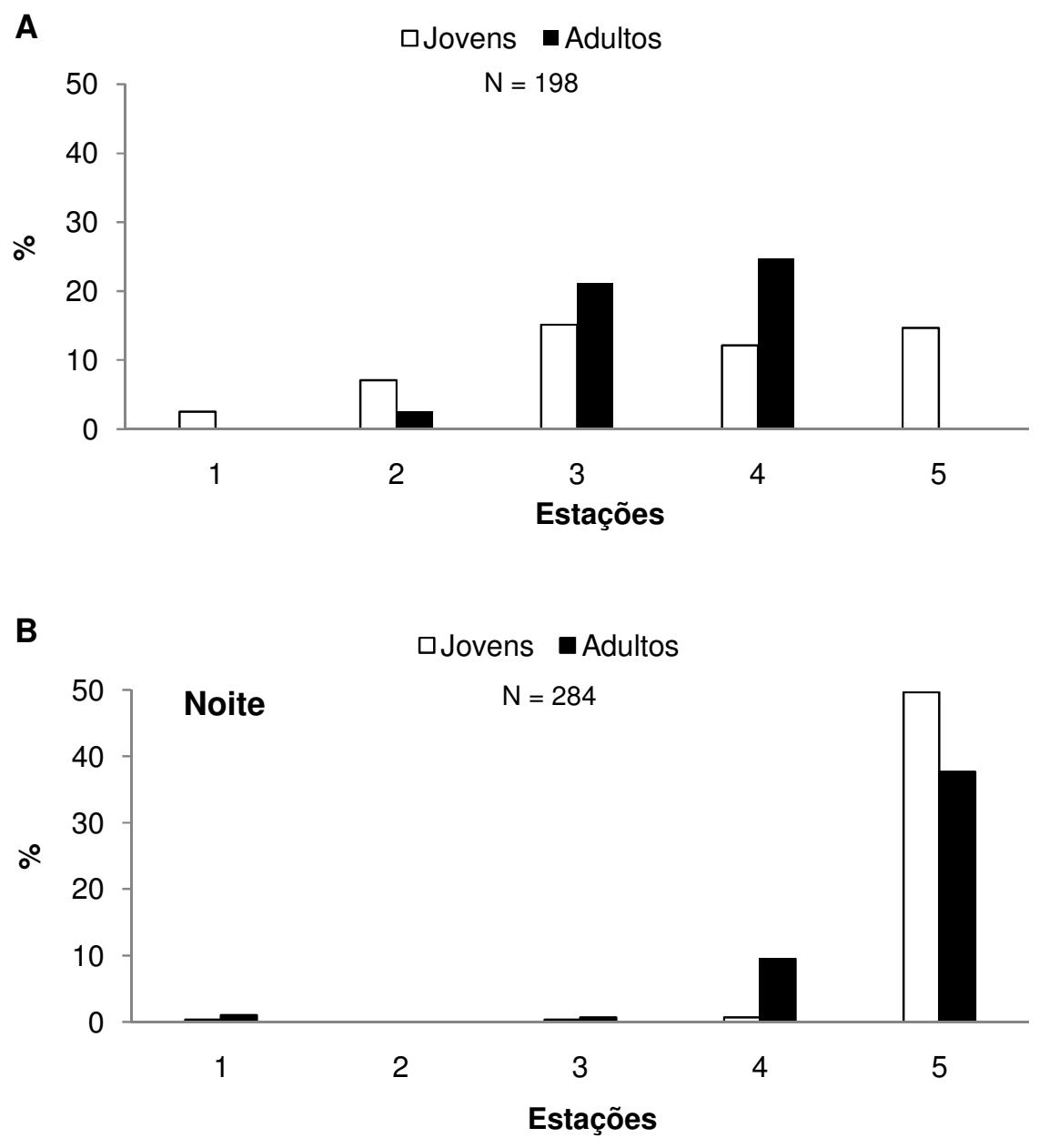

Figura 16. Porcentagem de indivíduos jovens e adultos de Atherinella brasiliensis capturados durante 0 dia (A) e de noite (B), por estação de coleta da praia de Itamambuca (SP), em todo o período estudado. 
$\mathrm{Na}$ análise macroscópica da maturação das fêmeas adultas, foram encontrados todos os estádios no período estudado, predominando indivíduos principalmente no estádio C (50,3\%), no estádio D (25,2\%) e no estádio B (17,2 \%). O estádio $E$ teve a menor freqüência, com somente $7,4 \%$ do total (Figura 17). Vale ressaltar que não foram levados em conta, para uma melhor análise dos dados, os indivíduos machos, porque as variações que ocorrem nos ovários marcam de maneira mais clara alterações relacionadas com o processo reprodutivo do que nos testículos, bem como os indivíduos imaturos, que ainda não participam desse processo, e cujas gônadas são de difícil discriminação quanto ao sexo.

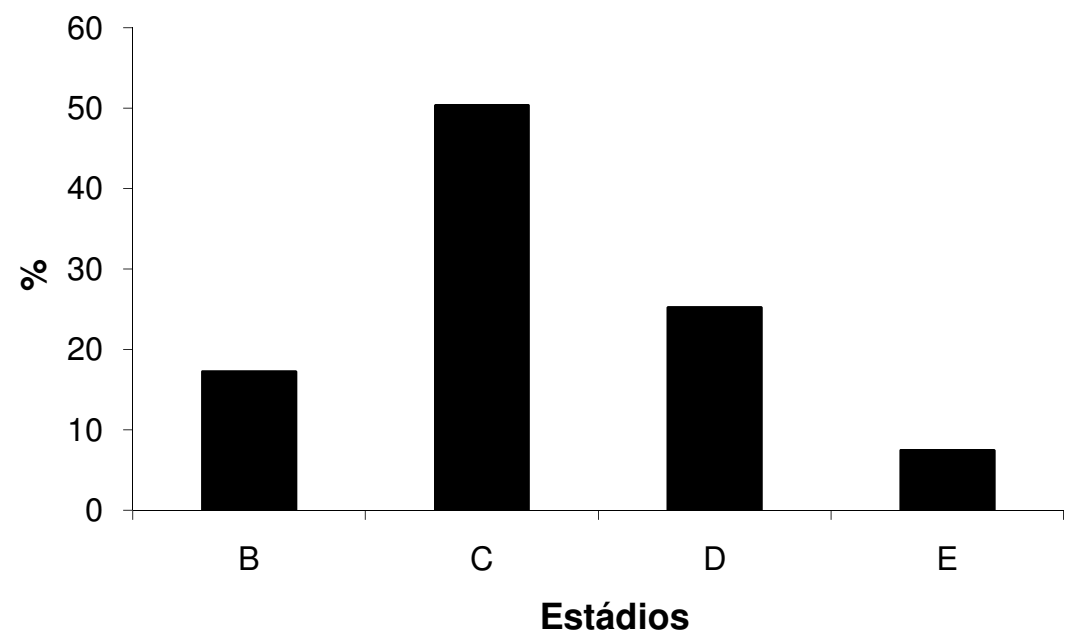

Figura 17. Proporção de fêmeas adultas de Atherinella brasiliensis capturadas na praia de Itamambuca (SP), em todo o período, nos diferentes estádios de maturidade gonadal verificados a partir da avaliação macroscópica.

Foram analisadas 95 preparações permanentes de cortes de ovários (Tabela 11), referentes a todo o período estudado. Estas análises revelaram um erro total de 26,1 \% da classificação macroscópica realizada anteriormente (Tabela 12). As fêmeas no estádio $B$ (em maturação) foram as que 
apresentaram a menor porcentagem de erro (0\%); entretanto, as fêmeas classificadas macroscopicamente no estádio E (desovadas) foram as que apresentaram uma maior porcentagem de erro (100\%); os ovários classificados macroscopicamente no estádio C (maduro) e D (hidratados) tiveram $15,9 \%$ e $18,7 \%$ de erro, respectivamente.

Tabela 11. Freqüência de preparações permanentes com cortes de ovários retirados de Atherinella brasiliensis da praia de Itamambuca (SP) de todo o período estudado.

\begin{tabular}{cccc}
\hline Estádio* & Gônadas & Histologia & $\%$ \\
\hline B & 30 & 5 & 16,67 \\
C & 80 & 44 & 55,00 \\
D & 40 & 32 & 80,00 \\
E & 11 & 11 & 100,00 \\
\hline * Estádio macroscópico & &
\end{tabular}

É importante notar que os indivíduos identificados no estádio E pela análise macroscópica foram identificados como machos pela análise microscópica das gônadas.

Tabela 12. Classificação dos estádios macroscópicos e microscópicos de ovários de Atherinella brasiliensis na praia de Itamambuca (SP) de todo o período estudado.

\begin{tabular}{ccccccccc}
\hline Microscópicos & B & C & D & E & D/E & Machos & TOTAL & \% Erro \\
\hline Macroscópicos & & & & & & & & \\
B & $\mathbf{5}$ & 0 & 0 & 0 & 0 & 0 & 5 & 0 \\
C & 0 & $\mathbf{3 7}$ & 5 & 0 & 2 & 0 & 44 & 15,90 \\
D & 0 & 3 & $\mathbf{2 6}$ & 0 & 3 & 0 & 32 & 18,75 \\
E & 0 & 0 & 0 & $\mathbf{0}$ & 0 & 11 & 11 & 100 \\
TOTAL & 5 & 40 & 31 & 0 & 5 & 11 & 92 & 26,08 \\
\hline
\end{tabular}

negrito - acertos da classificação macroscópica em relação à classificação microscópica

Assim, a análise macroscópica dos estádios de maturidade gonadal não identificou ovários completamente desovados (E). A análise microscópica 
mostrou que ocorre grande quantidade de ovócitos vitelogênicos e avitelogênicos nos ovários coletados em todo o período estudado (Figura 18). Para os ovários no estádio $D$ a porcentagem de erro foi relativamente baixa.

A alta freqüência de desova e o fato desta ser parcelada pode ser atestada pela ocorrência de gônadas com ovócitos hidratados e folículos pósovulatórios (FPO), revelando mais um erro na avaliação macroscópica. A eliminação dos ovócitos hidratados é realizada aos poucos, durante um longo período de tempo. Em decorrência dos resultados encontrados, para corrigir o erro causado pela identificação macroscópica da maturação gonadal no estádio D, neste estudo propõe-se classificar as gônadas hidratadas com ocorrência de FPO como indivíduos desovantes (D/E), já que esses indivíduos estão participando ativamente da desova.

$\mathrm{Na}$ figura 18 estão ilustradas diversas fases do desenvolvimento ovocitário para $A$. brasiliensis, bem como estruturas derivadas, os folículos pósovulatórios, encontradas nas gônadas femininas analisadas. 


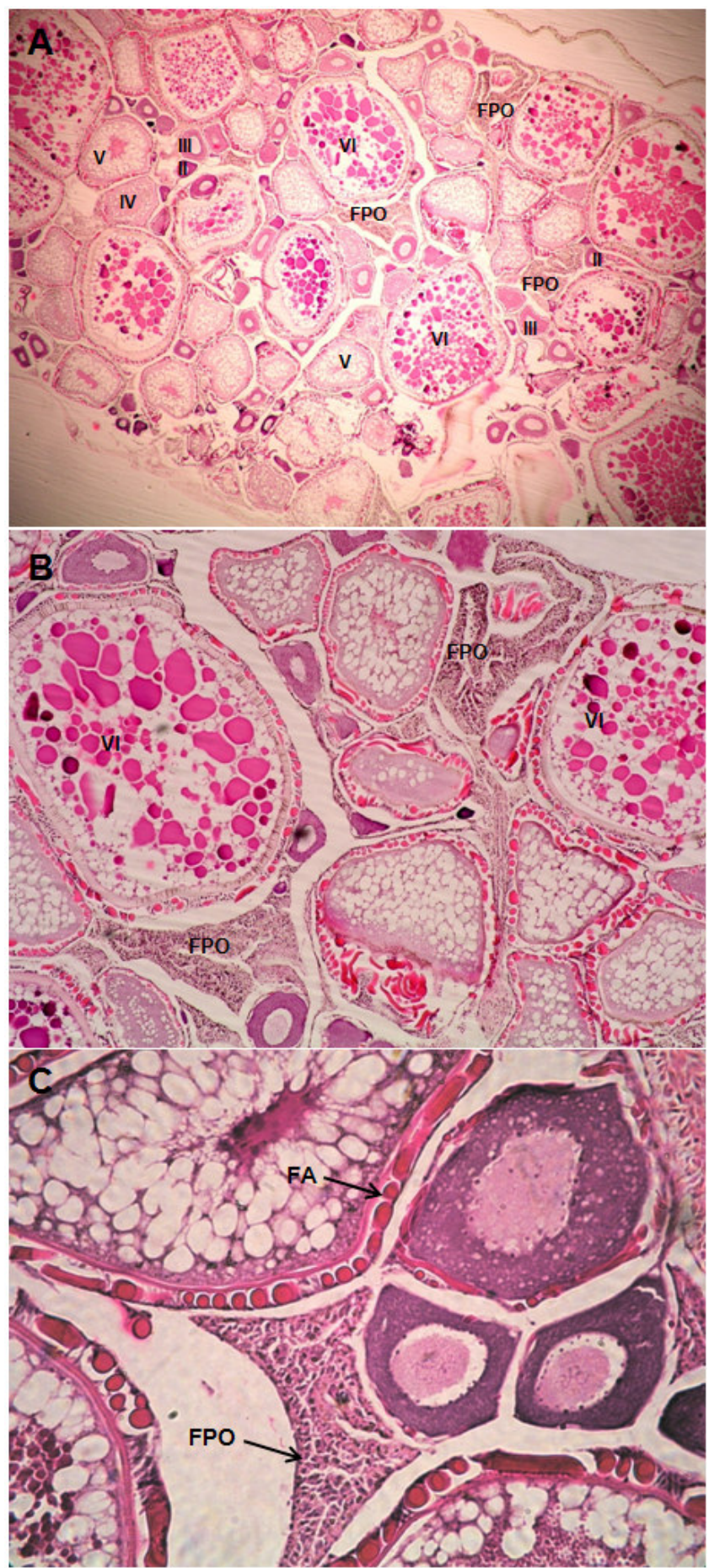

Figura 18. Cortes de gônadas de fêmeas de Atherinella brasiliensis coletadas na praia de Itamambuca - Ubatuba (SP). (A) = representação das fases de desenvolvimento ovocitário ( $\mathrm{HE}, 4 \mathrm{x})$; $(\mathrm{B})$ = ocorrência de ovócitos hidratados e folículos pósovulatórios $(\mathrm{HE}, 10 \mathrm{x}) ;(\mathrm{C})=$ detalhe do folículo pós-ovulatório. Il= ovócitos avitelogênicos; III= ovócitos com início de vitelogênese lipídica; IV= ovócitos com início de vitelogênese protéica; $\mathrm{V}=$ ovócito maduro; $\mathrm{VI}=$ ovócito hidratado; $\mathrm{FPO}=$ folículo pós-ovulatório; FA= filamentos adesivos. 
Após aplicada a correção aos resultados anteriormente obtidos, levando em consideração a nova escala proposta, as freqüências dos estádios de maturação passaram a: no estádio B com 21,3 \%, no estádio C com 50,7 \%, no estádio D com 24,7 \% e no estádio D/E com 3,3 \% do total (Figura 19). As análises a partir de então foram realizados considerando-se os novos resultados obtidos.

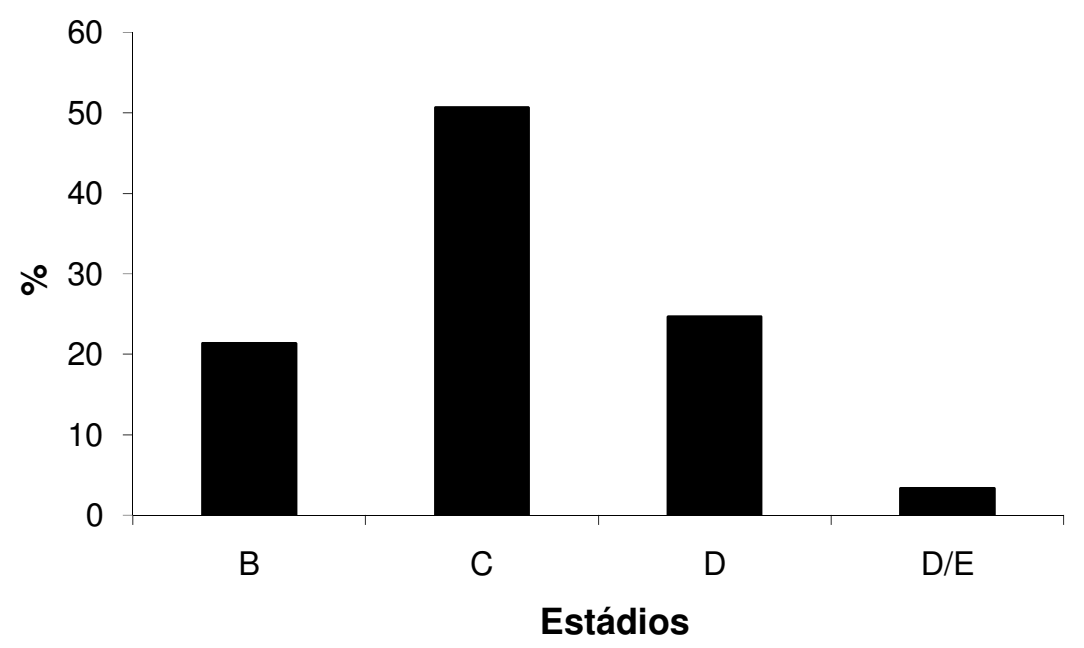

Figura 19. Proporção de fêmeas adultas de Atherinella brasiliensis da praia de Itamambuca (SP) de todo o período estudado por estádio de maturação gonadal, a partir da identificação macro- e microscópica proposta, com a introdução do estádio D/E, que representa a ocorrência de ovários com ovócitos hidratados e folículos pósovulatórios.

As fêmeas no estádio C (maduras) e D (com ovócitos hidratados) ocorreram em quase todos os meses de coleta, com exceção do mês de dezembro de 2004 para indivíduos em estádio C, e em março, maio, novembro de 2004 e janeiro de 2005 para indivíduos no estádio D (Figura 20). A figura também indica a ocorrência, em dezembro de 2004, de somente indivíduos com gônadas hidratadas (D). Os indivíduos em maturação (estádio B) 
ocorreram somente a partir de abril de 2004, com exceção dos meses de setembro e dezembro de 2004, apresentando uma maior freqüência em maio de 2004. Nos meses de novembro e dezembro de 2003 e junho de 2004 foram capturados indivíduos desovados (estádios D/E) como mostra a figura 20.

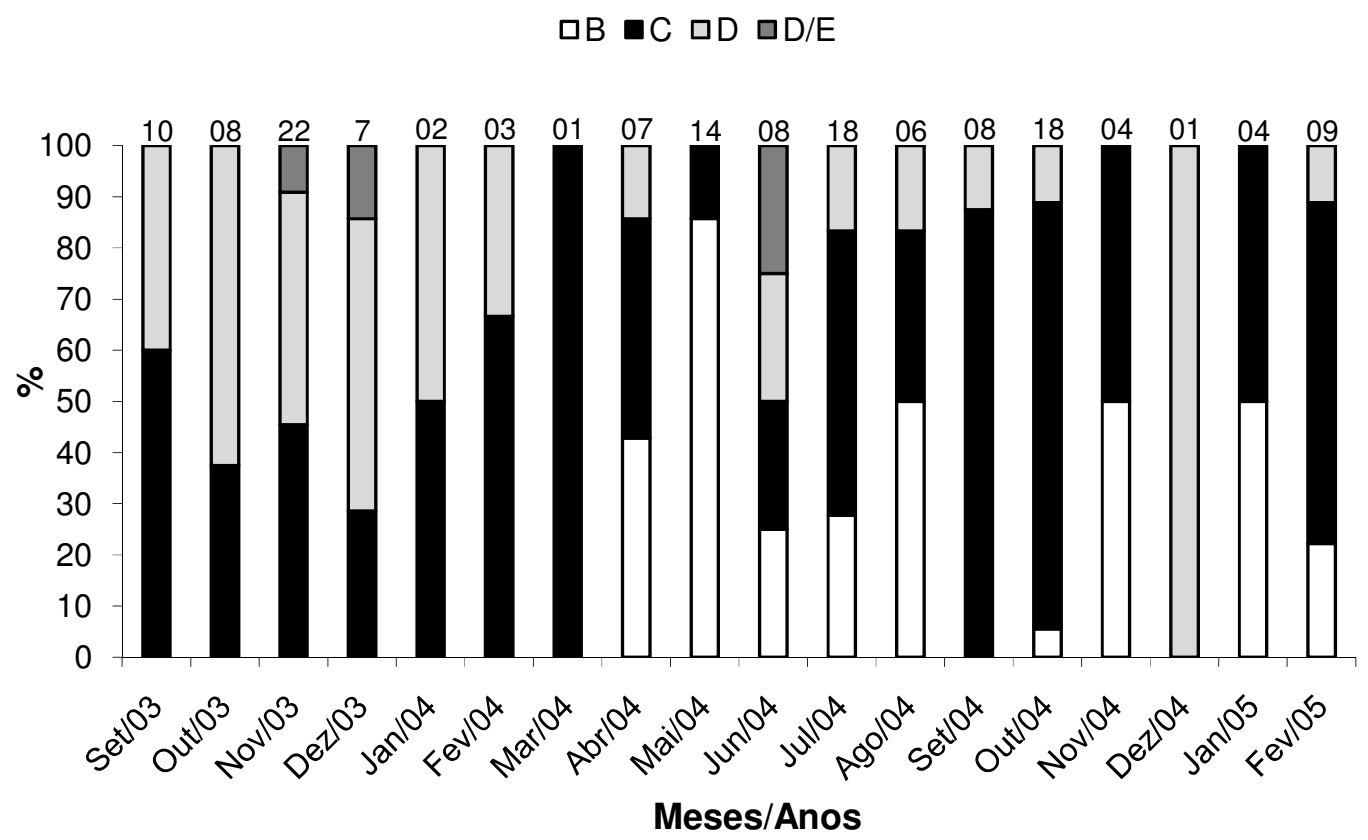

Figura 20. Variação mensal da proporção de fêmeas adultas de Atherinella brasiliensis da praia de Itamambuca (SP) de todo o período estudado em diferentes estádios de maturação gonadal.

Na figura 21 as freqüências dos estádios de maturação de fêmeas estão agrupadas sazonalmente mostrando um aumento significativo de fêmeas no estádio B (em maturação) no outono de 2004 que vai diminuindo gradativamente, aumentando um pouco novamente no verão de 2005 e uma maior freqüência de indivíduos desovados, ou seja, no estádio D/E principalmente na primavera de 2003, verão de 2003/04 e inverno de 2004, como já visto anteriormente. Estes valores sugerem que a espécie desova em todas as épocas do ano. 
$\square B \square C \square D D / E$

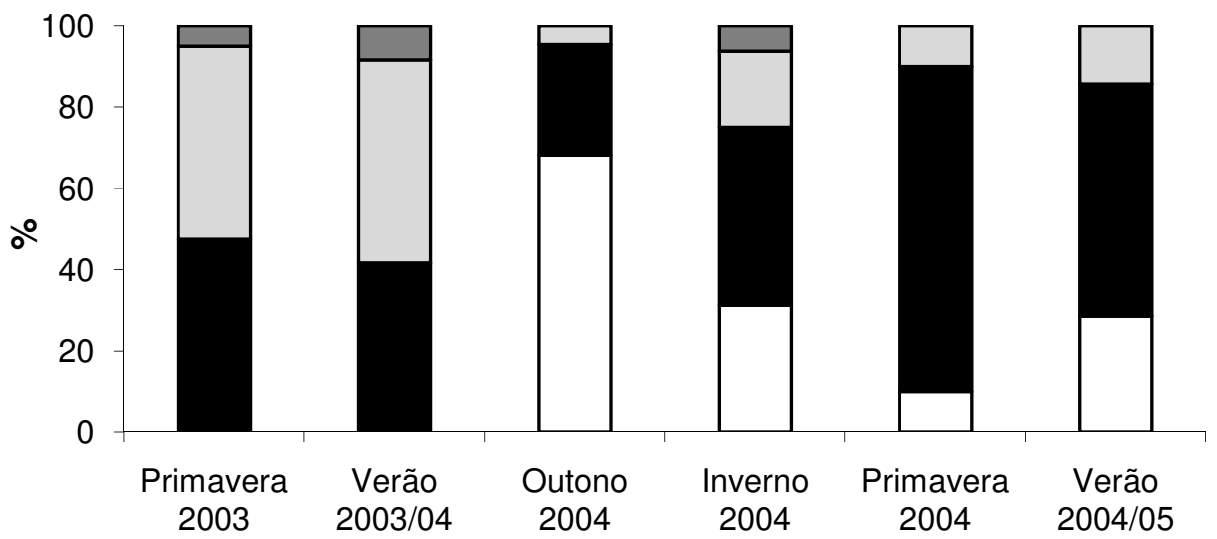

Figura 21. Variação sazonal da proporção de fêmeas adultas de Atherinella brasiliensis da praia de Itamambuca (SP) de todo o período estudado em diferentes estádios de maturação gonadal.

Além dos estádios de maturação, a análise histológica revelou a ocorrência de testículos entre os ovários examinados, o que altera as proporções sexuais. Assim, a tabela 13 apresenta os valores das proporções sexuais corrigidas para todos os períodos de coleta e o resultado também corrigido do $x^{2}$, considerando a proporção 1:1 bem como a proporção encontrada no presente estudo na região, sendo agora 1:1,7 (aproximadamente um macho para duas fêmeas). Dos dezoito meses, em apenas quatro meses (setembro e dezembro de 2003 e maio e junho de 2004) houve diferença significativa $(p<0,05)$, levando em consideração as proporções sexuais 1:1, e somente em dois meses (março e maio de 2004) houve diferença significativa entre as proporções do total capturado e os valores das proporções mensais. Somente em maio de 2004 houve coincidência na diferença entre proporções de machos e fêmeas em $\chi^{2}$ (1:1 e encontrado), quando ocorreu uma freqüência muito superior de fêmeas. Como no resultado 
obtido anteriormente, não se pôde constatar qualquer padrão espaço-temporal na distribuição de machos e de fêmeas, mas somente a ocorrência significativamente maior de fêmeas do que de machos na região, para o período estudado.

Tabela 13. Valores numéricos, proporção sexual e valores de $\chi^{2}$ (1:1 e encontrado) corrigidos de Atherinella brasiliensis por época do ano para todo o período estudado na praia de Itamambuca (SP).

\begin{tabular}{|c|c|c|c|c|c|c|}
\hline \multirow{2}{*}{ Meses/Ano } & \multicolumn{2}{|c|}{ Fêmeas } & \multicolumn{2}{|c|}{ Machos } & \multirow{2}{*}{$\chi 2(1: 1)$} & \multirow{2}{*}{$\chi^{2}$ (encontrado } \\
\hline & $\mathbf{N}$ & $\%$ & $\mathbf{N}$ & $\%$ & & \\
\hline Set/03 & 14 & 93,33 & 1 & 6,66 & 11,33 & 4,63 \\
\hline Out/03 & 8 & 44,44 & 10 & 55,55 & 0,28 & 4,75 \\
\hline Nov/03 & 24 & 60,00 & 16 & 40,00 & 1,63 & 1,42 \\
\hline Dez/03 & 8 & 88,89 & 1 & 11,11 & 5,56 & 2,13 \\
\hline Jan/04 & 2 & 66,67 & 1 & 33,33 & 0,67 & 0,36 \\
\hline Fev/04 & 3 & 50,00 & 3 & 50,00 & 0,17 & 0,88 \\
\hline Mar/04 & 1 & 16,67 & 5 & 83,33 & 2,83 & 6,99 \\
\hline Abr/04 & 10 & 58,82 & 7 & 41,17 & 0,59 & 0,73 \\
\hline Mai/04 & 14 & 93,33 & 1 & 6,66 & 11,33 & 4,63 \\
\hline Jun/04 & 8 & 88,89 & 1 & 11,11 & 5,56 & 2,13 \\
\hline $\mathrm{Jul} / 04$ & 18 & 60,00 & 12 & 40,00 & 1,23 & 1,04 \\
\hline Ago/04 & 6 & 75,00 & 2 & 25,00 & 2,13 & 0,38 \\
\hline Set/04 & 8 & 72,73 & 3 & 27,27 & 2,36 & 0,24 \\
\hline Out/04 & 26 & 76,47 & 8 & 23,52 & 9,56 & 1,03 \\
\hline Nov/04 & 4 & 66,67 & 2 & 33,33 & 0,83 & 0,17 \\
\hline Dez/04 & 1 & 50,00 & 1 & 50,00 & 0,50 & 0,59 \\
\hline Jan/05 & 4 & 80,00 & 1 & 20,00 & 2,00 & 0,71 \\
\hline Fev/05 & 11 & 91,67 & 1 & 8,33 & 8,42 & 3,36 \\
\hline Total & 170 & 69,11 & 76 & 30,89 & 35,92 & 0,00 \\
\hline
\end{tabular}

Quanto às proporções sexuais corrigidas por classe de comprimento total (Figura 22), observou-se uma diminuição gradativa da diferença entre as proporções de machos e fêmeas até a classe de 110 - 119, sendo que, a partir dessa classe não houve diferenças significativas entre machos e fêmeas, o que voltou a ocorrer somente na classe de 130 - 139, com uma maior freqüência 
de indivíduos machos, voltando à igualdade entre as proporções na última classe de comprimento (140 - 149).

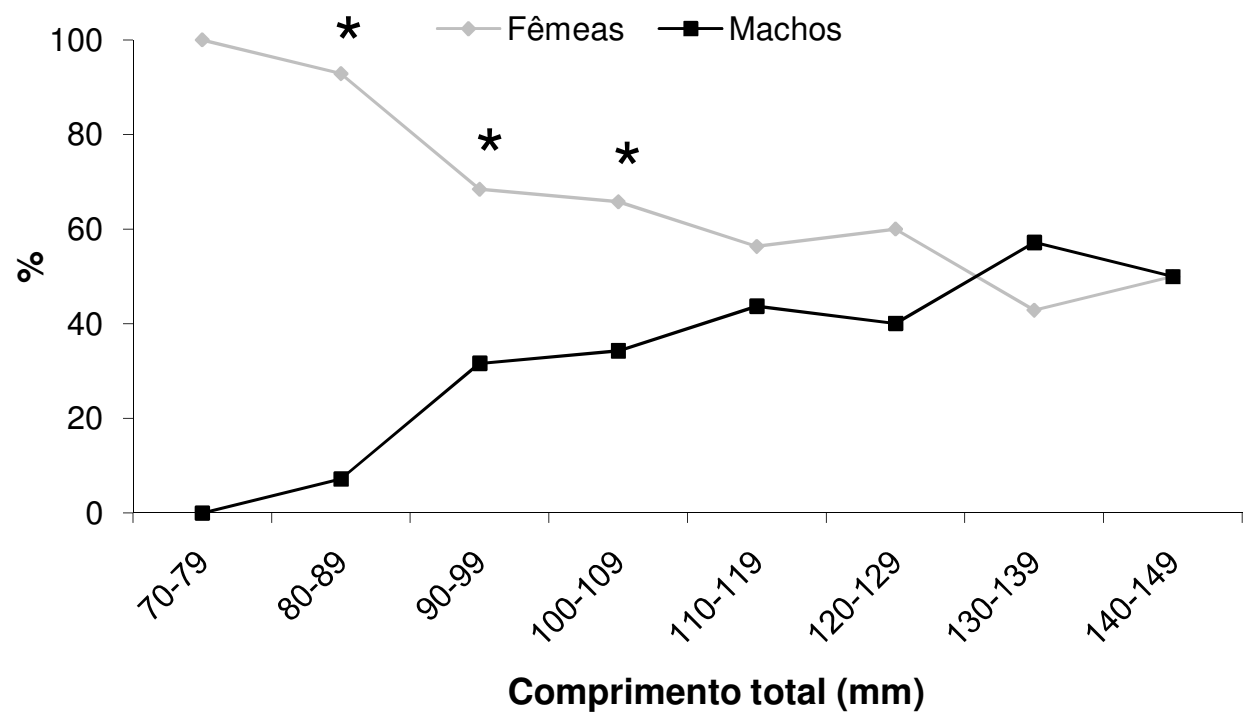

Figura 22. Porcentagens de machos e fêmeas corrigidas de Atherinella brasiliensis, por classe de comprimento total da praia de Itamambuca (SP) de todo o período estudado. ${ }^{*}=$ diferença significativa.

\subsubsection{Tamanho médio de início de maturação gonadal}

Na figura 23 está representada a proporção de indivíduos adultos por classe de comprimento total e a estimativa do $L_{50}$. $O$ comprimento médio de início de primeira maturação gonadal é aquele com o qual 50\% dos indivíduos apresentam gônadas em desenvolvimento, ou seja, iniciaram o ciclo reprodutivo. 


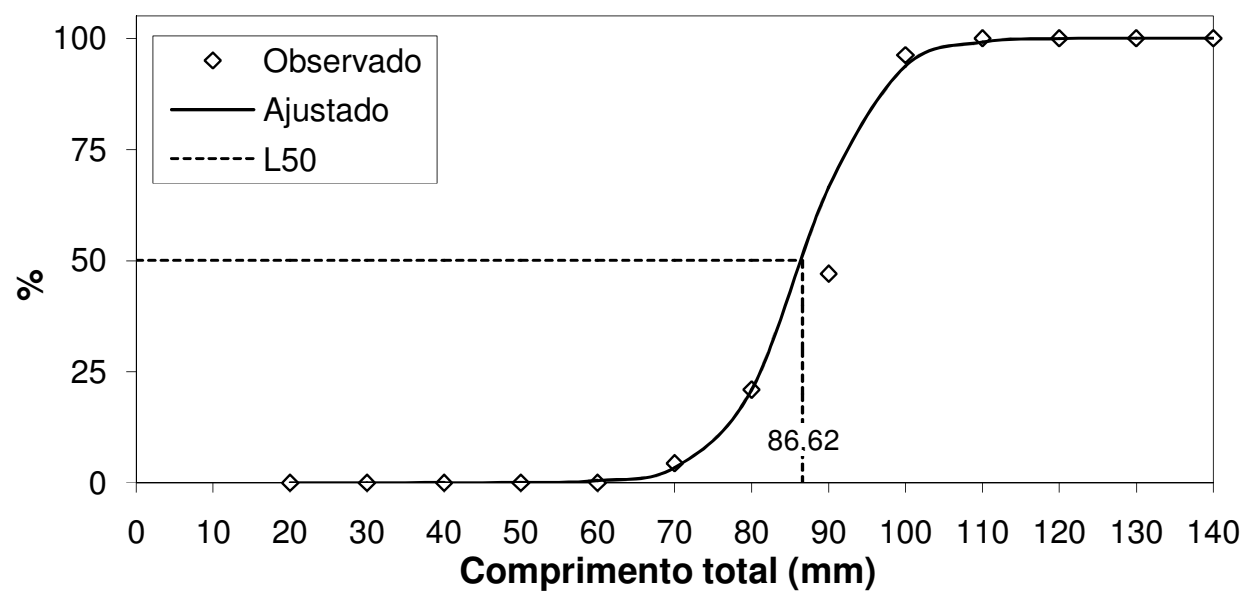

Figura 23. Porcentagem de indivíduos adultos por classe de comprimento total para Atherinella brasiliensis da praia de Itamambuca (SP) em todo o período estudado. A linha tracejada indica o tamanho médio de início de primeira maturação gonadal $\left(L_{50}\right)$.

\subsubsection{Indicadores quantitativos}

\section{a. Fator de condição alométrico (K) e $\Delta K$}

$\mathrm{Na}$ figura 24 estão representados os valores do fator de condição $(\mathrm{K})$ em relação ao comprimento total dos indivíduos capturados. Verificou-se que esses valores não variaram muito com o comprimento dos exemplares.

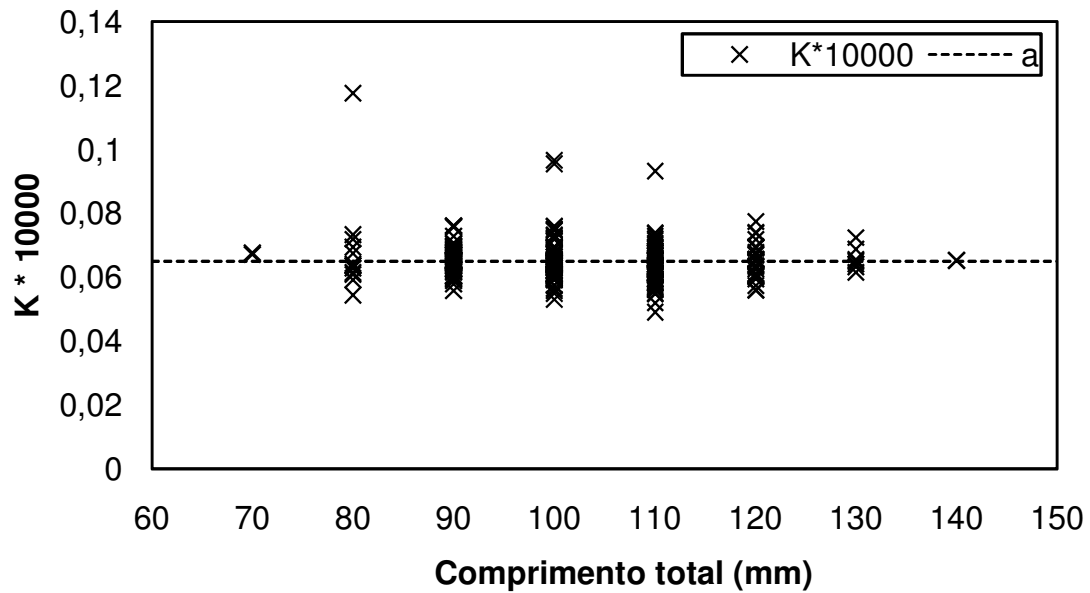

Figura 24. Valores do valor de condição $(K)$ em função do comprimento total de Atherinella brasiliensis da praia de Itamambuca (SP) de todo o período estudado. A reta tracejada representa o valor de "a" da relação peso/comprimento. 
Os valores médios do fator de condição K e K' por época de coleta estão representados na figura 25 , em que se observam os valores mais altos de $\mathrm{K}$ em março e dezembro de 2004 e em fevereiro de 2005 e os menores valores em outubro de 2004, julho e outubro de 2005. Nos meses de maiores valores de $\mathrm{K}$ a higidez é máxima, ou seja, as condições alimentares recentes indicam a possibilidade de acúmulo de reservas sob a forma de lipídios, glicogênio ou mesmo proteínas estruturais (musculatura).

Já os valores obtidos de $\Delta \mathrm{K}$ (figura 26) são mais altos nos meses de novembro de 2003 a janeiro de 2004, e de outubro a dezembro de 2004, indicando maior peso gonadal nessas épocas.

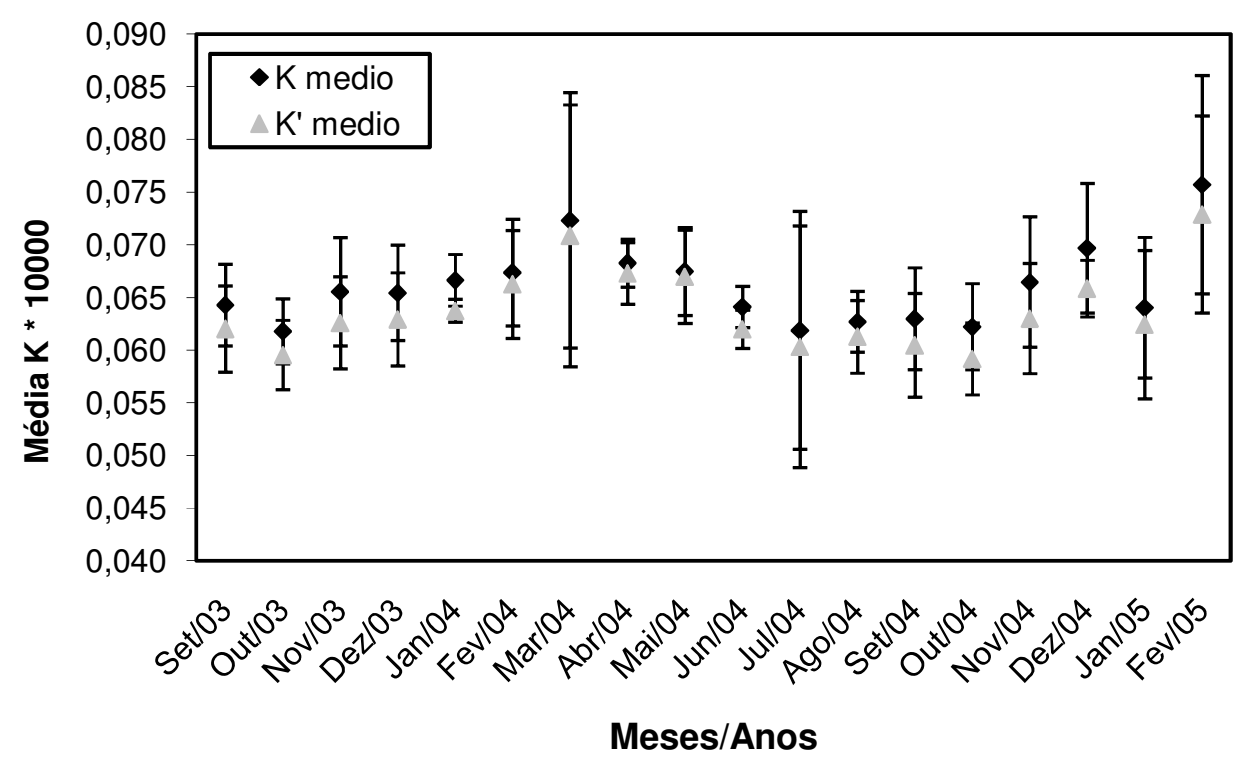

Figura 25. Variação mensal dos valores médios do fator de condição total $(K)$ e somático (K') com seus respectivos desvios padrão, em Atherinella brasiliensis da praia de Itamambuca (SP) para todo o período. 


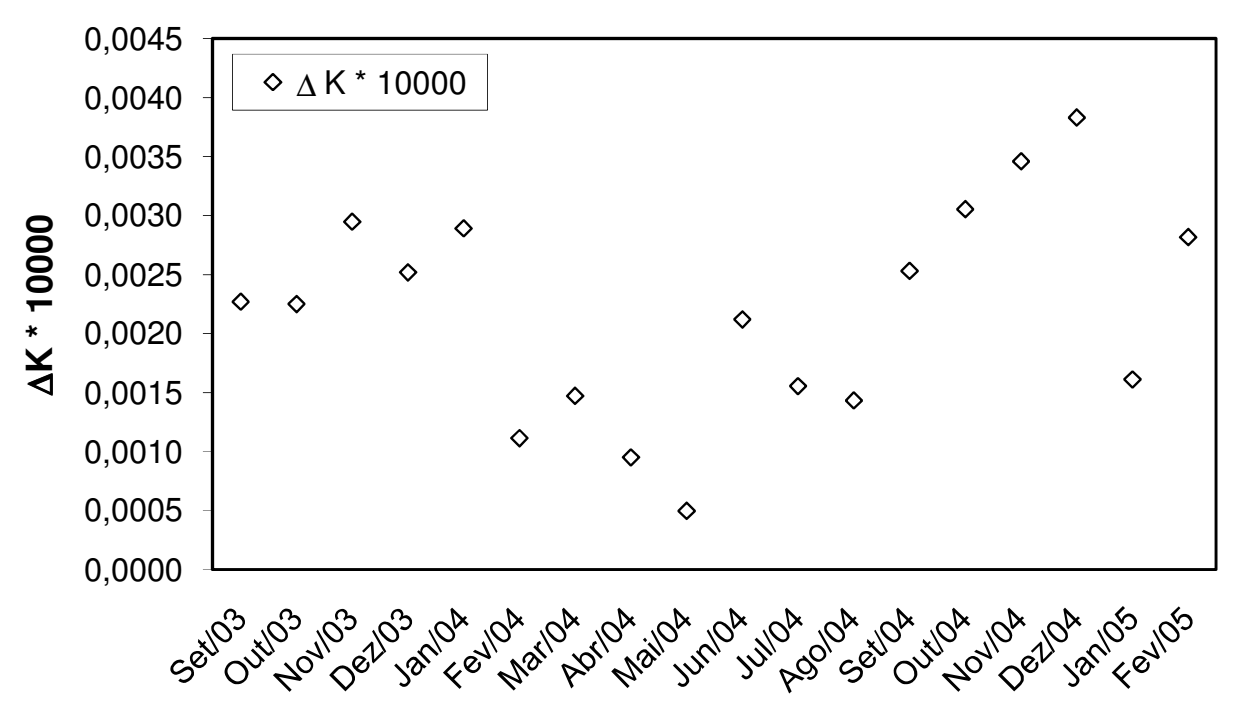

Meses/Anos

Figura 26. Variação mensal dos valores médios da diferença do fator de condição total e somático $(\Delta \mathrm{K})$, em Atherinella brasiliensis da praia de Itamambuca (SP) para todo o período.

\section{b. Relação gonadossomática (RGS)}

Os valores médios da relação gonadossomática (RGS) das fêmeas capturadas em todo o período estudado estão representados pela figura 27 . Observa-se que os valores médios mais baixos ocorreram em maio de 2004, e valores mais altos nos meses de outubro de 2003 a fevereiro de 2004, e de outubro a dezembro de 2004, estes relacionados a períodos de máxima maturação. As quedas nos valores da RGS, entre março e maio de 2004 e entre dezembro de 2004 e janeiro de 2005 podem caracterizar picos de atividade de desova da população. 


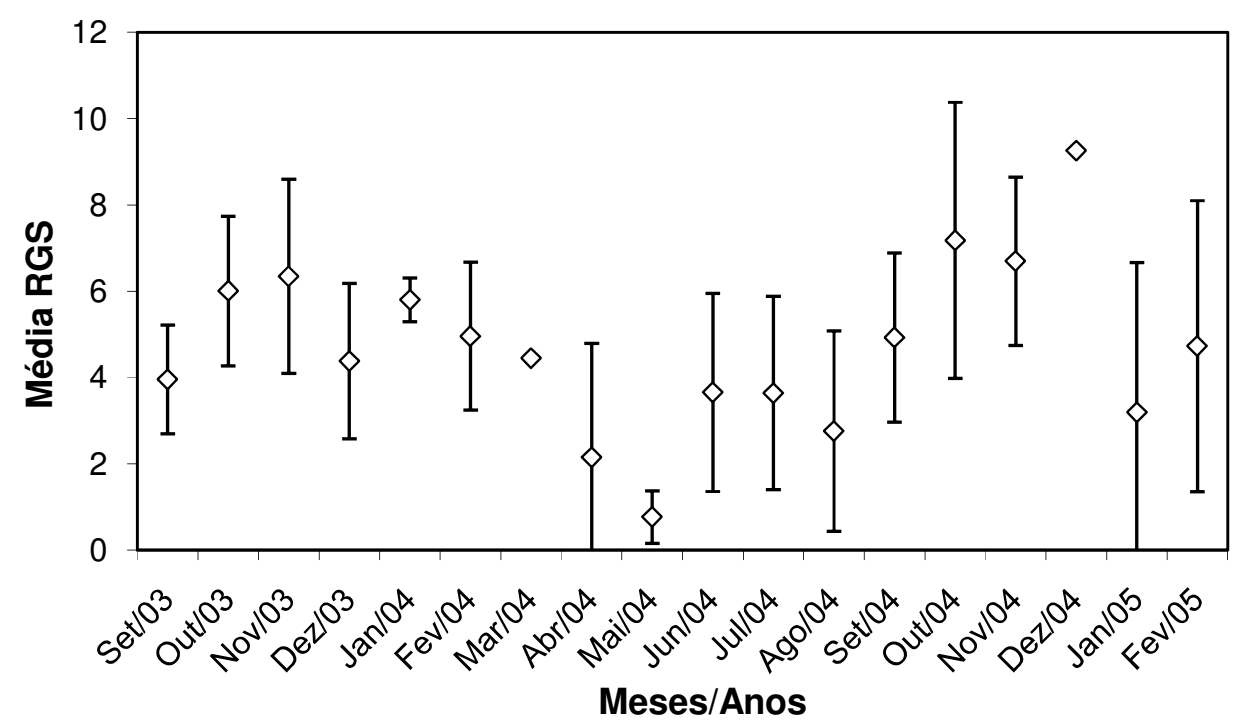

Figura 27. Variação mensal da média da relação gonadossomática (RGS) de fêmeas adultas de Atherinella brasiliensis da praia de Itamambuca (SP) de todo o período estudado. As barras verticais indicam os desvios padrão.

$\mathrm{Na}$ figura 28 estão representadas as variações da relação gonadossomática em função do comprimento total, mostrando que os valores de mais altos de RGS, como aqueles acima de $6 \%$, incluindo indivíduos com gônadas classificadas como D (ovários hidratados), ocorreram em indivíduos de comprimento pequeno, a partir de $85 \mathrm{~mm}$, sendo que valores máximos são encontrados para as gônadas das fêmeas de maiores comprimentos (RGS maior que 10 em fêmeas acima de $110 \mathrm{~mm}$ de comprimento). As gônadas classificadas como D atingiram RGS máxima com 14,6 \%, seguidas daquelas no estádio C, ou seja, maduras com máximos de 10,2 \%, enquanto que fêmeas em maturação apresentaram valores máximos da RGS de 1,9 \%. Estes resultados evidenciaram um aumento da massa gonadal em relação ao comprimento total do peixe. O mesmo ocorre na média da RGS por estádio de maturação (Figura 29), com aumento da relação gonadossomática relacionada 
aos estádios gonadais, ou seja, atingindo máximos valores no estádio D, quando as gônadas se encontram hidratadas, havendo uma pequena diminuição nos valores da RGS nos indivíduos no estádio D/E, devido à eliminação de uma parcela dos ovócitos.

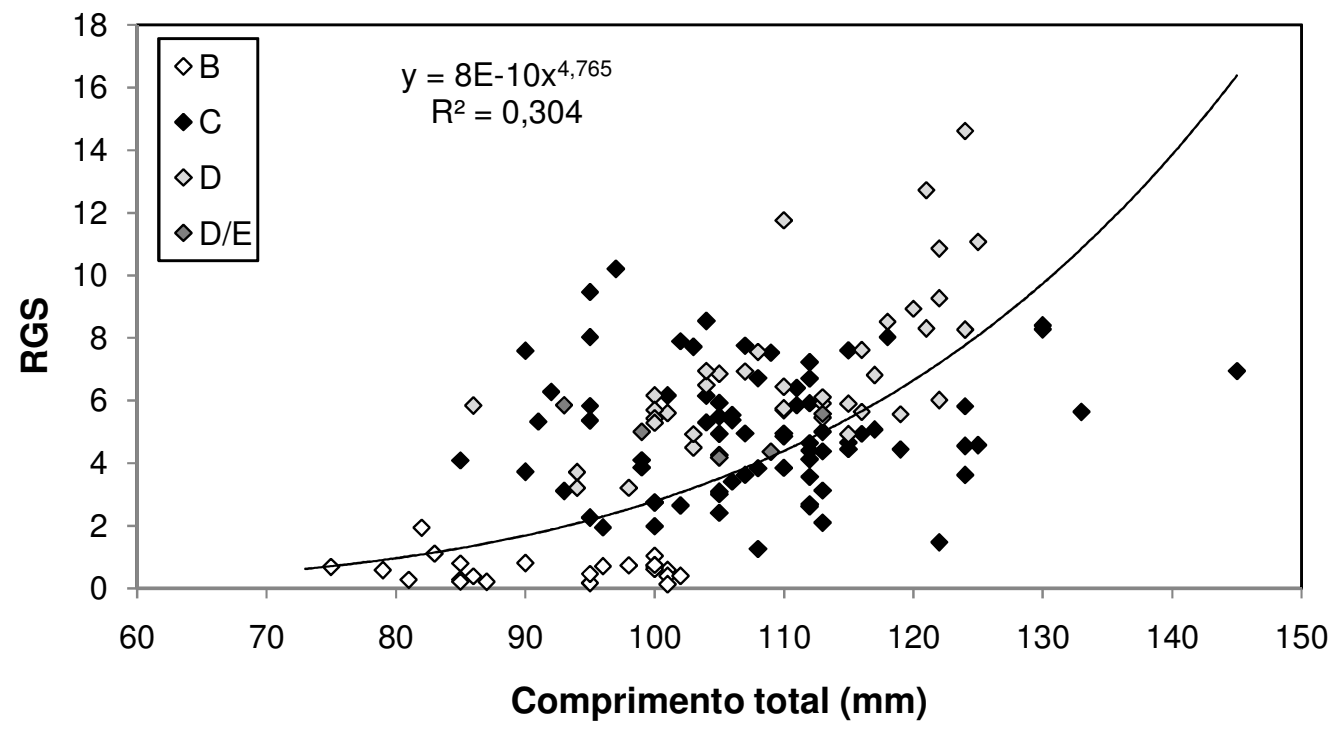

Figura 28. Valores da relação gonadossomática (RGS) em relação ao comprimento total das fêmeas adultas de Atherinella brasiliensis da praia de Itamambuca (SP) de todo o período estudado por estádio de maturação gonadal.

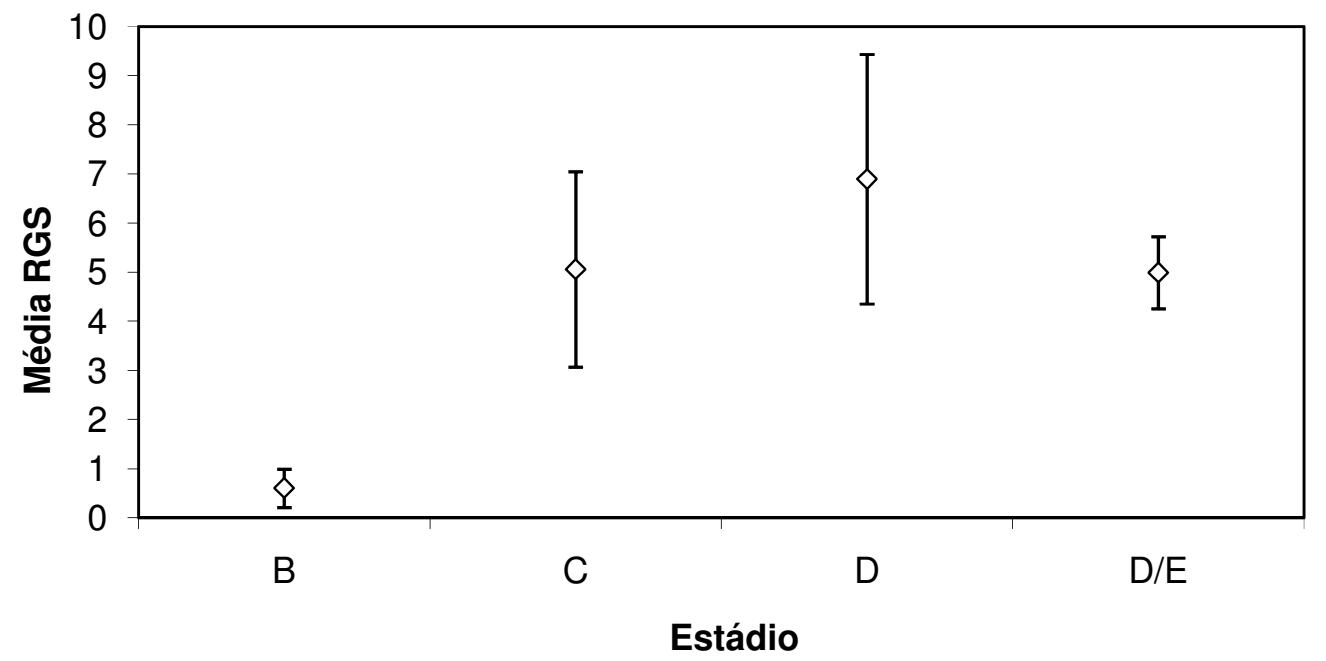

Figura 29. Valores médios da relação gonadossomática (RGS) por estádio de maturação gônadas das fêmeas adultas de Atherinella brasiliensis da praia de Itamambuca (SP) de todo o período estudado. 


\subsubsection{Fecundidade}

A contagem dos ovócitos hidratados das três alíquotas retiradas de porções diferentes das trinta gônadas de Atherinella brasiliensis não apresentou diferenças significativas $(p>0,05$, ANOVA), sugerindo que 0 desenvolvimento ovocitário ocorre homogeneamente em toda a gônada.

Os ovócitos hidratados apresentaram uma forma esférica com aparência relativamente translúcida e filamentos coronários adesivos, com uma amplitude de tamanho variando entre 1250 a $1500 \mu \mathrm{m}$.

Os valores de fecundidade para Atherinella brasiliensis variaram entre 73,3 e 1022,0 ovócitos hidratados por lote, com uma média de 381,5 ovócitos por fêmea (d.p.=253,7).

As estimativas de fecundidade variaram de acordo com os comprimentos e massa dos indivíduos de Atherinella brasiliensis, sendo que as fêmeas das maiores classes de comprimento e massas apresentaram maior fecundidade (Figuras 30 e 31). Entretanto, os valores medianos dos coeficientes de determinação $\left(\mathrm{r}^{2}\right)$, obtidos através dos ajustes do modelo potencial, estão relacionados principalmente a um indivíduo, cujas gônadas se encontravam no início do processo de hidratação, reduzindo o valor de $r^{2}$. Se esse único indivíduo fosse retirado das análises, os ajustes ao modelo potencial em ambos os casos seriam melhorados (de 0,485 para 0,721 na relação número de ovócitos/massa do corpo, e de 0,584 para 0,594 na relação número de ovócitos/comprimento total). 


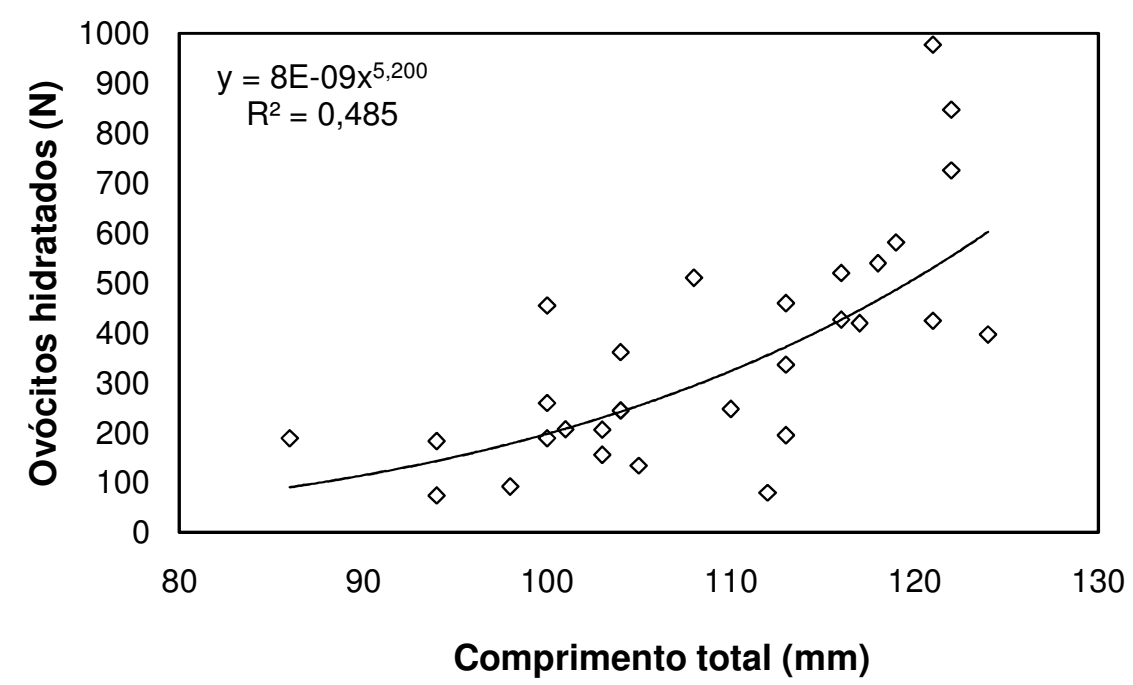

Figura 30. Relação entre o comprimento total $(\mathrm{mm})$ e a quantidade de ovócitos hidratados nas gônadas de Atherinella brasiliensis da praia de Itamambuca - Ubatuba (SP).

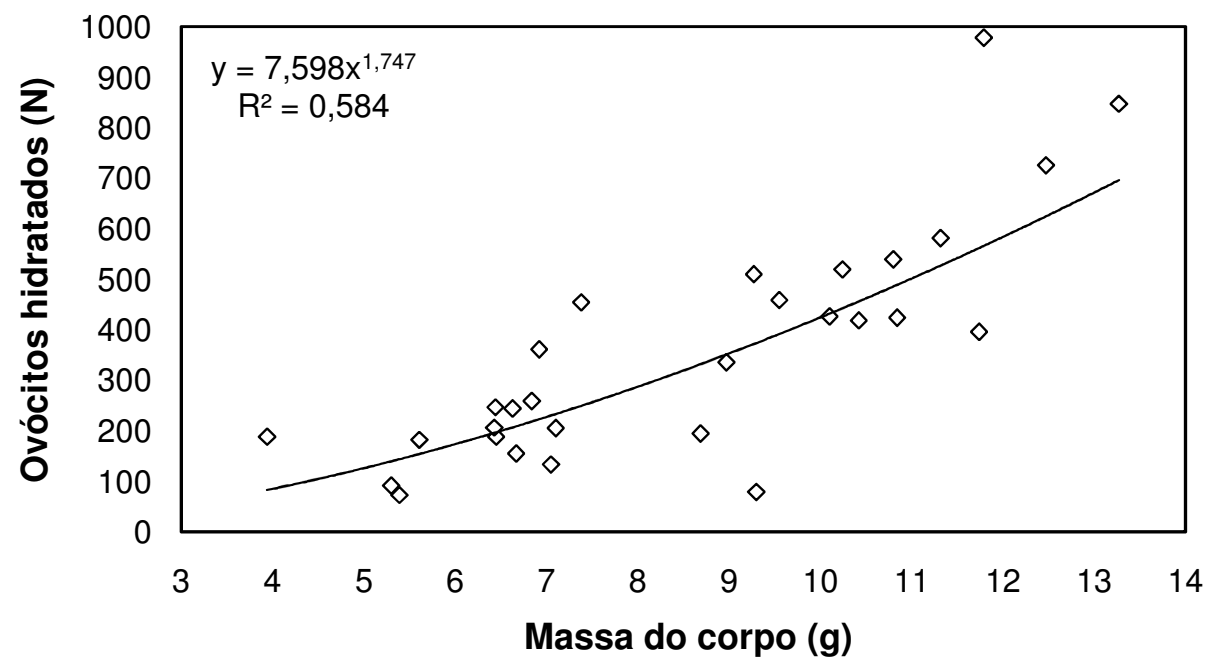

Figura 31. Relação entre a massa corpórea ( $g$ ) e a quantidade de ovócitos hidratados nas gônadas de Atherinella brasiliensis da praia de Itamambuca - Ubatuba (SP). 


\subsection{Análise espectroscópica por emissão de raios-x induzida por}

partículas

O resultado preliminar da composição elementar da musculatura médiolateral de Atherinella brasiliensis da praia de Itamambuca em dois períodos do ano, em julho e setembro (inverno) e janeiro e fevereiro (verão), através da técnica PIXE estão apresentadas na figura 32, sob a forma de espectro (energia $x$ contagem) e de concentração em ppm (partes por milhão).

Foram detectados $\mathrm{Na}, \mathrm{Mg}, \mathrm{Al}, \mathrm{Si}, \mathrm{P}, \mathrm{S}, \mathrm{Cl}, \mathrm{K}, \mathrm{Ca}$ e $\mathrm{Ti}$ em maiores quantidades, e os elementos traço $\mathrm{Cr}, \mathrm{Mn}, \mathrm{Fe}, \mathrm{Ni}, \mathrm{Cu}, \mathrm{Zn}, \mathrm{As}, \mathrm{Se}, \mathrm{Br}, \mathrm{Rb}$ e $\mathrm{Sr}$. Dentre os elementos traço, as concentrações médias de cromo $(\mathrm{Cr})$, ferro $(\mathrm{Fe})$ e zinco $(Z n)$ se destacam. Os maiores valores médios desses três metais foram encontrados no período do verão, quando a região apresenta uma maior atividade turística, com valores de concentração média de 33,65 (erro padrão e.p. $=14,37)$ ppm para cromo, 73,83 (e.p. $=25,84)$ ppm para o ferro e 51,80 (e.p. $=3,84)$ ppm para o zinco (Figura 32). No inverno, as concentrações médias estão mais baixas, porém a diferença entre inverno e verão não é significativa: cromo $=22,83($ e.p. $=7,85)$ ppm, ferro $=57,33($ e.p. $=18,15)$ ppm e zinco $=48,06$ (e.p.=5,39) ppm (Figura 32). 


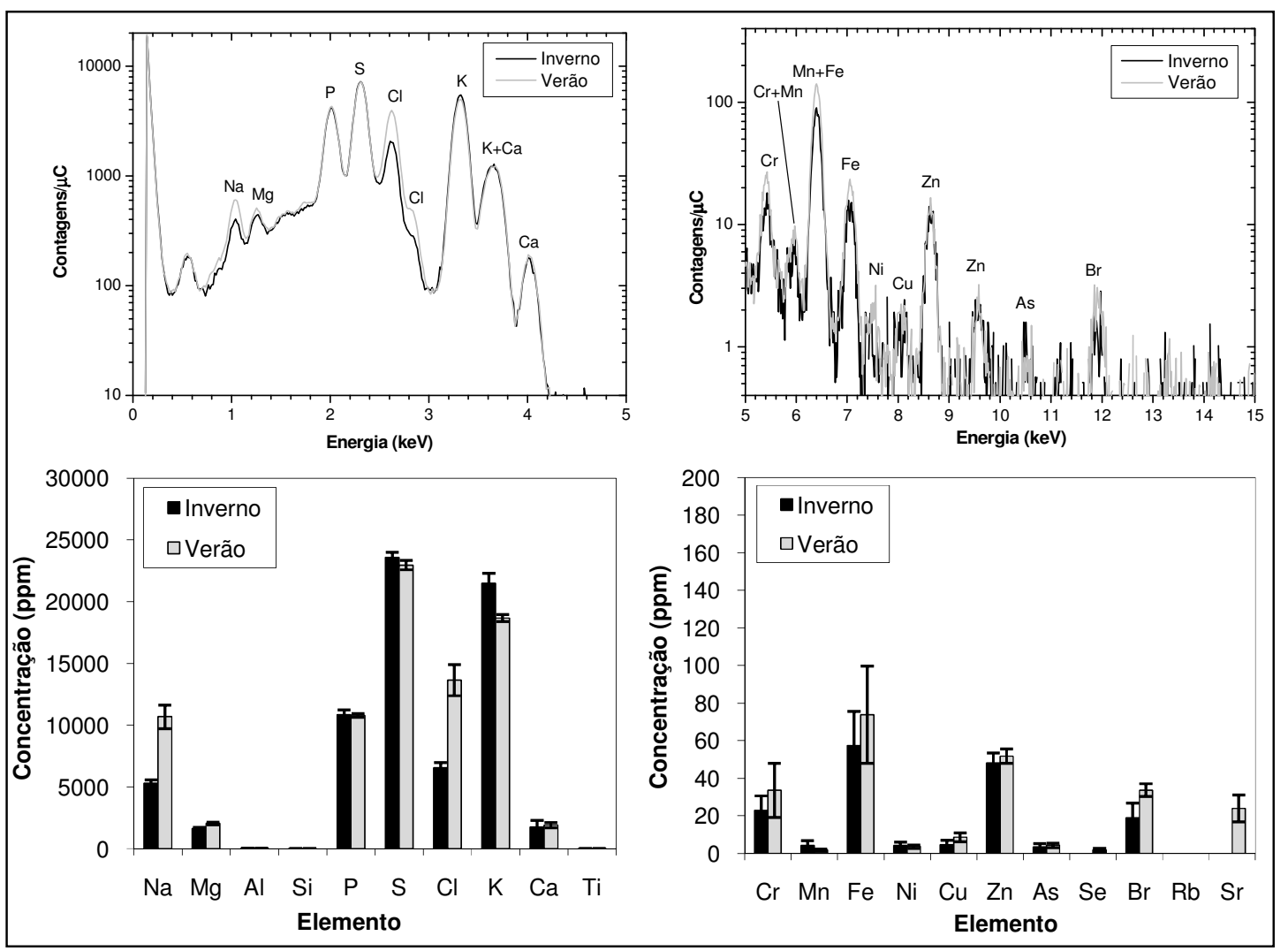

Figura 32. Composição elemental da musculatura médio-lateral de Atherinella brasiliensis da praia de Itamambuca - Ubatuba (SP) em dois períodos do ano, medidas a partir da técnica PIXE. Acima: espectro; Abaixo: concentração (ppm).

Como as amostras coletadas eram as mesmas, médias dos indivíduos de menor tamanho em relação a maiores espécimes coletados da população de $A$. brasiliensis na região foram calculadas para averiguar a biocumulação de metais. Os mesmos cromo, ferro e zinco apresentaram uma concentração média mais alta na musculatura dos exemplares analisados, em relação aos outros elementos químicos. As maiores concentrações médias desses metais foram encontradas nos indivíduos jovens $(<100 \mathrm{~mm})$, como se segue: para 0 cromo foi 53,86 (e.p.=38,46) ppm, o ferro 107,10 (e.p.=70,73) ppm e o zinco 52,33 (e.p.=10,41) ppm. Já nos indivíduos de maior porte a concentração média de cromo foi 19,63 (e.p.=3,29) ppm, do ferro 52,15 (e.p.=8,55) ppm e de zinco 52,64 (e.p.=2,65) ppm (Figura 33). 


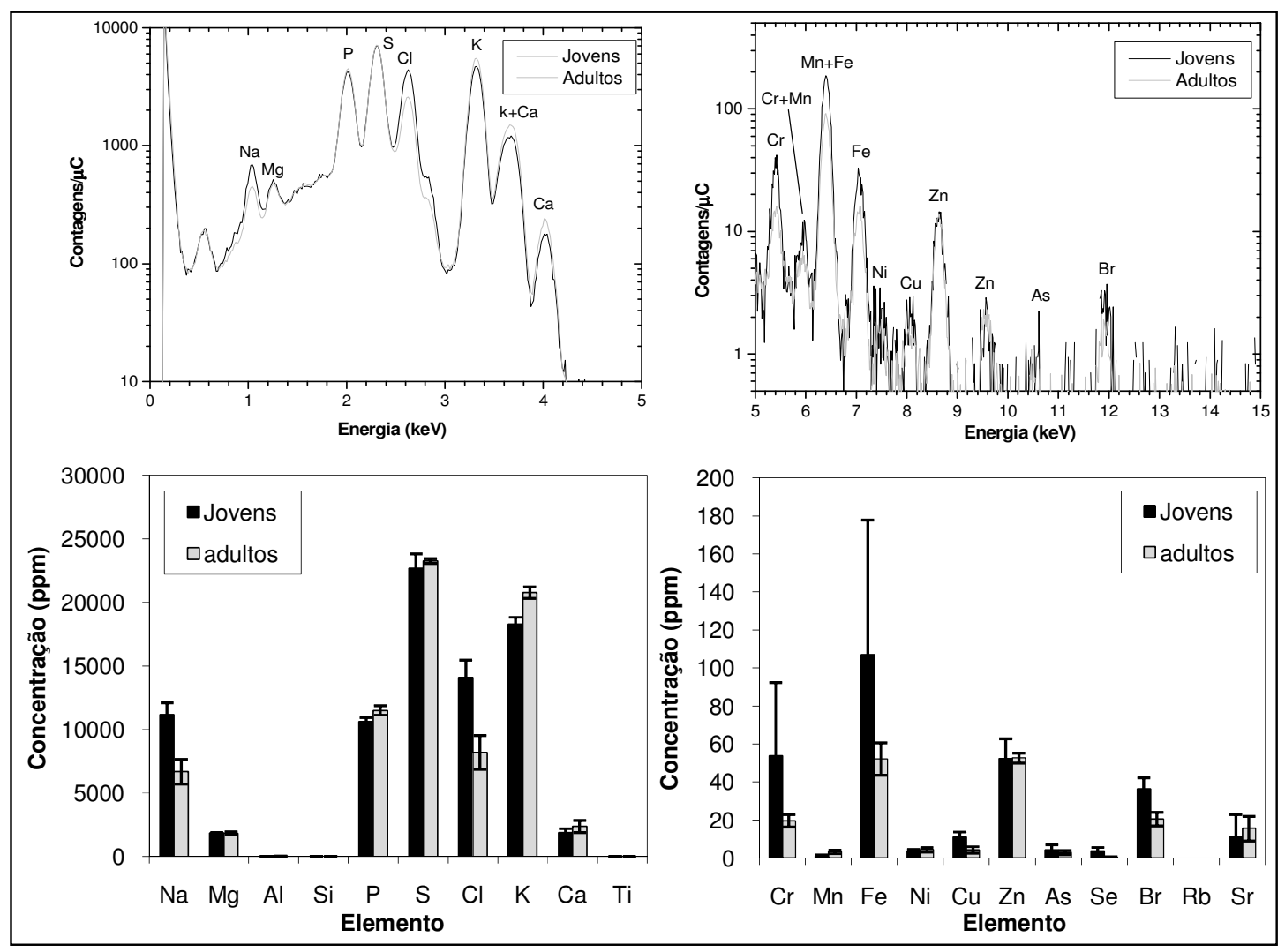

Figura 33. Composição elemental da musculatura médio-lateral de jovens e adultos de Atherinella brasiliensis da praia de Itamambuca - Ubatuba (SP), medidas a partir da técnica PIXE. Acima: espectro; Abaixo: concentração (ppm).

\section{DISCUSSÃO}

\subsection{Ocupação espaço-temporal de Atherinella brasiliensis na praia} de Itamambuca

A partir dos resultados obtidos foi possível verificar que Atherinella brasiliensis ocorre ao longo de todo o ano, tanto na praia como no rio Itamambuca. O número de indivíduos capturados pelo esforço empregado foi baixo, quando comparado aos resultados obtidos por outros trabalhos, utilizando a mesma arte de pesca: 21.425, 2.100 e 660 indivíduos capturados 
por Neves et al., 2006; Pessanha \& Araújo, 2001 e Santos et al. 1999, respectivamente. Com a ressalva de que as unidades dos esforços adotadas tenham sido diferentes, a maior abundância em outras áreas pode estar relacionada ao menor grau de exposição e batimento dos locais de captura, quando comparados aos deste trabalho realizado na praia de Itamambuca, a mais exposta do litoral norte paulista, atestada pela declividade acentuada e pela presença de areia média (Barros, 1997). Assim, o número de indivíduos capturados reflete a ocorrência local, cuja dinâmica praial limitaria a abundância dos indivíduos, mas não sua ocorrência. Neves et al. (2006) também concluiu que sistemas semi-fechados, tais como manguezais, são ambientes favoráveis para a espécie, enquanto que praias arenosas, especialmente aquelas pouco protegidas e com baixo nível de estruturação, apresentam limitações para a abundância da espécie.

A temperatura e a salinidade também não foram consideradas fatores limitantes para a distribuição de Atherinella brasiliensis na praia de Itamambuca no presente estudo, corroborando os resultados encontrados por Bemvenuti (1987). Porém, outros estudos mostraram relação direta entre a abundância desta espécie com os fatores ambientais citados, sendo que, em maiores temperaturas e salinidades a abundância da espécie é maior (Bemvenutti, 1987; Santos et al., 1999; Hostim-Silva et al., 1995), diferentemente do encontrado no presente estudo; entretanto, Andreata et al. (1997) não encontraram nenhuma tendência, de abundância ou ocorrência, relacionada à temperatura e salinidade para a espécie na Lagoa Rodrigo de Freitas.

Os resultados obtidos ao longo de dezoito meses de estudo também sugerem que Atherinella brasiliensis realiza migrações diárias ao longo da praia 
de Itamambuca, nas quais os indivíduos adultos da espécie sairiam do rio Itamambuca e se concentrariam principalmente nas estações 3 (primeira da praia) e 4 (boca do rio) nos períodos de luz. No período de escuro (noite) os indivíduos migrariam novamente para dentro do rio, se concentrando na estação 5 (dentro do rio). Os indivíduos jovens também realizam essa migração diária, porém são encontrados, em menor quantidade, ao longo de toda a praia durante o dia, permanecendo uma grande parcela de indivíduos menores dentro do rio Itamambuca. No período da noite esses indivíduos jovens apresentam o mesmo padrão de distribuição que os adultos, concentrando-se na estação localizada dentro do rio. Confrontando-se os dados de abundância nas diferentes estações de coleta, nos diferentes períodos do dia, com os dados de maré, constatou-se que o regime de maré não interfere no deslocamento dos indivíduos do rio Itamambuca para a praia e vice-versa. Independentemente do regime de maré os padrões de abundância diurna e noturna se mantiveram iguais nos dezoito meses de amostragem.

Pode-se supor que a migração diária realizada por Atherinella brasiliensis para dentro do rio Itamambuca esteja relacionada a dois fatores principais: disponibilidade de alimento e proteção contra predadores. Layman (2000) realizou um estudo na zona de arrebentação na costa leste de Virginia e constatou que existem muitas espécies carnívoras que migram para esta área durante o período noturno para se alimentar, espécies estas caracterizadas como "predadoras noturnas". Apesar da disponibilidade de alimento, a zona de arrebentação é tipicamente dominada por poucas espécies de peixes que conseguem se beneficiar da turbulência e da pouca profundidade (Lasiak, 1984; Ross et al., 1987; Brown \& McLachlan, 1990; Romer, 1990). Além disso, 
as espécies de peixes residentes nessas áreas realizam movimentos de pequena escala para dentro dos rios, que estariam relacionados a uma série de fatores, tais como a diminuição do estresse das ondas, um efeito indireto de preferência pela turbidez, o aumento da disponibilidade de alimento, como forma de evitar a predação ou ainda com a combinação de todos os fatores citados. Por outro lado, a zona de arrebentação apresenta uma fauna diversificada, otimizando a oferta de alimento para os indivíduos das espécies da ictiofauna com maior capacidade competitiva.

\subsection{Crescimento de Atherinella brasiliensis na praia de Itamambuca}

As estimativas dos parâmetros das variáveis descritoras do processo de crescimento do peixe-rei, como a taxa de crescimento e o comprimento assintótico, obtidas através do método indireto, haviam sido estimadas para outras duas áreas, uma de manguezal e outra de praia (Neves et al., 2006; Pessanha \& Araújo, 2001). Os resultados obtidos neste trabalho apresentaram maior semelhança com aqueles de Neves et al. (op. cit.), que sugere que maiores comprimentos assintóticos refletem não somente diferenças na estrutura da população em tamanho da espécie entre as localidades, mas também que em locais com melhores condições ambientais e maior disponibilidade de recursos, os indivíduos apresentariam maiores comprimentos assintóticos. Neste sentido, a presença do rio Itamambuca, principalmente a região próxima de sua foz, cercada por vegetação, forneceria condições favoráveis (abrigo e alimento) semelhante àquelas encontradas na região de manguezal. 
Com relação à estimativa da taxa de crescimento, o presente estudo apresentou maiores valores; porém, os resultados podem estar relacionados à quantidade de indivíduos amostrados, já que os dois trabalhos mencionados acima apresentam um número amostral muito maior que o obtido neste estudo. Além disso, houve variação no comprimento máximo dos indivíduos capturados entre Itamambuca (20 a $145 \mathrm{~mm}$ ) e o das outras localidades, sendo de 10 a $160 \mathrm{~mm}$ do comprimento total (Neves et al., 2006) e de 13 a $138 \mathrm{~mm}$ (Pessanha \& Araújo, 2001), o que poderia interferir sobremaneira nas estimativas das taxas de crescimento.

Nos trabalhos acima relatados, a malha das redes de picaré utilizadas foi 7 mm de distância entre nós consecutivos, enquanto a utilizada neste estudo foi $10 \mathrm{~mm}$ entre nós na panagem central e $20 \mathrm{~mm}$ entre nós nos dois panos laterais. Assim, justificam-se as diferenças nos valores encontrados das variáveis de crescimento, bem como a ausência de indivíduos menores neste estudo, e a de um segundo recrutamento para a rede em Itamambuca.

Entretanto, o valor do índice de performance de crescimento estimado por Neves et al. (2006) e Pessanha \& Araújo (2001) foi praticamente igual ao do presente estudo, como era esperado, uma vez que, segundo Munro \& Pauly (1983), ocorre uma tendência à igualdade do valor deste índice para membros de uma mesma família que apresentarem taxas metabólicas semelhantes.

As relações obtidas entre 0 comprimento dos espécimes e o comprimento e massa dos otólitos, para o estudo do crescimento através do método direto, se ajustaram adequadamente aos conjuntos de dados, visto os altos valores de $r^{2}$ obtidos. O caráter linear constatado entre o comprimento total dos exemplares (CT) e o comprimento do otólito (Co) reflete o aspecto 
contínuo e constante na deposição de carbonato de cálcio e de matéria orgânica na estrutura, naquele que é o eixo típico do crescimento do peixe ao longo do tempo. Uma eventual não-linearidade poderia ser revelada, através da análise de resíduos padronizados, o que não ocorreu nos dados obtidos já que a maioria dos resíduos se encontrou dentro do intervalo de -3 a 3 . O caráter potencial constatado nas relações entre a massa do otólito (Mo) e o comprimento do otólito (Co), bem como o da massa do otólito (Mo) e comprimento total dos exemplares (CT) também mostra o ajuste adequado do modelo, já que as duas variáveis apresentam diferentes grandezas, evidenciando um incremento típico de volume.

Os resultados obtidos através da validação dos otólitos corroboram a hipótese da formação diária de anéis para os indivíduos de Atherinella brasiliensis. Essa periodicidade diária de incrementos nos otólitos é citada na revisão realizada por Stevenson \& Campana (1992) para diversas espécies de peixes, e estaria associada ao ritmo circadiano endógeno dos mesmos, regido principalmente pela temperatura e alimentação. Os autores também ressaltam que o método direto de marcação no otólito, usando-se um componente químico, é o melhor tipo de validação, mas é raramente conseguido em laboratório devido ao grande esforço exercido na captura, marcação e manutenção ou recaptura dos indivíduos, que causaria estresse nos indivíduos. De fato, a sobrevivência dos indivíduos marcados foi baixa, corroborando a menção das dificuldades inerentes a esta metodologia de obtenção de resultados.

A formação das bandas de quatorze dias nos otólitos de Atherinella brasiliensis pode estar associada principalmente ao ciclo lunar. O ciclo lunar 
tem duração de 28 dias, dividido em quatro períodos de sete dias (luas nova, crescente, cheia e minguante), porém a cada quatorze dias (lua nova e cheia) ocorrem as maiores variações de maré, conhecidas como marés de sizígia, sendo que muitos organismos são afetados por tal fenômeno, principalmente aqueles da região entre-marés (Nybakken, 1997). A magnitude das mudanças no ambiente e seus impactos na função fisiológica de muitos organismos implicam no desenvolvimento de ritmos biológicos circamaré (Naylor, 1996). Esses ritmos marcam o tempo e sincronizam comportamentos endógenos e fisiológicos com os ritmos ambientais, sendo que a expressão e a base endógena de ritmos biológicos em organismos marinhos têm sido documentadas por inúmeros autores (Meisel et al., 2003).

A periodicidade lunar no crescimento foi discutida por Rahman \& Cowx (2006) para Tenualosa ilisha (Clupeidae) capturada nos dois principais rios (Padma e Meghna) de Bangladesh, cuja maior problemática no estudo do crescimento da espécie era a ausência das bandas anuais nas estruturas utilizadas para o estudo do crescimento. Entretanto, após examinar cuidadosamente os anéis diários dos otólitos, os autores averiguaram a existência de bandas definidas relacionadas ao ciclo lunar. Hayashi et al. (2001) também constataram a periodicidade lunar nos otólitos de Myctophum asperum (Myctophidae) em águas ao oeste do Pacifico Norte, ocasionadas pelas migrações para mais perto da superfície nos períodos de lua cheia e nova. Arkhipkin (2005), em sua revisão sobre estatólitos, mencionou a periodicidade lunar para Ancistrocheirus lesueurii, anteriormente relatada por Arkhipkin (1997) e também para outras duas espécies de lulas, Loligo apalescens e Gonatus fabricci, relatadas por Spratt (1978) e Kristensen (1980), 
respectivamente. Essa mesma periodicidade lunar também foi encontrada nos otólitos de Atherinella brasiliensis capturados na praia de Itamambuca, Ubatuba (SP).

Os resultados obtidos através da estrutura etária da população da espécie na região mostraram claramente um maior crescimento no início da vida desses indivíduos. Segundo Fuiman \& Werner (2002), a diferenciação nos padrões de crescimento em peixes marinhos ao longo da vida é relativamente comum, sendo que os peixes imaturos apresentam um crescimento mais acelerado do que os peixes que já atingiram a maturidade gonadal. Entretanto, foi observada uma sobreposição de comprimentos principalmente nas primeiras bandas. Esse padrão de sobreposição de comprimentos no início da vida já foi discutido por diversos autores, tais como Giussi et. al. (1994) e Lorenzo (1999), para diferentes espécies, e estaria relacionado às maiores taxas de crescimento nesse período de vida.

Os parâmetros das variáveis de crescimento, obtidos através de diversos métodos, apresentaram diferentes ajustes, sendo que aquele que melhor representou o conjunto de dados foi o proposto por Ford-Walford. Porém, nenhum modelo matemático de crescimento descreve perfeitamente todo o ciclo de vida de uma espécie, sendo que diversos modelos deveriam ser aplicados a diferentes fases de desenvolvimento (Pitcher \& Hart, 1996). Segundo esses autores, o modelo mais largamente utilizado para descrever o crescimento, o de von Bertalanffy, assume que os peixes crescem até um determinado tamanho máximo e, quanto mais se aproximam deste tamanho menor é sua taxa de crescimento. Segundo Bertalanffy (1938), o crescimento resultaria do balanço da estruturação e da desestruturação de seus 
componentes orgânicos, sendo que o organismo aumenta (cresce) se a estruturação dos componentes orgânicos é maior do que o que é desestruturado. Tal fenômeno, chamado pelo autor de "sistema estacionário", resultaria da tendência de manutenção de uma constância ao longo do tempo devido ao desgaste do organismo.

Estudos sobre crescimento para outros membros dos Atherinopsidae foram realizados somente para duas espécies, Atherina boyeri e A. presbyter, cujos parâmetros de crescimento estimados estão representados na tabela 14, juntamente com as estimativas feitas para Atherinella brasiliensis. Observa-se que os valores de $k, t_{0}$ e $C T_{\infty}$ estimados no presente estudo pelos métodos de Ford-Walford e de Gulland e Holt se encontram entre os valores obtidos pelos diferentes autores para outras espécies da família. Entretanto, os valores de $C T_{\infty}$ e $k$ obtidos através do método de von Bertalanffy estão acima dos valores obtidos para os membros da família, sendo mais uma evidência de que os parâmetros dessas variáveis de crescimento estimados por este método foram superestimados.

De maneira mais geral, as diferenças nos valores estimados dos parâmetros das variáveis de crescimento podem estar relacionadas tanto a fatores internos, como fatores filogenéticos relativos à Atherinopsidae, quanto a fatores externos, como a já mencionada diferença nas características de crescimento em diferentes áreas por razões de qualidade e quantidade de alimento ou nas condições climáticas e hidrográficas de cada região. 
Tabela 14. Parâmetros de crescimento estimados por diferentes autores para espécies da família Atherinopsidae, obtidos da literatura. Em subscrito as diferentes metodologias empregadas para as estimativas.

\begin{tabular}{|c|c|c|c|c|c|c|}
\hline Autor (ano) & Espécie & Área & $C T_{\infty}(\mathrm{mm})$ & $K\left(\right.$ ano $\left.^{-1}\right)$ & $\mathrm{t}_{0}$ (ano) & Método utilizado \\
\hline Moreno \& Morales-Nin (2003) & Atherina presbyter & Ilhas Canarias - Espanha & 106 & 2,51 & 0,07 & direto $^{2}$ \\
\hline Lorenzo \& Pajuelo (1999) & Atherina presbyter & Ilhas Canarias - Espanha & 122 & 0,79 & 0,21 & direto $^{2}$ \\
\hline Turnpenny et al. (1981) & Atherina presbyter & Southampton - Reino Unido & 166 & 0,70 & $-0,11$ & direto $^{2}$ \\
\hline Bartulović et al . (2004) & Atherina boyeri & rio Mala Neretva - Croácia & 135 & 0,37 & $-0,97$ & direto $^{2}$ \\
\hline Koutrakis et al. (2004) & Atherina boyeri & sistema estuarino - Norte da Grécia & 116,97 & 0,35 & $-0,99$ & direto $^{4}$ \\
\hline Leonardos (2001) & Atherina boyeri & lago Trichonis - Grécia & 112,4 & 0,42 & $-0,4$ & direto $^{1}$ \\
\hline Leonardos \& Sinis $(2000)$ & Atherina boyeri & lagos Mesolongi e Etolikon - Grécia & 115,79 & 0,24 & $-1,27$ & direto $^{1}$ \\
\hline Neves et al. (2006) & Atherinella brasiliensis & manguezal de Guaratiba - RJ (Brasil) & 168,4 & 0,9 & - & indireto ${ }^{5}$ \\
\hline Pessanha \& Araújo (2001) & Atherinella brasiliensis & baía de Sepetiba - RJ (Brasil) & 112,6 & 0,93 & $-0,231$ & indireto $^{5}$ \\
\hline Presente estudo & Atherinella brasiliensis & Praia de Itamambuca - SP (Brasil) & 164,85 & 2,16 & $-0,0038$ & direto $^{1}$ \\
\hline Presente estudo & Atherinella brasiliensis & Praia de Itamambuca - SP (Brasil) & 168,42 & 2,87 & $-0,0032$ & direto $^{2}$ \\
\hline Presente estudo & Atherinella brasiliensis & Praia de Itamambuca - SP (Brasil) & 159,74 & 2,51 & $-0,085$ & direto $^{3}$ \\
\hline Presente estudo & Atherinella brasiliensis & Praia de Itamambuca - SP (Brasil) & 147 & 1,21 & 0,031 & indireto $^{5}$ \\
\hline
\end{tabular}

O índice de performance de crescimento foi anteriormente citado como um indicador da posição trófica dentro do ambiente em que os indivíduos de um determinado grupo taxonômico se encontram (Issac-Nahum, 1989). Apesar da citação estar restrita às espécies de Sciaenidae, este conceito pode ser ampliado a outras espécies. Os valores do índice de performance para os cienídeos analisados variaram entre 2,5 e 3,0, sugerindo que as espécies são consumidoras secundárias (Isaac-Nahun, op. cit.), considerando-se como sendo 1 o valor de incremento por nível trófico. Pauly (1979), calculando os índices de performance para 64 espécies de peixes marinhos encontrou valores similares para peixes costeiros de pequeno porte e que possuem as mesmas dietas que $A$. brasiliensis, tais como Spicara smaris (Centracanthidae) e Leocottus kesslerii (Cottoconephoridae).

Como os valores do índice de performance de crescimento calculados neste trabalho variaram entre 2,77 e 2,91 podemos afirmar, com base nos resultados obtidos, que os indivíduos de Atherinella brasiliensis pertenceriam 
ao mesmo nível trófico que as espécies citadas anteriormente, sendo consumidores secundários. Estudo sobre a alimentação da espécie realizado por Carvalho (1953) conclui que os principais componentes da dieta da espécie são: matéria orgânica vegetal; crustáceos, representados principalmente pelos copépodes, Peneus, anfípodes e tanaidáceos; peixes, muitas vezes da mesma espécie; e em uma menor freqüência insetos (Hemiptera), moluscos, poliquetos, protozoários, nemátodes e tremátodes, confirmando, de forma bastante generalizada, seu posicionamento na cadeia trófica.

Comparando-se os resultados obtidos das taxas de mortalidade natural de Atherinella brasiliensis com os dados obtidos por Pauly (1980), foram encontradas taxas equiparadas às de mortalidade natural das espécies de pequeno porte sob condições de temperaturas relativamente próximas como, por exemplo, para Engraulis japonicus (Engraulidae) no mar do Japão, com temperatura média de $20^{\circ} \mathrm{C}$, e cuja taxa de mortalidade natural foi 1,63 ano $^{-1}$. As estimativas da mortalidade natural, obtidas a partir da fórmula empírica de Pauly (1980) utilizam um grande número de valores independentes de mortalidade para sua derivação, cobrindo uma ampla gama de categorias de tamanhos e habitats das espécies. Vale ressaltar que no estudo de Pauly (op. cit.) a maioria dos 175 estoques investigados pertencem a regiões temperadas, dificultado a comparação, já que em tais regiões as temperaturas médias são freqüentemente mais baixas do que aquelas encontradas no presente estudo. Em virtude disso, nem sempre a comparação direta dos valores das taxas de mortalidade obtidas em regiões muito diferentes pode ser feita.

Assim, Sparre \& Venema (1997) demostraram que altas taxas de mortalidade natural, calculadas através da equação empírica de Pauly (1980), 
estão associadas a três fatores: menores comprimentos, maiores taxas de crescimento $(k)$ e maiores temperaturas, já que espécies que possuem essas características e estão sujeitas a essas condições ambientais têm uma maior predisposição à predação (incluindo canibalismo), doenças, fome e velhice. Isso justifica os altos valores das taxas de mortalidade natural para Atherinella brasiliensis da praia de Itamambuca, Ubatuba (SP).

Na literatura, estimativas de mortalidade natural estão relatadas somente para Atherina boyeri, sendo estimada por Leonardos (2001), Leonardos \& Sinis (2001), Bartulović et al. (2004) e Koutrakis et al. (2004), cujos valores foram

1,07 anos $^{-1}, 0,93 \mathrm{ano}^{-1}, 0,91 \mathrm{ano}^{-1}$ e $0,95 \mathrm{ano}^{-1}$, respectivamente, estando relacionadas a menores taxas de crescimento e temperaturas mais baixas.

Os resultados sobre a longevidade apresentaram uma grande variação, sendo os menores obtidos através do método de von Bertalanffy e Gulland e Holt: um ano e nove dias e um ano e um mês respectivamente. Esses valores baixos são decorrentes da superestimativa dos valores da taxa de crescimento, já discutida anteriormente. O valor da longevidade obtido com os parâmetros de crescimento calculados com o método de Ford-Walford foi o que melhor representou o ciclo de vida de Atherinella brasiliensis da praia de Itamambuca, sendo de aproximadamente um ano e cinco meses.

\subsection{A praia de Itamambuca como local de reprodução de} Atherinella brasiliensis

De acordo com outros estudos sobre os aspectos reprodutivos da espécie, coletada em diferentes regiões, as fêmeas foram predominantes em 
praticamente todos os meses amostrados (Benvenuti, 1984; Peres-Rios, 2000; e Favaro et al., 2003), sendo que este também foi o padrão encontrado no presente estudo.

A maior proporção de indivíduos imaturos e de pequeno porte, coletada no início do verão, sugere o recrutamento para o aparato de pesca. A mesma época de recrutamento de Atherinella brasiliensis foi encontrada por Benvenuti (1987) na região da Lagoa dos Patos, por Paiva-Filho \& Giannini (1990) na região do complexo baía-estuário de Santos e São Vicente, por Pessanha \& Araújo (2001) e Neves et al. (2006) ambos na baía de Sepetiba, e por Santos et al. (1999) na baía de Todos os Santos. Porém, tanto Neves et al. (2006) como Pessanha \& Araújo (2001) e Santos et al. (1999) estimaram um segundo período de recrutamento, no inverno na baía de Sepetiba e no outono na baía de todos Todos os Santos. Segundo Santos et al. (1999) a existência de dois recrutamentos anuais pode estar relacionada à sazonalidade das variáveis ambientais. Além disso, a malha da rede utilizada neste trabalho é maior que aquela utilizada em outros, como o já relatado acima, o que explica a não ocorrência de indivíduos menores que $2 \mathrm{~cm}$ nas amostras coletadas.

O predomínio de indivíduos imaturos e de pequeno porte dentro do rio Itamambuca durante o período estudado sugere que Atherinella brasiliensis utiliza o local como área de crescimento, em que esses indivíduos permanecem dentro do rio sem realizar a migração diária, até atingir certo comprimento. Suporte para essa suposição está nos dados sobre a distribuição dos jovens e adultos, em que predominam os indivíduos imaturos na estação dentro do rio Itamambuca nos dois períodos do dia, bem como nos de Bemvenuti (1983), em que um padrão semelhante é descrito. Alguns autores 
como, por exemplo, Fuiman \& Werner (2002) relacionam regiões estuarinas e de rios como sendo regiões de crescimento devido à maior disponibilidade de alimento e proteção contra predadores.

O acesso ao estado dos indivíduos em relação ao processo reprodutivo nem sempre é fácil. Todos os indicadores apresentam limitações em sua aplicação e somente o uso concomitante de diversos índices, de natureza diversa, podem fornecer subsídios para o entendimento da reprodução das populações da ictiofauna.

Os principais problemas relacionados com a classificação macroscópica dos estádios de maturação gonadal foram listados por Dias et al. (1998): subjetividade, generalização, não-detecção de desova recente e nãoidentificação de desova iminente. No caso particular de Atherinella brasiliensis, a incapacidade de reconhecimento do estádio de maturidade denominado $\mathrm{E}$ (desovado) está associada aos três primeiros itens listados. Tanto o estádio E como o D, relativo aos ovários com ovócitos hidratados, são aqueles que identificam indubitavelmente a desova dos indivíduos no contexto espaçotemporal, caracterizando os indivíduos desovantes e revelando que ocorre desova do peixe-rei na praia de Itamambuca.

A desova prolongada encontrada em Atherinella brasiliensis, já havia sido detectada para a espécie (Peres-Rios, 2000) bem como para outras espécies, como a cabrinha (Prionotus punctatus) por Vazzoler et al. (1991) e Peres (1995), para Stellifer rastrifer, Anchoviella lepidnetostole e Achirus lineatus por Peres-Rios (op. cit.) e Dias (1990), e está normalmente associada ao tipo de desova parcelada. Além disso, quando somada a uma baixa 
fecundidade parcial, este seria um dos principais fatores que impediriam a exata identificação de ovários no estádio $\mathrm{E}$.

Nesse sentido, a análise microscópica dos ovários foi fundamental para a identificação do sexo e a confirmação dos estádios de maturidade avaliados macroscopicamente, a partir de uma escala geral. Além disso, a histologia dos ovários revelou a ocorrência concomitante de ovócitos hidratados e de folículos pós-ovulatórios nas mesmas gônadas, o que confirma desova parcelada para a espécie. O tipo de desova da espécie havia sido caracterizado como parcelada (Favaro et al., 2003), porém, os argumentos usados pelos autores não são suficientemente robustos para tal afirmação, uma vez que a ocorrência concomitante de folículos pós-ovulatórios e ovócitos com vitelogênese proteica ou completa não implica em uma próxima desova, podendo haver atresia folicular dos ovócitos maduros. Além disso, a constatação de um longo período de desova para a população não caracteriza eliminação parcelada de ovócitos. Neste estudo, a partir da análise microscópica dos ovários, foi mostrada a ocorrência de folículos pós-ovulatórios recentes e de ovócitos hidratados nos mesmos ovários, comprovando que a desova da espécie é parcelada.

Com base na avaliação dos indicadores qualitativos utilizados, Atherinella brasiliensis desova o ano todo, mas, considerando-se os meses em que a freqüência relativa de indivíduos desovantes é maior que $50 \%$, os picos de desova ocorreram na primavera e verão de 2003/2004 (outubro de 2003 a janeiro de 2004) e verão de 2004 (dezembro). Indivíduos desovados ocorreram também no inverno, particularmente em junho de 2004, com mais que $50 \%$ de desovantes. 
Os resultados obtidos do comprimento médio de início de primeira maturação gonadal são semelhantes aos obtidos em outros estudos, ressaltando-se que, no presente estudo, devido às dificuldades encontradas na identificação do sexo dos indivíduos imaturos e por medida de precaução, realizou-se somente o cálculo para os sexos agrupados. Bemvenuti (1987) estimou o comprimento médio de primeira maturação gonadal na região da Lagoa dos Patos para Atherinella brasiliensis em 100 mm para as fêmeas e 90 $\mathrm{mm}$ para os machos, valores mais altos do que aqueles aqui estimados $(86,5$ mm). Já as estimativas realizadas por Peres-Rios (2000) para A. brasiliensis no sistema costeiro Cananéia-Iguape foram $72,8 \mathrm{~mm}$ para as fêmeas, $60 \mathrm{~mm}$ para os machos e $66,3 \mathrm{~mm}$ para os sexos agrupados, enquanto as de Favaro et al. (2003) na gamboa de Bagaçu, baía de Paranaguá, foram 76,1 mm para fêmeas e $69,1 \mathrm{~mm}$ para os machos.

As diferenças entre os valores do comprimento de primeira maturação gonadal para uma mesma espécie em diferentes épocas podem estar associadas à própria localização geográfica das populações estudadas. Esse fenômeno já foi verificado em outras espécies como Micropogonias furnieri (Vazzoler, 1991) e Prionotus punctatus (Peres, 1995) e, de fato, se as coletas deste estudo contemplassem estações oceanográficas cada vez mais para o interior do rio Itamambuca, a maior quantidade de indivíduos jovens influenciaria a proporção de adultos e, por conseguinte, os valores de $L_{50}$.

Com relação aos indicadores quantitativos empregados, os valores obtidos do fator de condição alométrico têm sido interpretados como medidas de vários eventos biológicos, revelados pela variação de peso dos indivíduos, tais como acúmulo de gordura, gastos na manutenção e adequação ao meio 
ambiente e desenvolvimento gonadal (Le Cren, 1951). Considerando-se os valores máximos da diferença entre os valores de condição $(\Delta K)$, estes coincidem com a maior ocorrência de indivíduos com gônadas maduras, quando a porcentagem de desovantes cai (de janeiro para fevereiro de 2003 e de dezembro de 2003 a janeiro de 2004), atingindo seu ápice antes da desova. Já os menores valores de $\Delta \mathrm{K}$ foram encontrados em fevereiro, maio e agosto de 2004 e janeiro de 2005, sendo que apenas para maio e agosto de 2004 e janeiro de 2005 estes coincidem com a maior ocorrência percentual de indivíduos em início de maturação (estádio de maturidade B),.

Estes maiores valores de $\Delta \mathrm{K}$ encontrados em períodos de maturação máxima para $A$. brasiliensis foram anteriormente observados por diferentes autores, tais como, Le Cren (1951), Vazzoler \& Rossi-Wongtschowski (1976), Isaac-Nahum \& Vazzoler (1983), Barbieri \& Verani (1987), Araujo et al. (2000), Querol et al. (2002), Araújo et al. (2003), Silva et al. (2005), para outras espécies de peixes.

Os resultados obtidos no presente estudo através da relação gonadossomática (RGS), corroborado por outros indicadores do processo reprodutivo, indicam que ocorre desova de Atherinella brasiliensis na praia de Itamambuca em todas as épocas do ano, com uma maior freqüência entre novembro e dezembro de 2003, de março a maio de 2004 e de dezembro de 2004 a janeiro de 2005, ou seja, entre a primavera até meados do outono. Estes resultados corroboram os de Benvenuti (1987), que concluiu que a desova dessa espécie na região da Lagoa dos Patos ocorre principalmente no verão, ainda que se estenda de novembro a março. Em contrapartida PeresRios (2000), no sistema costeiro Cananéia-Iguape, encontrou resultados 
indicando que a desova da espécie ocorre com maior intensidade no inverno e primavera, embora outras épocas do ano também apresentassem indicação de desova. Favaro et al. (2003) citam como período reprodutivo, na gamboa de Bagaçu, os meses entre junho e novembro, com base nos valores do índice gonadossomático; porém, na verdade, estão se referindo ao desenvolvimento gonadal com conseqüente ganho em peso. Analisando-se as figuras do trabalho, verifica-se a ocorrência de fêmeas semi-desovadas e desovadas em todos os meses de coleta, exceto outubro, sendo que a soma das freqüências desses estádios de maturidade apresentaram valores acima de $40 \%$ nos meses de dezembro a fevereiro, agosto e setembro. Este fato reforça a necessidade de se analisar mais de um indicador da reprodução simultaneamente.

A presença de uma grande quantidade de indivíduos imaturos dentro do rio Itamambuca durante todo o período estudado, associado com a migração diária exercida pela espécie citada anteriormente e a presença de uma vasta quantidade de vegetação aquática, sugere que a desova de Atherinella brasiliensis na região da praia de Itamambuca ocorre dentro do rio Itamambuca. Os ovos dos aterinopsídeos são demersais apresentando filamentos adesivos, distribuídos em padrões espécie-específicos, sendo que para Atherinella brasiliensis ocorrem nove grandes filamentos adesivos, distribuídos unicamente no pólo vegetativo do ovo. Esses filamentos têm como finalidade aderir à vegetação aquática, sendo uma adaptação encontrada principalmente na família Atherinopsidae (Huaquím,1980; Marín et al.,1995).

A contagem do número de ovócitos hidratados foi utilizada como medida da fecundidade por lote para Atherinella brasiliensis. Os baixos valores 
encontrados para a espécie, em relação a outros pequenos pelágicos como a sardinha-verdadeira (35 mil ovócitos por lote - Dias, 1989), já haviam sido relatados: a fecundidade de 11 fêmeas amostradas na Lagoa dos Patos variou de 148 a 791 ovócitos maduros (diâmetro superior a 0,7 mm) (Bemvenuti, 1987), sendo bastante próximos dos encontrados no presente estudo (73,3 a 1022 ovócitos hidratados). Contudo, a autora não conseguiu ajustar nenhuma relação entre a fecundidade e o comprimento total para a espécie devido ao baixo número de fêmeas amostradas. Carreño, 1975 (apud Rio et. al., 2005) no Golfo de Cariaco, Venezuela e Moreno et. al. (2005), nas Ilhas Canárias também estimaram baixos valores de fecundidade por lote para Atherina presbyter, outro membro da família Atherinopsidae. Esta estratégia está relacionada à alta freqüência de desova, não estimada neste trabalho, mas confirmada pela ocorrência de folículos pós-ovulatórios recentes e ovócitos hidratados em um mesmo ovário.

Ocorre um aumento da fecundidade proporcional ao crescimento corpóreo para $A$. brasiliensis, da mesma forma que para Atherina presbyter das Ilhas Canárias (Moreno et al., 2005) e para Odontesthes bonariensis em lagoas da Argentina (Valette, 1938). A tendência de aumento da fecundidade ao longo do crescimento corpóreo, tanto para Atherinella brasiliensis quanto para outras espécies de peixes, pode estar relacionada com o aumento do tamanho da cavidade abdominal dos indivíduos ao longo do crescimento, com possibilidade de aumento de tamanho das gônadas, e, conseqüentemente, do número de ovócitos. Esse aumento na fecundidade atinge o pico no ápice da maturidade gonadal e tende a diminuir a partir do momento que o indivíduo começa a 
atingir a senilidade, principalmente para espécies de vida mais longa, como a merluza (Vaz-dos-Santos, 2002).

\subsection{Avaliação da ocorrência de metais traço na população de $\boldsymbol{A}$. brasiliensis da praia de Itamambuca: uma análise preliminar}

Metais, em formas biodisponíveis e em concentrações tóxicas, podem resultar em efeitos diretos, ou seja, morte, alterações no crescimento ou na reprodução, bem como indiretos nos organismos (Alquezar et al., 2006b). Estudos relacionados com os níveis de metais em tecidos de peixes sugerem que múltiplos fatores influenciam a acumulação de metais, tais como a fonte (se água, sedimento ou alimento), os tecidos (gônadas, músculo, brânquias, pele, mesentério ou fígado) ou substâncias como a bile, a idade ou fase do ciclo de vida (jovens ou adultos), bem como o sexo (Eisler \& LaRoche, 1972; Tallandini et al., 1989; Ishikawa et al., 1993; Westerlund et al., 1998; Yilmaz, 2003; De Mora et al., 2004; Burger \& Gochfeld, 2005; Alquezar et al., 2006a; Alquezar et al., 2006b; Burger et al., 2007; Fernandes et al., 2007).

Poucos são os trabalhos na literatura focados em estudos sobre os efeitos dos metais na higidez ou em aspectos do ciclo de vida, como a reprodução de peixes (Alquezar et al., 2006a), pois estes necessitam de muitos dados sobre as fontes potenciais dos metais, bem como de um conhecimento aprofundado sobre a espécie alvo. Na literatura especializada são poucos os trabalhos que utilizaram a técnica PIXE em tecidos de peixes e nenhum deles com Atherinella brasiliensis. 
Os valores médios das concentrações encontradas de cromo, ferro e zinco podem ser comparados com aqueles da literatura em que se empregou a mesma técnica de análise (PIXE) ou não, guardadas as limitações de uma comparação entre metodologias diferentes de análises em que a precisão, a acurácia, o uso de padrões para a calibração dos sistemas e os limites mínimos de detecção são diferentes, bem como as espécies e mesmo os locais em que foram coletadas. A tabela15 apresenta resultados de concentrações (ppm) dos elementos $\mathrm{Cr}$, Fe e $\mathrm{Zn}$ na musculatura de algumas espécies de teleósteos. A variação dos valores é bastante ampla, mesmo para uma mesma técnica, e relacionada a diversos fatores, que incluem as próprias metodologias, se a concentração era expressa em ppm de peso seco ou úmido, as espécies e os locais, contaminados ou não. De maneira geral, e guardadas as ressalvas já mencionadas, os valores aqui encontrados dos elementos $\mathrm{Cr}$, Fe e $\mathrm{Zn}$ foram os maiores, exceto os dados de Eisler \& LaRoche (1972), que utilizaram espectrometria de absorção atômica. 
Tabela 15. Concentrações (ppm) dos elementos $\mathrm{Cr}$, Fe e $\mathrm{Zn}$ na musculatura de diferentes espécies de teleósteos, estimadas a partir de diferentes técnicas. PIXE = Particle Induced X-Ray Emission; ICP-AES= Inductively Coupled Plasma Atomic Emission Spectrometry; AAS= Atomic Absorption Spectrometry; GFAA= Graphite Furnace Atomic Absorption: FAAS= Flame Atomic Absorption Spectrometrv.

\begin{tabular}{ccccccc}
\hline Espécie & Cr & Fe & Zn & Técnica & Referência \\
\hline Atherinella brasiliensis (verão) & 33,65 & 73,83 & 51,80 & PIXE & Presente estudo, 2007 \\
Atherinella brasiliensis (inverno) & 22,83 & 57,33 & 48,06 & PIXE & Presente estudo, 2007 \\
Champsocephalus gunnari & 2,2 & 49,20 & 5,9 & PIXE & Ishikawa \& Nakamura, 1990 \\
Trachurus japonicus & 0,09 & 8,20 & 6,6 & PIXE & Ishikawa \& Nakamura, 1990 \\
Champsocephalus gunnari & 4,0 & 302 & 30 & PIXE & Ishikawa et al., 1993 \\
Thunnus thunnus & 0,6 & 25 & 19 & PIXE & Ishikawa et al., 1993 \\
Sphyraena pinguis & 0,4 & 6,9 & 12 & PIXE & Ishikawa et al., 1993 \\
Zosterissessor ophiocephalus & 3,3 & 66 & 42,3 & PIXE & Tallandini et al., 1989 \\
Mugil cephalus & 1,46 & 70,28 & 38,23 & ICP-AES & Yilmaz, 2003 \\
Trachurus mediterraneus & 1,28 & 41,84 & 19,55 & ICP-AES & Yilmaz, 2003 \\
Fundulus heteroclitus (pequenos) & -- & 504 & 1010 & AAS & Eisler \& LaRoche, 1972 \\
Fundulus heteroclitus (grandes) & -- & 398 & 788 & AAS & Eisler \& LaRoche, 1972 \\
Myxocephalus polyacanthocephalus & 90 & -- & -- & GFAA & Burger et al., 2007 \\
Hippoglossoides elassodon & 95 & -- & -- & GFAA & Burger et al., 2007 \\
Liza saliens & -- & -- & 26 & FAAS & Fernandes et al., 2007 \\
\hline
\end{tabular}

As mais altas concentrações de ferro, zinco e cromo encontradas na musculatura dos indivíduos de Atherinella brasiliensis podem estar relacionadas a duas possíveis fontes, a natural e a antropogênica, já que a técnica PIXE não é capaz de identificar nem o estado de oxidação desses elementos, nem sua fonte. Neste estudo não foram feitas análises da água do local nem do sedimento, inviabilizando comparações diretas ou mesmo inferências sobre as vias de entrada dos elementos nos indivíduos; porém, não invalidam inferências gerais e uma breve discussão geral sobre os resultados.

As fontes naturais do ferro são aquelas provenientes principalmente do desgastes natural das rochas contendo minérios de ferro, tais como hematita $\left(\mathrm{Fe}_{2} \mathrm{O}_{3}\right)$, limonita $\left[\mathrm{FeO}(\mathrm{OH}) \cdot \mathrm{nH}_{2} \mathrm{O}\right]$, magnetita $\left(\mathrm{Fe}_{3} \mathrm{O}_{4}\right)$ e siderita $\left(\mathrm{FeCO}_{3}\right)$. Entre 
as fontes antropogênicas de ferro, de origem urbana, estão os efluentes de esgotos municipais e o escoamento superficial urbano (Lima \& Pedrozo, 2001).

Rochas graníticas, rochas ultramáficas, xisto, argila e incêndios florestais são as principais fontes naturais do cromo. Em áreas onde ocorrem depósitos significativos de cromo, as fontes de água podem apresentar concentrações superiores a $50,0 \mu \mathrm{g} / \mathrm{L}$, valores estes que ultrapassam os padrões nacionais e internacionais de potabilidade da água. As principais atividades humanas nas quais o cromo e seus compostos são liberados para o meio ambiente são: construção civil (resíduos provenientes do cimento), soldagem de ligas metálicas, lâmpadas, esgoto e lixo urbano, incineração de lixo, cinzas de carvão e preservativos de madeiras (Lima \& Pedrozo, 2001).

A fonte natural do zinco também está relacionada com o desgaste natural das rochas contendo minério de zinco, tais como sfalerita, wurtzita, smithsonita e hemimorfita. As principais atividades humanas nas quais o zinco e seus compostos são liberados para o meio ambiente, são: tintas, produtos de borracha, cosméticos, telas de televisão, lâmpadas fluorescentes, endurecedor de cimento e esgoto urbano (Oliveira, 2002).

A região costeira do estado de São Paulo, incluindo algumas ilhas continentais, é recortada por diques com direção preferencial NE-SW. Constitui-se de rochas precambrianas polimetamorfizadas do complexo costeiro, compreendendo gnaisses facoidais, leptitos, kinzigitos, charnockitos e migmatitos dos mais variados tipos (Schobbenhaus et al.,1984). A região de Ubatuba é formada por diques compostos por rochas básicas e intermediárias caracterizada pela presença de ferro e titânio (Garda \& Garda, 2001). Assim, a presença de ferro nas rochas da região de Ubatuba pode explicar uma possível 
fonte natural desse elemento: devido ao desgaste dessas rochas, tanto fluvial como pluvial, o ferro pode ser transferido para o ambiente aquático e assimilado pelos organismos, o que explicaria sua presença na musculatura de A. brasiliensis em Itamambuca, uma vez que não há fontes antropogências.

O cromo é encontrado no sedimento, em altas concentrações, porém tem origem geogênica, sendo que suas concentrações, com base nos valores de referência PEL (Probable Effects Levels) e TEL (Threshold Effects Levels) são dignas de monitoramento (Guimarães, 2007). Entretanto, as concentrações de zinco não podem ser explicadas por nenhuma fonte natural.

As possíveis fontes antropogênicas desses elementos podem estar associadas ao aumento de aglomerados humanos na região nos últimos anos. Segundo o CENSO 2006 realizado pelo IBGE, a população no município de Ubatuba em 1997 era de aproximadamente 57.249 habitantes, saltando para 81.246 habitantes em 2006, representando um crescimento populacional de 29,53\% em 9 anos. Entretanto, em época de temporada de férias, a população de Ubatuba atinge 180 mil habitantes, sem contar os turistas que vão para o município para passar o dia e retornam a sua cidade de residência à noite.

A praia de Itamambuca, como todo o município de Ubatuba, também sofreu um rápido aumento populacional. Segundo Barros (1997), em meados da década de 1990, apesar da praia de Itamambuca estar fora da área das unidades de conservação, esta apresentava uma ocupação rarefeita, levando a poucas alterações em seu ambiente natural. Entretanto, atualmente o número de casas, principalmente de veraneio, áreas de "camping", restaurantes e pousadas aumentou significativamente. 
O aglomerado urbano e o número de turistas podem explicar, em parte, a deterioração da qualidade da água e das condições de balneabilidade. Os anos com maior fluxo de pessoas tendem a apresentar piores condições de balneabilidade (CETESB, 2005). O crescimento desordenado, decorrente do rápido crescimento populacional somado à inadequação ou inexistência de um sistema sanitário local e às dificuldades na implantação dos mesmos, fato comum nas cidades litorâneas, fazem com que os esgotos sejam despejados diretamente no ambiente aquático.

A região de Ubatuba tem um dos menores percentuais de coleta e tratamento de esgotos do estado de São Paulo, sendo que somente $33 \%$ da população são atendidas por redes de esgotos (CETESB, 2005). Cerca de $4.120 \mathrm{~kg}$ de demanda bioquímica de oxigênio por dia (DBO/dia) de esgoto doméstico é produzido pelo município fora de temporada, sendo $1.088 \mathrm{~kg}$ DBO/dia do total são removidos e tratados através dos sistemas de esgotos e de tratamentos; entretanto, $3.032 \mathrm{~kg} \mathrm{DBO} /$ dia são despejados diretamente sem qualquer tipo de tratamento em fossas, rios e córregos, sendo em muitos casos levados diretamente para o ambiente marinho. De um modo geral, os esgotos domésticos são compostos essencialmente de 99,9 \% de água com um conteúdo de matéria sólida seca de aproximadamente menos que 0,1\% (Takamatsu, 1995).

Além do aumento significativo do lançamento de esgotos sem tratamento na praia de Itamambuca, as altas concentrações de cromo e zinco na musculatura de Atherinella brasiliensis da região também podem estar associadas ao aumento significativo das construções civis na praia de Itamambuca, cujos resíduos do cimento usado nessas construções estão de 
alguma maneira sendo levados para o rio Itamambuca, através das águas pluviais ou até mesmo sendo lançados diretamente no rio Itamambuca como descarte. Esses resíduos de cimento, como dito anteriormente, apresentam alta concentração de cromo e zinco.

As maiores concentrações desses três metais na época de temporada (verão), como discutido anteriormente, estariam associadas a um maior número de turistas nessa época do ano na região da praia de Itamambuca, o que aumentaria a quantidade de esgoto in natura despejado no ambiente.

As médias mais altas das concentrações de cromo, ferro e zinco na musculatura dos indivíduos jovens da população de Atherinella brasiliensis na praia de Itamambuca, comparadas às dos indivíduos adultos, podem estar relacionadas às mais altas taxas metabólicas dos indivíduos jovens. Liang et al. (1999) verificaram que o acúmulo de alguns metais ( $\mathrm{Zn}, \mathrm{Cu}, \mathrm{Cd}, \mathrm{Cr}, \mathrm{Pb}$ e Ni) é inversamente proporcional ao tamanho dos exemplares de peixes. Aparentemente, a energia metabólica é o fator determinante do acúmulo de certos metais em peixes e está relacionada ao comprimento do animal, o qual influencia a velocidade do metabolismo que, por sua vez, estaria correlacionada com a velocidade de seqüestro e eliminação dos metais. Peixes menores apresentariam maior velocidade de absorção dos metais, e estes se concentrariam nas vísceras e musculatura dos peixes (Liang et al.,1999). Além disso, os exemplares menores se concentram no rio Itamambuca, local mais próximo das possíveis fontes de descartes, o que causaria maiores concentrações (Yilmaz, 2003).

Entretanto, ferro, cromo e zinco são considerados elementos-traço indispensáveis para o desenvolvimento de todos os organismos, mas quando 
ocorrem altas concentrações esses metais pesados podem afetar diretamente o ciclo de vida dos mesmos (Pereira et al., 2002; Silva \& Pedrozo, 2001). Na reprodução o acúmulo de metais pode afetar diferentes níveis, levando a uma redução na quantidade e a qualidade dos ovócitos produzidos pelas fêmeas, podendo resultar deformações do saco vitelínico e dos olhos, anomalias na boca, defeitos nas nadadeiras e malformação da coluna vertebral reduzindo a taxa de sobrevivência das larvas de peixes (Alquezar et al., 2006a). O crescimento também é afetado, principalmente nos estágios iniciais do ciclo de vida, por serem mais sensíveis aos metais pesados, levando a uma redução do desenvolvimento larval e no crescimento dos juvenis (Heath, 1987). Além disso, certos metais como o zinco e o cromo podem causar, em todos os estágios do ciclo de vida, anúria (deficiência renal), nefrite (processo inflamatório difuso dos glomérulos renais) e lesões extensivas no fígado e brânquias (Mansour \& Sidky, 2002).

De acordo com os resultados obtidos no presente trabalho, estudos mais aprofundados devem ser realizados na praia de Itamambuca para averiguar a fonte dos metais, a partir de análises na água, no sedimento e nas presas do peixe-rei, e a presença de efeitos subletais ou letais nos organismos. Além disso, verificar se esses metais estão biomagnificados na trama trófica, pelo consumo por peixes dos níveis tróficos mais elevados, que são explorados comercialmente na região, o que poderia levar a algum risco para a saúde da comunidade local. 


\section{CONCLUSÕES}

- A população de Atherinella brasiliensis (Quoy \& Gaimard, 1824) da praia de Itamambuca, Ubatuba (SP) se distribui ao longo de toda a praia, em todas as épocas do ano, apresentando um padrão migratório diário para dentro do rio Itamambuca durante o período noturno, que pode estar relacionado à disponibilidade de alimento, proteção e desova.

- O método indireto, como um estudo preliminar de crescimento para Atherinella brasiliensis, apresentou-se como um bom estimador para os parâmetros das variáveis de crescimento; porém, quando comparados àqueles obtidos pelo método direto, estes parâmetros se mostraram subestimados.

- As análises dos otólitos de Atherinella brasiliensis da praia de Itamambuca apresentaram bandas formadas por 14 anéis diários, sendo o último mais evidente. A formação dessas bandas estaria associada principalmente ao ciclo lunar e à maré de sizígia, cuja periodicidade ocorre também num período de 14 dias.

- O modelo de von Bertalanffy e a longevidade apresentaram melhores ajustes ao conjunto de dados utilizando os parâmetros de crescimento estimados através do método de Ford-Walford, sendo os mais fidedignos a expressar o crescimento de Atherinella brasiliensis. Entretanto, a estimativa do índice de performance de crescimento e da mortalidade natural, 
utilizando os parâmetros das variáveis obtidos pelos diferentes métodos, mostrou-se bastante similar entre si.

- Os valores da relação gonadossomática (RGS), da diferença do fator de condição alométrico $(\Delta \mathrm{K})$ e das proporções de indivíduos com estádios gonadais mais avançados (desovantes) de Atherinella brasiliensis sugerem que a desova ocorre em todas as épocas do ano, com uma maior freqüência no final da primavera até meados do outono, com picos entre novembro e dezembro de 2003, março e maio de 2004 e de dezembro de 2004 a janeiro de 2005. A freqüência de desova é alta, a desova é parcelada e a eliminação dos ovócitos hidratados em pequenos lotes ocorre durante um longo período.

- Concentrações mais altas de cromo, ferro e zinco foram detectadas na musculatura médio-lateral de Atherinella brasiliensis da praia de Itamambuca, utilizando-se a técnica PIXE. Nos indivíduos jovens e nos coletados em época de alta temporada essas concentrações foram maiores. A técnica não identifica a origem de uma possível contaminação, sugerindo que estudos mais aprofundados devem ser realizados na região, para averiguar também se a quantidade esses elementos estão sendo biomagnificados na trama trófica local, o que poderia apresentar algum risco para a saúde da comunidade local. 


\section{BIBLIOGRAFIA}

Alquezar, R.; Markich, S.J. \& Booth, D.J. 2006. Effects of metals on condition and reproductive output of the smooth toadfish in Sydney estuaries, southeastern Australia. Environ. Pollut., 142: 116 - 122.

Andreata, J.V.; Marca, A.G.; Soares, C.L. \& Santos, R.S. 1997. Distribuição mensal dos peixes mais representativos da Lagoa Rodrigo de Freitas, Rio de Janeiro, Brasil. Revta Bras. Zool., 14: 121 - 134.

Arai, N.; Sakamoto, W. \& Maedab, K. 1996. An attempt to analyze fish otoliths by in-air PIXE. Nucl. Instr. and Meth. in Phys. Res. B, 109/ 110: 341 - 344.

Araújo, F.G.; Duarte, S. \& Goldberg, R.S. 2000. Ciclo reprodutivo de Parauchenipterus striatulus (Pisces - Auchenipteridae) na represa de Ribeiro das Lajes - RJ. Arq. Bras. Med. Vet. Zootec., 52(3): 276 - 284.

Araújo, S.A.; Gurgel, H.C.B. \& Nascimento, R.S.S. 2003. Indicadores do desenvolvimento gonadal e nutricional de Prochilodus cearensis (Steindachner, 1911) (Characiformes, Prochilodontidae) no açude Itans/Caicó, Rio Grande do Norte, Brasil. Acta Sci. Biol. Scien., 25(2): 377 $-384$.

Arkhipkin, A.I. 2005. Statoliths as "black boxes" (life recorders) in squid. Mar. Freshw. Res., 56: 573 - 583. 
Babaluk, J.A.; Campbell, J.L.; Evans, C.L.; Halden, N.M.; Meija, S.R.; Nejedly, Z.; Reist, J.D. \& Teesdale, W.J. 2002. Micro-PIXE analysis of strontium in Artic char, Salvelinus alpinus, otoliths from Quttinirpaaq National Park, Nunavut, Canada. Nucl. Instr. and Meth. in Phys. Res. B, 189: 190 - 195.

Barbieri, G. \& Verani, J. R. 1987. O fator de condição como indicador do período de desova em Hypostomus aff. plecostomus (Linnaeus, 1758) (Osteichthyes, Loricariidae), na represa do Monjolinho, São Carlos, SP. Ciênc. Cult., 39(7): 655 - 658.

Barros, M.O. 1997. Dinâmica e evolução dos ambientes praias da Fazenda, do Puruba e de Itamambuca, Ubatuba, litoral norte do estado de São Paulo. Dissertação de mestrado. Universidade de São Paulo, Instituto Oceanográfico. $163 \mathrm{p}$.

Bartulović, V.; Glamuzina, B.; Conides, A.; Dulĉić, J.; Luĉić, D., Njire, J. \& Kožul, V. 2004. Age, growth, mortality and sex ratio of sand smelt, Atherina boyeri Risso, 1810 (Pisces: Atherinidae) in the estuary of the Mala Neretva River (middle-eastern Adriatic, Croatia). J. Appl. Ichthyol., 20: 427 - 430.

Becker, F.G.; Bruschi Jr.; W. \& Peret, A.C. 2003. Age and growth of three Odontesthes species from southern Brazil (Atherinopsidae), with reference to phylogenetic constraints in their life-history. Braz. J. Biol., 63(4): 567 578. 
Bemvenuti, M.A. 1990. Hábitos alimentares de peixe-rei (Atherinidae) na região estuarina da Lagoa dos Patos, RS. Brasil. Atlântica, 12(1): 79 - 102.

Bemvenuti, M.A. 1984. Abundância, distribuição, reprodução e hábitos alimentares de peixe-rei (Atherinidae) na região estuarina da Lagoa dos Patos, R.S. Brasil. Dissertação de mestrado. Universidade do Rio Grande. $93 \mathrm{p}$.

Bemvenuti, M.A. 1987. Abundância, distribuição e reprodução de peixe-rei (Atherinidae) na região estuarina da Lagoa dos Patos, R.S. Brasil. Atlântica, 9(1): 5 - 32.

Bertalanffy, L. Von. 1938. A quantitative theory of organic growth (Inquiries on growth laws. II). Human Biol., 10: 181 - 213.

Bolz, G.R. \& Lough, R.G. 1988. Growth through the first six mouths of Atlantic cod, Gadus morhua, and haddock, Melenogrammus aeglefinus, based on daily otolith increments. Fish. Bull., 86: 223 - 236.

Braga, F.M.S. 1986. Estudo entre fator de condição e relação peso/comprimento para alguns peixes marinhos. Rev. Brasil. Biol., 46(2): $339-346$. 
Bremer, O.A.; Tolosa, E.M.C. \& Freitas Neto, A.G. 1976. Manual de técnicas para histologia normal e patológica. São Paulo, Edart/EDUSP, 256 p.

Brown, A.C. \& Mclachlan, A. 1990. Ecology of sandy shores. New York: Elsevier Science Publishers B.V., 327 p.

Burger, J. \& Gochfeld, M. 2005. Heavy metals in commercial fish in New Jersey. Env. res., 99:403-412.

Burger, J.; Gochfeld, M.; Jeitner, C.; Burke, S. \& Stamm, T. 2007. Metal levels in flathead sole (Hippoglossoides elassodon) and great sculpin (Myxocephalus polyacanthocephalus) from Adak Island, Alaska: potential risk to predators and fishermen. Env. Res., 103:62-69.

Cadwallader, P.L. 1978. Age, growth, and condition of the common river galaxias, Galaxia vulgares Stokell, in the Glentui River, Cantebury, Fish. Res. Bull., 17: 15 - 20.

Carreño, R. 1975. Algunos aspectos de la biología del tinícalo, Xenomelaniris brasiliensis (Quoy \& Gaimard) (Pisces:Atherinidae), del Golfo de Cariaco, Edo. Sucre. Tesis de pregrado, Universidad de Oriente, Cumaná, Venezuela. $43 \mathrm{p}$. 
Carvalho, J.P. 1953. Alimentação de Xenomelaniris brasiliensis (Quoy \& Gaimard)(Pisces-Mugiloidei - Atherinidae). Bolm. Inst. oceanogr., S Paulo, 4(1/2): $127-144$.

Carvalho, J.P. 1954. Nótulas Ictiológicas III. Sobre a ocorrência de Atherinella brasiliensis (Quoy \& Gaimard, 1824) no litoral do estado de São Paulo (Brasil) (Pisces-Mugiloidei-Atherinidae). Bolm. Inst. oceanogr., S Paulo, 5(1/2): $241-259$.

Castro Filho, B.M.; Miranda, L.B. \& Miyao, S.Y. 1987. Condições oceanográficas na plataforma continental ao largo de Ubatuba: variações sazonais e em média escala. Bolm. Inst. oceanogr., S Paulo, 35(2): 135 151.

Castro, B. M. de \& Miranda, L. B. 1998. Physical oceanography of the western Atlantic continental shelf located between $4^{\circ} \mathrm{N}$ and $34^{\circ} \mathrm{S}$. In: ROBINSON, A.R \& BRINK, K.H. 1998. The Sea, vol 11, Oxford, John Wiley \& Sons, $209-251 \mathrm{p}$.

CETESB, 2005. Relatório de qualidade das águas litorâneas do Estado de São Paulo - Balneabilidade das praias. Relatório Técnico, v1.

Chernoff, B. 1986. Systematics of american atherinid fishes of genus Atherinella. I. The subgenus Atherinella. Proc. Acad. Nat. Sci. Phil., 138(1): $86-188$. 
Collins, L.A.; Johnson, A.G. \& Keim, C.P. 1996. Spawning and annual fecundity of the red snapper (Lutjanus campechanus) from the northestern Gulf of Mexico. In: Arregin-Sanchez, F., Munro, J.L.; Balgos, M.C. \& Pauly, D. (eds.). Biology, fisheries and culture of the tropical groupers and snappers. ICLARM Conf.Proc. 48: 174 - 188.

Da Silva Cortinhas, M.C.; Cestari, M.M.; Swarça, A.C.; Fenocchio, A.S. 2003. First Chromosome Data about the silverside Atherinella brasiliensis (Atheriniformes, Pisces) from the South coast of Brazil. Conventional, CNOR and CMA3 bandings and FISH studies. Caryologia, 56(2): 191 - 195.

De Mora, S.; Fowler, S. W.; Wyse, E. \& Azemard, S. 2004. Distribution of heavy metals in marine bivalvs, fishes and coastal sediments in the Gulf and Gulf of Oman. Mar. Pol. Bull., 49:410-424.

Del Río, V.; Jesús, R.J.; Velásquez, A. \& Cabrera, T. 2005. Desarrollo embrionario-larval y tiempo de metamorfosis del pez tropical Xenomelaniris brasiliensis (Pisces: Atherinidae). Rev. Biol. Trop., 53 (3-4): $503-513$.

Dias, J.F. 1989. Estimativa da fecundidade instantânea de Sardinella brasiliensis (Steindachner, 1879). In: Simpósio sobre Oceanografia I, São Paulo. Resumos. São Paulo, Instituto Oceanográfico da Universidade de São Paulo. 
Dias, J.F.; Peres-Rios, E.; Chaves, P.T.C. \& Rossi-Wongtschowski, C.L.D.B. 1998. Análise macroscópica dos ovários de teleósteos: problemas de classificação e recomendações de procedimentos. Rev. Brasil. Biol., 58(1): $55-69$.

Eisler, R. \& LaRoche, G. 1972. Elemental composition of the estuarine teleost Fundulus heteroclitus (L.). J. exp. mar. Biol. Ecol., 9:29-42.

Elfman, M; Limburg, K.E.; Kristiansson, P.; Malmqvist, K. \& Pallon, J. 1999. Application of micro-PIXE to fish life history analyses: trace element analysis of otoliths. Nucl. Instr. and Meth. in Phys. Res. B, 150: $272-276$.

Favaro, L.F.; Lopes, S.C.G. \& Spach, H.L. 2003. Reprodução do peixe, Atherinella brasiliensis (Quoy \& Gaimard) (Atheriniformes, Atherinidae), em uma planície de maré adjacente à gamboa do Baguaçu, Baía de Paranaguá, Paraná, Brasil. Revta bras. Zool., 20(3): 501 - 506.

Fernandes, C.; Fontaínhas-Fernandes, A; Peixoto, F. \& Salgado M.A. 2007. Bioaccumulation of heavy metals in Liza saliens from the EsmorizParamos coastal Lagoon, Portugal. Ecotoxicol. Env. safety, 66:426-431.

Figueiredo, J.L. \& Menezes, N.A. 1978. Manual de peixes marinhos do sudeste do Brasil. II. Teleostei (1). São Paulo, Museu de Zoologia da Universidade de São Paulo, EDUSP, 110 p. 
Folkvord, A.; Blom, G.; Johannessen, A. \& Moksness, E. 2000. Growthdependent age estimation in herring (Clupea harengus L.) larvae. Fish. Res., 46: 91 - 103.

Fonteles-Filho, A.A. 1989. Recursos pesqueiros: biologia e dinâmica populacional. Imprensa Oficial do Cear, Fortaleza. 296 p.

Francis, R.I.C.C. 1990. Back Calculation of Fish Length: a Critical Review. J. Fish. Biol., 36: 883 - 902.

Fuiman, L.A. \& Werner, R.G. 2002. Fishery Science: The unique contribution of early life stages. Oxford, Blackwell Science. $326 \mathrm{p}$.

Garda, G.M. \& Garda, B.M. 2001. Quimismo dos Minerais Máficos e Óxidos em Diques Alcalinos e de Composições Básicas a Intermediárias da Região Costeira entre São Sebastião e Ubatuba, Estado de São Paulo. Geo. USP Sér. Cient., São Paulo, 1: 17 - 44.

Gasalla, M. A. 1995. Organização trófica da ictiofauna do saco de Mamanguá, Parati, RJ. Dissertação de mestrado. Universidade de São Paulo, Instituto Oceanográfico. São Paulo, 145 p.

Giannini, R. \& Paiva Filho, A.M. 1995. Análise comparativa da ictiofauna da zona de arrebentação de praias arenosas do Estado de São Paulo, Brasil. Bolm. Inst. Oceanogr., S. Paulo, 43(2): 141 - 152. 
Giannini, R. 1994. Alimentação dos Sciaenidae Ctenosciaena gracilicirrhus, Cynoscion jamaicensis, Cynoscion guatucupa e Paralonchurus brasiliensis, da região costeira de Ubatuba, São Paulo, Brasil. Dissertação de mestrado. Universidade de São Paulo, Instituto Oceanográfico, 64 p.

Giussi, A.R.; Villarino, M.F. \& Dato, C.V. 1994. Distribuicion geografica por grupos de edad de la merluza (Merluccius hubbsi) en el Mar Argentino entre los 35- 47ํㅡㄴ LS en el año 1983. Frente Marit., 15(A): 7 - 19.

Grier, H.J. 1981. Cellular organization of the testis and spermatogenesis in fishes. Amer. Zool., 21: 345 - 357.

Guerra, A. \& Sánchez, J.L. 1998. Fundamentos de explotación de recursos marinos. Zaragoza, Editorial Acribia, $249 \mathrm{p}$.

Guimarães, V. 2007. Resíduos de mineração e metalurgia: efeitos poluidores em sedimentos e em espécie biomonitora - rio Ribeira de Iguape-SP. Tese de doutoramento. Univers. de São Paulo. Inst. Geociências, 160 p.

Gulland, J.A. \& Holt, S.J. 1959. Estimation of growth parameters for data at unequal time intervals. J. Cons., 25: 47 - 49.

Hayashi A.; Kawaguchi, K.; Watanabe, H. \& Ishida, M. 2001. Daily growth increment formation and its lunar periodicity in otoliths of the myctophid fish Myctophum asperum (Pisces: Myctophidae). Fish. Sci., 67: 811 - 817. 
Hostin-Silva, M.; Clezar, L.; Ribeiro, G.C. \& Machado, C. 1995. Estrutura populacional de Xenomelaniris brasiliensis (Quoy \& Gaimard, 1824) (Osteichthyes-Atherinidae) na Lagoa da Conceição, SC, Brasil. Arq. Biol. Tecnol., 38(3): 949 - 960.

Huaquím, L.G. 1980. Filamentos coriales en ovócitos y huevos de Basilichthys australis Elgenmann (Osteichthyes: Atherinidae). Arquivos de Biologia y Medicina Experimental, 13(1): $70 \mathrm{p}$.

Isaac-Nahum, V.J. 1989. Analysis of methods for the estimation of fish growth parameters, based on data from the family Scianidae and on simulated data. Tese de doutorado, Institut fur Meereskunde, Universitat Kiel, 244 p.

Issac-Nahum, V.J. \& Vazzoler, A.E.A.M. 1983. Biologia reprodutiva de Micropogonias furnieri (Desmarest, 1823) (Teleostei, Sciaenidae). I. Fator de condição como indicador do período reprodutivo. Bolm. Inst. Oceanogr., S. Paulo, 32(1): 63 - 69.

Ishikawa, M.; Nakamura, K,; Ishii, T.; Bassari, A.; Okoshi, K. \& Kitao, K. 1993. Elements in tissues and organs of an Antarctic fish, Champsocephalus gunnari. Nuclear Instr. Meth. Physics res., B75:204-208.

Ishikawa, M. \& Nakamura, K. 1990. Trace elements in tissues and organs of an Antarctic icefish, Chamsocephalus gunnari. Nuclear Instr. Meth. Physics res., B49:220-229. 
King, M. 1995. Fisheries biology, assessment an managent. Oxford, Fishing Books News, $346 \mathrm{p}$.

Koutrakis, E.T.; Kamidis, N.I. \& Leonardos, I.D. 2004. Age, growth and mortality of a semi-isolated lagoon population of sand smelt, Atherina boyeri (Risso, 1810) (Pisces: Atherinidae) in an estuarine system of northern Greece. J. Appl. Ichthyol., 20: 382 - 388.

Kristensen, T.K. 1980. Periodical growth rings in cephalopod statoliths. Dana, 1: $9-51$.

Tallandini, F.; Giacobini, F.; Turchetto, M.; GAlassini, S.; Liu, Q.X.; Shao, H.R.; Moschini, G.; Moro, S.; Gialanella, G.; Ghermandi, G.; Cecchi, R.; Injuk, J. \& Valkovic, V. 1989. Naturally occurring levels of elements in fishes as determined by PIXE and XRF methods. Nuclear Instr. Meth. Physics res., B40/41:630-638.

Lasiak, T.A. 1984a Structural aspects of the surf-zone fish assemblages at Kings Beach, Algoa Bay, South Africa: short-term fluctuations. Est. Coast. Shelf Sci., 18: 347 - 360.

Layman, C.A. 2000. Fish assemblage structure of the shallow ocean surf-zone on the Eastern Shore of Virginia Barrier Islands Est. Coast. Shelf Sci., 5(1): $201-213$. 
Le Cren, E.D. 1951. The length-weight relationship and seasonal cycle in gonad weight and condition in the perch (Perca Fluviatilis). J. Anim. Ecol., 20(2): $201-219$.

Leonardos, I. 2001: Ecology and exploitation pattern of a landlocked population of sand smelt, Atherina boyeri (Risso 1810), in Trichonis Lake (western Greece). J. Appl. Ichthyol., 17: 262 - 266.

Leonardos, I. \& Sinis, A. 2000. Age growth and mortality of Atherina boyeri Risso, 1810 (Pisces: Atherinidae) in the Mesolongi and Etolikon lagoons (W. Greece). Fish. Res., 45: 81 - 91.

Leonardos, J., Petridis, D., Kokkinidou, A. 1993. Population dynamics of Atherina boyeri (Risso 1810) in the Trichonis lake (W. Greece). Proc. Sixth Panhel. Symp. Ichthyol., 19 p.

Liang Y.; Cheung R.Y.H. \& Wong M.H. 1999. Reclamation of wastewater for polyculture of freshwater fish: bioaccumulation of trace metals in fish. Water Res., 33: 2690 - 2700.

Lima, I.V. \& Pedrozo, M.F.M. 2001. Ecotoxologia do ferro e seus compostos. Salvador, CRA., v. 4, 111 p. 
Lorenzo, M.I. 1999. Estimación del crecimiento de la merluza Merluccius hubbsi en la Zona Común de Pesca Argentina-Uruguaya. In: REY, M. \& ARENA, G. Merluza (Merluccius hubbsi): estudios realizados dentro de la Zona Común de Pesca Argentina-Uruguaya en la marco del plan de investigación pesquera (Proyeto URU/92/2003). Montevideo, INAPE/PNUD, 34 - 49 p.

Mansour, S.A. \& Sidky, M.M. 2002. Ecotoxicological Studies. 3. Heavy metals contaminating water and fish from Fayoum Governorate, Egypt. Food Chemistry, 78: 15 - 22.

Marín, B.M.; Diaz, O. \& Briceño, R. 1995. Aspectos descriptivos de los ovocitos y postlarva de tinicalo Xenomelaniris brasiliensis (Quoy \& Gaimard) (Pisces: Atherinidae). Bol. Inst. Oceanogr. Venezuela, Univ. Oriente, 34(1\&2): 59 - 68.

Mclachalan A. 1983. Sandy beach ecology - a review. In: MacLachlan A.,Erasmus T. (eds) Sandy beach as ecosystems. The Hague, Dr. Junk Publishers, $321-380 \mathrm{p}$.

Mclachlan, A. 1990. Dissipative beaches and macrofauna communities on exposed intertidal sands. J. Coast. Res., 6(1): 57 - 71.

Meisel, D.V.; Byrne, R.A.; Kuba, M.; Griebel, U. \& Mather, J. A. 2003. Circadian rhythms in Octopus vulgaris. Berliner Palãobiol. Abh., 03: 171 - 177. 
Menezes, N.A.; Buckup, P.A.; Figueiredo, J.L. \& Moura, R.L. 2003. Catálogo das espécies de peixes marinhos do Brasil. São Paulo: Museu de Zoologia, EDUSP, $160 \mathrm{p}$.

Mesquita, A.R. de \& Harari, J. 1999. Propagation of Tides and Circulation of Tidal Currents of the Sotheastern Brazilian Shelf. Afro America Gloss News, São Paulo, 3(2): 2 - 8.

Moreno, T. \& Morales-Nin, B. 2003. Age determination and validation on otoliths of sand-smelt Atherina presbyter (Cuvier, 1829) (Pisces: Atherinidae) from the central-east Atlantic. Fish. Res., 62: 77 - 87.

Motelica-Heino, M; Coustumer, L.E.P.; Thomassin, J.H.; Gauthier, A. \& Donard, O.F.X. 1998. Macro and microchemistry of trace metals in vitrified domestic wastes by laser ablation ICP-MS and scanning electron microprobe X-ray energy dispersive spectrocopy. Talanta, 46: 407 - 422.

Munro J.L. \& Pauly D. 1983. A simple method for comparing the growth of fishes and invertebrates. Fishbyte, 1(1): 5 - 6.

Naylor, E. 1996. Crab clockwork: the case for interactive circatidal and circadian oscillators controlling rhythmic locomotor activity of Carcinus maenas. Chronobiol Intern., 13(3): 153 - 161. 
Negreiros-Fransozo, M.L.; Fransozo A.; Pinheiros, A.A.; Mentelatto, F.L.M. \& Santos, S. 1991. Caracterização física e química da enseada de Fortaleza - Ubatuba, SP. Rev. Bras. de Geo., 21: 114 - 120.

Neves, L.M.; Pereira, H.H.; Marcus, R.C. \& Araújo, F.G. 2006. Uso do manguezal de Guaratiba, Baia de Sepetiba, Rio de Janeiro, pelo peixe-rei Atherinella brasiliensis (Qouy \& Gaimard) (Atheriniformes, Atherinopsidae). Revta Brás. Zool., 23(2): 421 - 428.

Nybakken, J.W. 1997. Marine biology: an ecological approach. Fourth edition. Menlo Park: Benjamin/Cummings, $481 \mathrm{p}$.

Oliveira, R.C. 2002. Avaliação do movimento de cádmio, chumbo e zinco em solo tratado com resíduo-calcário. Lavras Dissertação de mestrado. Universidade Federal Lavras, Instituto de Agronomia, 84 p.

Paiva-Filho, A.M. \& Giannini, R. 1990. Contribuição ao conhecimento da biologia do peixe-rei, Xenomelaniris brasiliensis (Quoy \& Gaimard, 1824) (Atherinidae), no complexo baía-estuário de Santos e São Vicente, Brasil. Bolm. Inst. Oceanogr., 38(1): 1 - 9.

Pauly, D. 1979. Gill size and temperature as governing factors in fish growth: a generalization of von Bertalanffy's growth formula. Berichte des Institut für Meereskund an der Universität Kiel. No. 63, xv + 156 p. 
Pauly, D. 1980. On the interrelationship between natural mortality, growth parameters and mean environmental temperature in 175 fish stocks. J. Cons. Int. Explor. Mer, 39(3): 175 - 192.

Pauly, D. 1983. Some simple methods for the assessment of tropical fish stocks. FAO fish. tech. Pap., v. 234, 52 p.

Pereira, O.M.; Henriques, M.B.; Zenebon, O.; Sakuma, A. \& Kira, C.S. 2002. Determinação dos teores de $\mathrm{Hg}, \mathrm{Pb}, \mathrm{Cd}$, $\mathrm{Cu}$ e $\mathrm{Zn}$ em MOLUSCOS (Crassostrea brasiliana, Perna perna e Mytella falcata). Rev. Inst. Adolfo Lutz, 61(1): $19-25$.

Peres-Rios, E. 1995. Aspectos reprodutivos de Prionotus punctatus (Bloch, 1797) (Teleostei: Triglidae) na região costeira de Ubatuba, São Paulo, Brasil. Dissertação de mestrado. Universidade de São Paulo, Instituto Oceanográfico. $62 \mathrm{p}$.

Peres-Rios, E. 2001. Papel do estuário no ciclo de vida das espécies dominantes da ictiofauna do Complexo estuarino-lagunar de CananéiaIguape. Dissertação de doutorado. Universidade de São Paulo, Instituto Oceanográfico, $128 \mathrm{p}$.

Perugini, M.; Cavaliere, M.; Giammarino, A.; Mazzone, P.; Olivieri, V. \& Amorena, M. 2004. Levels of polychlorinated biphenyls and organochlorine 
pesticides in some edible marine organisms from the Central Adriatic Sea. Chemosphere, 57: 391 - 400.

Pessanha, A.L. \& Araújo F.G. 2001. Recrutamento do peixe-rei Xenomelaniris brasiliensis (Atheriniformes, Atherinopsidae), na margem continental da Baía de Sepetiba, Rio de Janeiro, Brasil. Revta bras. Zool., 18(4): 1265 1274.

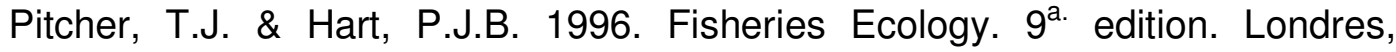
Chapman \& Hall. 414 p.

Poots G.W. \& Wootton, R.J. 1984. Fish reproduction: strategies and tactics. London, Academic Press. 409 p.

Querol, M.V.M.; Querol, E. \& Gomes, N.N.A. 2002. Fator de condição gonadal, índice hepatossomático e recrutamento como indicadores do período de reprodução de Loricariichthys platymetopon (Osteichthyes, Loricariidae), bacia do rio Uruguai médio, sul do Brasil. Iheringia, Sr. Zool., 81: 97 - 100.

Rahman, M.J. \& Cowx, I.G. 2006. Lunar periodicity in growth increment formation in otoliths of hilsa shad (Tenualosa ilisha, Clupeidae) in Bangladesh waters. Fish. Res., 81: 342 - 344.

Romer, G. S. 1990. Surf zone fish community and species response to a wave energy gradient. J. Fish Biol., 36: 279 - 287. 
Ross, S.T., McmicheaL, R.H., JR. \& Ruple, D.L. 1987 Seasonal and diel variation in the standing crop of fishes and macroinvertebrates from a Gulf of Mexico Surf Zone. Est., Coast. Shelf Sci., 25: 391 - 412.

Santos, A.C.A.; Castellucci, F.R.C.; Nepomuceno, C.F.; Santos, E.P. \& Sena, M.P. 1999. Distribuição e recrutamento do peixe-rei Xenomelaniris brasiliensis (Osteichthyes, Atherinidae) na margem continental oeste da Baia de Todos os Santos, Bahia, Brasil. Acta Biol. Leopoldensia, 21(1): $107-118$.

Saquet, M.; Halden, N.M.; Babaluk, J.; Campebell, J.L. \& Nejedly, Z. 2002. Micro-Pixe analysis of trace element variation in otoliths from fish collected near acid mine tailings: Potential for monitoring contaminant dispersal. Nucl. Instr. and Meth. in Phys. Res. B., 189: 196 - 201.

Schobbenhaus, C.; Campos, D.A.; Derze, G.R. \& Asmus, H.E. 1984. Geologia do Brasil: texto explicativo do Mapa Geológico do Brasil e da área oceânica adjacente incluindo depósitos minerais, escala 1:2.500.000 Brasília, MME-DNPM, 501 p.

Short, A.D. \& Wright, L.D. 1983. Physical variability of sand beach. In: Mclachlan, A. \& Erasmus, T. (eds.). Sandy beach as ecosystems. The Hague, Dr. Junk Publishers, 133-144 p. 
Silva, G.C.; Castro, C.L.C. \& Gubiani, E.A. 2005. Estrutura populacional e indicadores reprodutivos de Scomberomorus brasiliensis Collette, Russo e Zavala-Camin, 1978 (Perciformes: Scombridae) no litoral ocidental maranhense. Acta Sci. Biol. Sci. Maringá, 27(4): 383 - 389.

Sparre, P. \& Venema, S.C. 1998. Introdução à avaliação de mananciais de peixes tropicais. Parte 1: Manual. FAO Documento Técnico sobre as Pescas. No. 306/1, Ver.2. Roma, FAO. 404 p.

Spratt, J.D. 1978. Age and growth of the market squid, Loligo opalescens Berry, in Monterey Bay. Fish Bull. Calif. Dep. Fish Game, 169: 35 - 44.

Springer V,G. \& Woodburn, K. D. 1960. An ecological study of the fishes of the Tampa Bay area. Fla. State Board Canserv. Mar. Lab. Prof. Pup. Ser., 104 p.

Stevenson, D.K. \& Campana, S.E. 1992. Otolith microstructure examination and analysis. Canadian Special Publications in Fisheries and Aquatic Sciences, $117 p$.

Tabacniks, M. H. 1998 Análise de filmes finos por PIXE e RBS. In: Santos, A.D.S.; Partiti, C. S M; Villas-Boas, V.; Neiva, A.C.; Oppenheim, I.C.. (Org.). I Escola brasileira de magnetismo, EMB'98. $1^{\text {ed }}$. São Paulo, 1: 14 21. 
Taylor, C.C. 1960. Temperature, growth and mortality-The Pacific cockle. J. Cons., 26(1): 177 - 224.

Taylor, C.C. 1962. Growth equations with metabolic parameters. J. Cons. Perm. Internat. L'Explor. de la Mer., 27: 270 - 286.

Türkmen, A.; Türkmen, M.; Tepe, Y. \& Akyurt, I. 2005. Heavy metals in tree commercially valuable fish species from Iskenderun Bay, Northern East Mediterranean Sea, Turkey. Food Chemistry, 91: 167 - 172.

Turnpenny, A.W.H., Bamber, R.N., Henderson, P.A. 1981. Biology of the sandsmelt (Atherina presbyter Valenciennes) around Fawley power station. J. Fish. Biol., 18: 417 - 427.

Vaz-Dos-Santos, A.M. 2002. Idade e crescimento de merluza, Merluccius hubbsi Marini, 1933 (Teleostei: Merlucciidae) na Zona Econômica Exclusiva entre Cabo de São Tomé (RJ) e o Chuí (RS), Brasil. Dissertação de mestrado. Universidade de São Paulo, Instituto Oceanográfico, 191 p.

Vazzoler, A.E.A.M. 1981. Manual de métodos para estudos biológicos de populações de peixes: reprodução e crescimento. Brasília, CNPq. 108 p.

Vazzoler, A.E.A.M. 1991. Síntese de conhecimento sobre a biologia da corvina Micropogonias furnieri (Desmarest, 1823), da costa do Brasil. Atlântica, 13(1): $55-74$. 
Vazzoler, A.E.A.M. 1996. Biologia da reprodução de peixes teleósteos: teoria e pratica. Maringá: EDUEM. 169 p.

Vazzoler, A.E.A.M.; Lizama, M.A.P. \& Cohen, M.R.G. 1991. Caracterização bioquímica da tainha Mugil sp. da região estuarina-lagunar de Cananéia, São Paulo. In: Seminário Projeto Tainha: Discussão e Perspectivas, São Paulo. Resumo. IP/SAA/CIRM. p. 1.

Vazzoler, A.E.A.M. \& Rossi-Wongtschowski, C.L.D.B. 1976. Sardinella brasiliensis: Tipo de desova, fecundidade e potencial reprodutivo relativo.

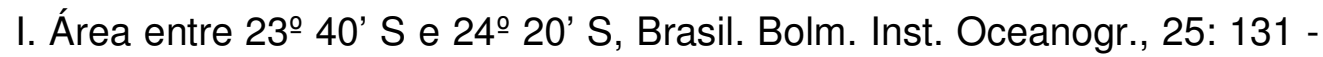
155.

Villwock, J.A. 1987. Os paleoambientes da Província Costeira do Rio Grande do Sul e a possível ocorrência de antigos manguezais na costa sul do Brasil. Anais I Simpósio sobre Ecossistemas da Costa Sul e Sudeste Brasileira - Síntese dos Conhecimentos, Publ. ACIESP, São Paulo, 1(54): $132-137$.

Walford, L.A. 1946. A new graphic method of describing the growth animals. Biol. Bull. Mar. Biol. Lab., 90: 141 - 147.

Weatherley, A.H. \& Gill, H.S. 1987. The biology of fish growth. London, Academic Press. 443 p. 
West, G. 1990. Methods of assessing ovarian development in fishes: a review. Aust. J. mar. freshwater Res., 41: 199 - 222.

Westerlund, S.; Aas, E \& Andersen, O. K. 1998. The use of bile in fish in a screening method for trace metal exposure. Mar. Environ. res., 46(15):601-604 .

Wootton, R.J. 1990. Ecology of teleostei fishes. Londres, Chapnan \& Hall. 404 p.

Wright, L.D. \& Short, A.D. 1983. Morphodynamics of beach and surf zone in Australia. In: C.R.C. Handbook of coastal processes and erosion. P.D. Komar (eds.), C.R.C. Press., London, 35 - 64.

Yilmaz, A.B. 2003. Levels of heavy metals ( $\mathrm{Fe}, \mathrm{Cu}, \mathrm{Ni}, \mathrm{Cr}, \mathrm{Pb}$ and $\mathrm{Zn}$ ) in tissues of Mugil cephalus and Trachurus mediterraneus from Iskenderun Bay, Turkey. Envir. Res., 92: 277 - 281.

Yoneama, M.L.; Dias, J.F. \& Dias, J. 2004. Espectroscopia por emissão de raios-X induzida por partículas (PIXE). In: Teixeira, E.C.; Rodrigues, M.J.P.; Ferraro, L.W.; Dobrovolski, R.L. \& Guerra, T. Estudos Ambientais em Candiota - Carvão e seus Impactos. 01ed. Porto Alegre, 04: 209 - 215.

Zar, J.H. 1996. Biostatistical analysis. New Jersey, Prentice Hall. 662 p. 
